Argonne

\title{
Vehicle Technologies and Fuel Cell Techonologies Office Research and Development Programs: Prospective Benefits Assessment Report for FY 2018
}

Energy Systems Division 


\begin{abstract}
About Argonne National Laboratory
Argonne is a U.S. Department of Energy laboratory managed by UChicago Argonne, LLC under contract DE-AC02-06CH11357. The Laboratory's main facility is outside Chicago, at 9700 South Cass Avenue, Argonne, Illinois 60439. For information about Argonne and its pioneering science and technology programs, see www.anl.gov.
\end{abstract}

\title{
DOCUMENT AVAILABILITY
}

Online Access: U.S. Department of Energy (DOE) reports produced after 1991 and a growing number of pre-1991 documents are available free via DOE's SciTech Connect (http://www.osti.gov/scitech/).

Reports not in digital format may be purchased by the public from the National Technical Information Service (NTIS):

U.S. Department of Commerce

National Technical Information Service

5301 Shawnee Road

Alexandria, VA 22312

www.ntis.gov

Phone: (800) 553-NTIS (6847) or (703) 605-6000

Fax: (703) 605-6900

Email: orders@ntis.gov

Reports not in digital format are available to DOE and DOE contractors from:

U.S. Department of Energy

Office of Scientific and Technical Information

P.O. Box 62

Oak Ridge, TN 37831-0062

\footnotetext{
Disclaimer

This report was prepared as an account of work sponsored by an agency of the United States Government. Neither the United States Government nor any agency thereof, nor UChicago Argonne, LLC, nor any of their employees or officers, makes any warranty, express or implied, or assumes any legal liability or responsibility for the accuracy, completeness, or usefulness of any information, apparatus, product, or process disclosed, or represents that its use would not infringe privately owned rights. Reference herein to any specific commercial product, process, or service by trade name, trademark, manufacturer, or otherwise, does not necessarily constitute or imply its endorsement, recommendation, or favoring by the United States Government or any agency thereof. The views and opinions of document authors expressed herein do not necessarily state or reflect those of the United States Government or any agency thereof, Argonne National Laboratory, or UChicago Argonne, LLC.
} 


\section{Vehicle Technologies and Fuel Cell Techonologies Office Research and Development Programs: Prospective Benefits Assessment Report for FY 2018}

prepared by:

T.S. Stephens, ${ }^{1}$ A. Birky, ${ }^{2}$ and D. Gohlke ${ }^{1,3}$

${ }^{1}$ Energy Systems Division, Argonne National Laboratory

2Energetics Incorporated

${ }^{3}$ U.S. Department of Energy, Office of Energy Efficiency and Renewable Energy

November 2017 



\section{CONTENTS}

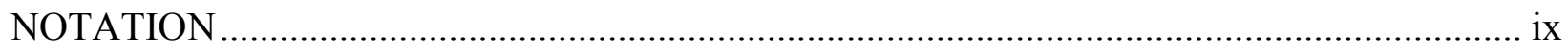

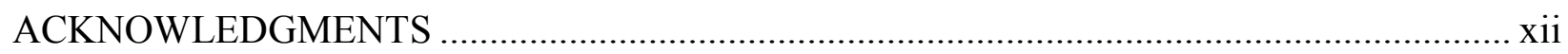

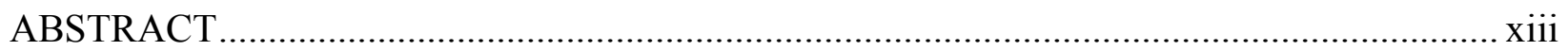

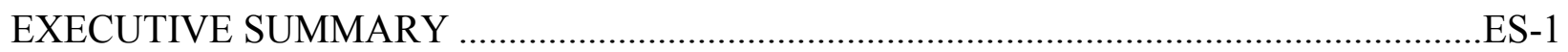

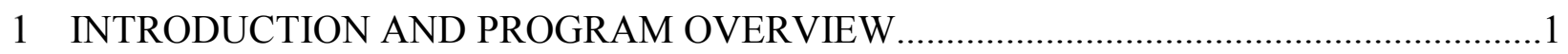

1.1 Office of Energy Efficiency and Renewable Energy Sustainable Transportation

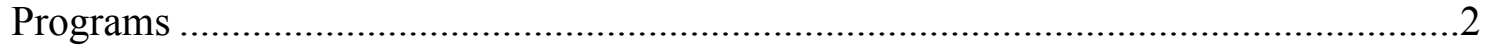

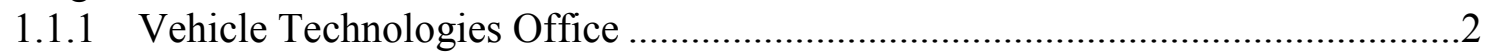

1.1.2 Fuel Cell Technologies Office .......................................................................

1.2 Transportation R\&D Programs ………………..................................................6

1.2.1 Electrification R\&D ................................................................................6

1.2.2 Advanced Combustion Systems and Fuels R\&D ..................................................

1.2.3 Materials Technology R\&D.......................................................................

1.2.4 Hydrogen and Fuel Cells Technologies R\&D ...................................................

2 TRANSLATING PROGRAM GOALS INTO MODEL INPUT …………………….............

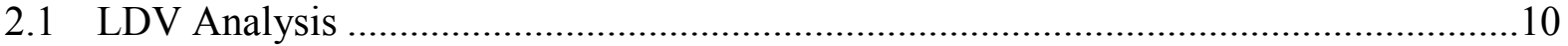

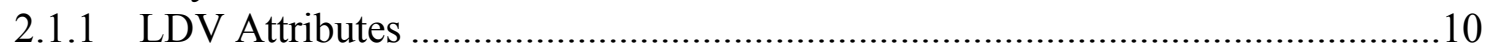

2.1.2 LDV Market Penetration Modeling .............................................................11

2.1.3 Fuel Savings Due to LDV Technology Improvement ........................................13

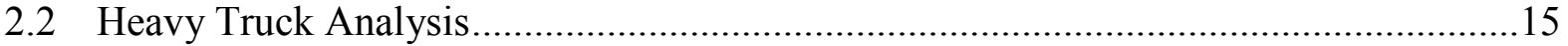

2.2.1 Heavy Truck Baseline.....................................................................................15

2.2.2 Heavy Truck Advanced Technology Modeling................................................17

2.2.3 Heavy Truck Market Penetration and Stock Modeling .......................................18

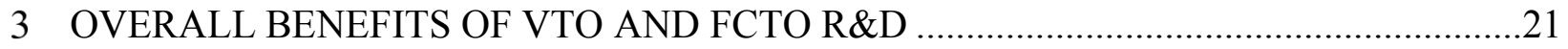

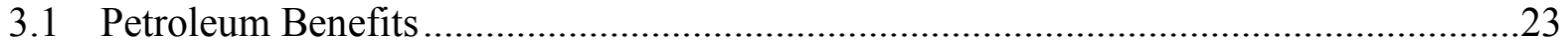

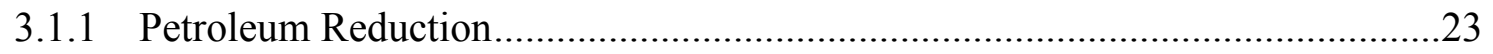

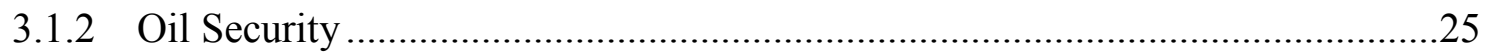

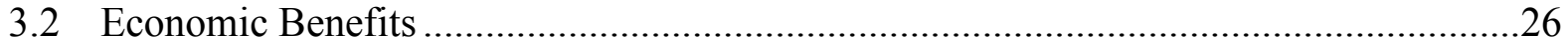

3.2.1 Consumer Fuel Economy ...........................................................................26

3.2.2 LDV Levelized Cost of Driving ...................................................................27

3.2.3 National-Level Vehicle Expenditures..........................................................29

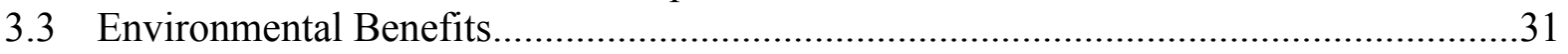

3.3.1 Reductions in GHG Emissions ..................................................................... 


\section{CONTENTS (Cont.)}

4 DISAGGREGATION OF BENEFITS BY TECHNOLOGY AREA ....................................33

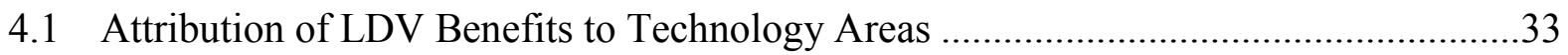

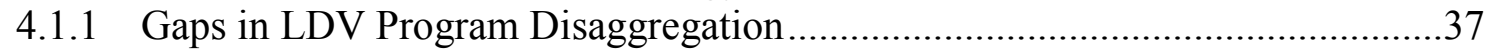

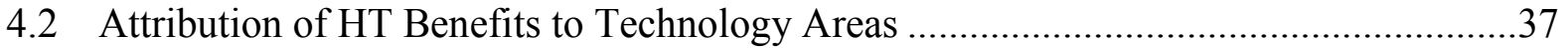

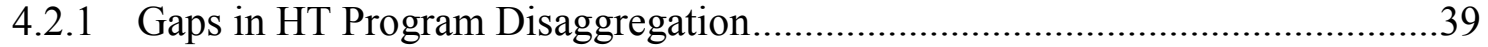

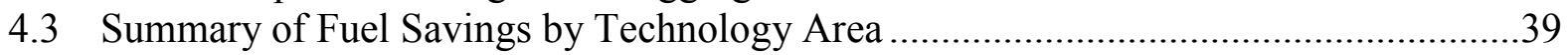

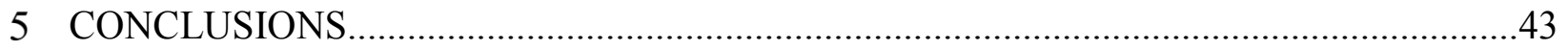

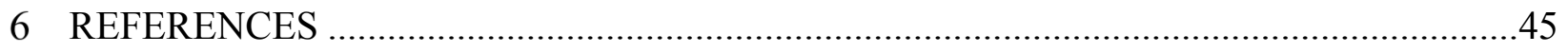

APPENDIX A: COMPARISON WITH EIA PROJECTIONS ......................................... A-1

APPENDIX B: LIGHT-DUTY VEHICLE MODEL INPUTS AND OUTPUTS.......................-1

B.1 Inputs of Light-Duty Vehicle Vehicle Choice Modeling............................................1

B.2 Comparison of LDV Market Penetration .....................................................................

B.3 LDV Fuel Economy ......................................................................................

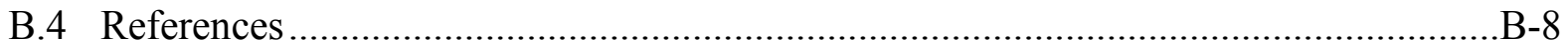

APPENDIX C: HEAVY TRUCK MODEL INPUTS AND OUTPUTS ...................................

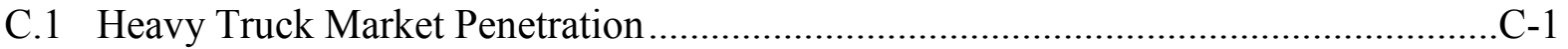

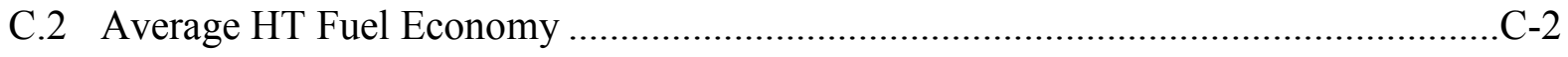

APPENDIX D: VARIATION IN AGGREGATE IMPACTS ACROSS LDV CHOICE

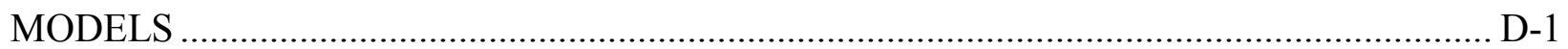

D.1 Oil Security Metrics Modeling Projections ........................................................... D-1

D.2 Consumer Costs of Light-Duty Vehicles ............................................................... D-3 


\section{FIGURES}

ES-1 Projected On-road Petroleum Consumption under the No Program and Program Success Cases in 2035 and 2050, and Projected Cumulative Petroleum Savings Attributed to All VTO and FCTO Technology Programs

ES-2 Fleet-averaged Fuel Efficiency through 2050 for Light-duty and Class 7-8

Combination Unit Trucks for the Program Success and No Program Cases.

ES-3 Difference in Annual National Consumer Costs of Vehicle Purchases and Fuel Costs for On-road Vehicles through 2050 for the No Program and Program Success Cases

1-1 General Approach and Information Flow in the Benefits Analysis....................................2

1-2 Organization of Programs in EERE's VTO and FCTO ....................................................

2-1 Example Average Annual Petroleum-based Fuel Consumption per Car in 2035 for the No Program and Program Success Cases, Based on Market Share Modeled by $\mathrm{MA}^{3} \mathrm{~T}$

2-2 Average Annual Petroleum-based Fuel Consumption per Car in 2035 for the No Program and Program Success Cases, Based on Market Share Projected by the $\mathrm{MA}^{3} \mathrm{~T}$ Model

3-1 On-road Fuel Consumption by Fuel Type through 2050 for the No Program and Program Success Cases.

3-2 Projected On-road Petroleum Consumption under the No Program and Program Success Cases in 2035 and 2050 and Projected Cumulative Petroleum Savings Attributed to All VTO and FCTO Technology Programs

3-3 Estimated Reduction in Annual Oil Security Costs from the Oil Security Metrics Model .26

3-4 Fleet-averaged Fuel Efficiency through 2050 for Light-duty and Heavy-duty Vehicles for the Program Success and No Program Cases.

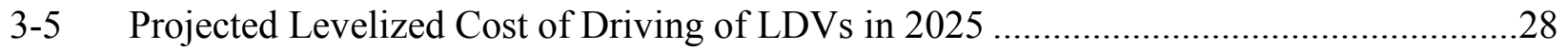

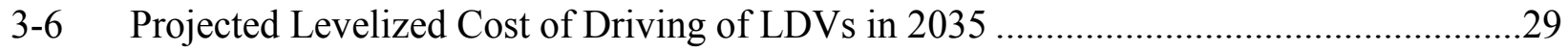

3-7 Differences in Annual National Consumer Expenditures for Vehicle Purchases and Fuel for LDVs through 2050 between the No Program and Program Success Cases ........30 


\section{FIGURES (Cont.)}

3-8 Differences in Annual National Costs of Vehicle Purchases and Fuel for Mediumand Heavy-duty Vehicles through 2050 between the No Program and Program Success Cases

3-9 Projected GHG Emissions under the No Program and Program Success Cases in 2035 and 2050 and Projected Cumulative GHG Reductions Attributed to All VTO and FCTO Technology Program since 2019

4-1 Average Annual Petroleum-based Fuel Consumption in Cars in 2035 for the No Program and Program Success Cases, with Savings Due to Drivetrain Efficiency Improvements, and Those Due to Changes in the Stock Shares of Drivetrain Technologies Disaggregated

4-2 Projected Petroleum Savings in 2025, 2035, and 2050 Attributable to VTO and FCTO Technology Programs.....

4-3 Projected Reductions in GHG Emissions in 2025, 2035, and 2050 Attributable to VTO and FCTO Technology Programs.

A-1 Projected Petroleum Consumption and GHG Emissions by LDVs in 2025 under the No Program and Program Success Cases and by the AEO 2016 Reference Case

A-2 Unadjusted, Combined City/Highway Fleet-averaged Fuel Economy of LDVs Projected under the No Program and Program Success Cases and by the AEO 2016 Reference Case......

B-1 Projected Fuel Prices Used for Modeling, in 2015\$ per gge

B-2 LDV Stock by Powertrain Type for the No Program and Program Success Cases Projected by the LVCFlex Model

B-3 LDV Stock by Powertrain Type for the No Program and Program Success Cases Projected by the $\mathrm{MA}^{3} \mathrm{~T}$ Model.

B-4 LDV Stock by Powertrain Type for the No Program and Program Success Cases Projected by the LAVE-Trans Model.

B-5 LDV Stock by Powertrain Type for the No Program and Program Success Cases Projected by the ParaChoice Model. B-6

B-6 Fleet-averaged Fuel Economies of New LDVs for the No Program and Program Success Cases Based on Market Projections of the Four LDV Consumer Choice Models. 


\section{FIGURES (Cont.)}

B-7 Average Fuel Economy of On-road LDVs for the No Program and Program Success Cases Based on Market Projections of the Four LDV Consumer Choice Models

C-1 Fleet-averaged Fuel Economy of New Medium- and Heavy-duty Trucks for the No Program and Program Success Cases

C-2 Average Fuel Economy of On-road Stock of Medium- and Heavy-duty Trucks for the No Program and Program Success Cases

D-1 Oil Security Metrics Model Results Using LAVE-Trans and TRUCK Model Projections

D-2 Oil Security Metrics Model Results Using LVCFlex and TRUCK Model Projections.

D-3 Oil Security Metrics Model Results Using MA ${ }^{3}$ T and TRUCK Model Projections ...... D-2

D-4 Oil Security Metrics Model Results Using ParaChoice and TRUCK Model

Projections.

D-5 Annual Expenditures for LDV Stock Modeled by LAVE-Trans for the No Program and Program Success Cases

D-6 Annual Expenditures for LDV Stock Modeled by LVCFlex for the No Program and Program Success Cases.

D-7 Annual Expenditures for LDV Stock Modeled by MA ${ }^{3} \mathrm{~T}$ for the No Program and Program Success Cases.

D-8 Annual Expenditures for LDV Stock Modeled by ParaChoice for the No Program and Program Success Cases 


\section{TABLES}

ES-1 Projected Ranges of Petroleum Savings and Emissions Reductions in 2025, 2035, and 2050 by VTO and FCTO Technology Programs ....

2-1 Upstream Energy- and GHG-Intensities of Hydrogen in the No Program and Program Success Cases.

3-1 Projected Benefits of VTO and FCTO R\&D.

4-1 Projected Reductions in Oil Consumption by the U.S. LDV Fleet Attributable to EERE, by Technology Area.

4-2 Projected Reductions in Petroleum Consumption by the U.S. Fleet of Medium- and Heavy-duty Trucks Attributable to VTO, by Technology Area

4-3 Projected Ranges of Petroleum Savings and Emissions Reductions in 2025, 2035, and 2050 Attributable to VTO and FCTO Technology Programs.

B-1 Comparison of Key Characteristics of the LDV Choice Models

B-2 LDV Market Penetration Estimates for the No Program and Program Success Cases from the LVCFlex Model

B-3 LDV Market Penetration Estimates for the No Program and Program Success Cases from the $\mathrm{MA}^{3} \mathrm{~T}$ Model .

B-4 LDV Market Penetration Estimates for the No Program and Program Success Cases from the LAVE-Trans Model

B-5 LDV Market Penetration Estimates for the No Program and Program Success Cases from the ParaChoice Model

C-1 Medium- and Heavy-duty Truck Market Penetration Estimates for the Program Success Case, as Percentage of VMT. 


\section{NOTATION}

\section{ACRONYMS AND INITIALISMS}

\begin{tabular}{|c|c|}
\hline AEO & Annual Energy Outlook \\
\hline Argonne & Argonne National Laboratory \\
\hline AsCEnTT & Assessment of Cycle Energy of Truck Technologies model \\
\hline BETO & Bioenergy Technologies Office \\
\hline $\mathrm{BEV}$ & battery electric vehicle \\
\hline CAFE & Corporate Average Fuel Economy \\
\hline $\mathrm{CD}$ & charge-depleting \\
\hline CI & compression-ignition \\
\hline $\mathrm{CO}_{2}$ & carbon dioxide \\
\hline $\mathrm{CO}_{2}$-eq & carbon dioxide equivalent \\
\hline Conv & conventional \\
\hline $\mathrm{CU}$ & combination unit (truck) \\
\hline DOE & U.S. Department of Energy \\
\hline DOT & U.S. Department of Transportation \\
\hline EEMS & Energy Efficient Mobility Systems \\
\hline EERE & Energy Efficiency and Renewable Energy \\
\hline EIA & Energy Information Administration \\
\hline EPA & Environmental Protection Agency (United States) \\
\hline FCTO & Fuel Cell Technologies Office \\
\hline FCV & fuel cell vehicle \\
\hline FY & fiscal year \\
\hline GDP & gross domestic product \\
\hline GEM & Greenhouse gas Emissions Model \\
\hline GHG & greenhouse gas \\
\hline GPRA & Government Performance and Results Act \\
\hline GREET & $\begin{array}{l}\text { Greenhouse Gases, Regulated Emissions, and Energy Use in Transportation } \\
\text { model }\end{array}$ \\
\hline $\mathrm{H}_{2}$ & hydrogen \\
\hline $\mathrm{HEV}$ & hybrid electric vehicle \\
\hline HT & heavy-duty truck \\
\hline ICE & internal combustion engine \\
\hline
\end{tabular}




\begin{tabular}{|c|c|}
\hline 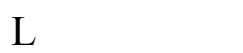 & liquid \\
\hline LAVE-Trans & Light-Duty Alternative Vehicle Energy Transitions model \\
\hline LCD & levelized cost of driving \\
\hline LDV & light-duty vehicle \\
\hline LT & light truck \\
\hline $\mathrm{MA}^{3} \mathrm{~T}$ & Market Acceptance of Advanced Automotive Technologies model \\
\hline NHTSA & National Highway Transportation Safety Administration \\
\hline NRC & National Research Council \\
\hline ORNL & Oak Ridge National Laboratory \\
\hline OSMM & Oil Security Metrics Model \\
\hline PEEM & power electronics and electric motors \\
\hline PEV & plug-in electric vehicle \\
\hline PHEV & plug-in hybrid electric vehicle \\
\hline PV & present value \\
\hline R\&D & research and development \\
\hline RD\&D & research, development, and deployment \\
\hline SI & spark-ignition \\
\hline SMR & steam methane reforming \\
\hline SNL & Sandia National Laboratories \\
\hline SU & single unit (truck) \\
\hline SUV & sport utility vehicle \\
\hline TAE & TAE Engineering, Inc. \\
\hline TRL & technology readiness level \\
\hline U.S. DRIVE & $\begin{array}{l}\text { United States Driving Research and Innovation for Vehicle Efficiency and } \\
\text { Energy Sustainability }\end{array}$ \\
\hline VMT & vehicle miles traveled \\
\hline VTO & Vehicle Technologies Office \\
\hline
\end{tabular}




\section{UNITS OF MEASURE}

$\begin{array}{ll}\text { bbl } & \text { barrel(s) } \\ \text { bpd } & \text { barrel(s) per day } \\ \text { Btu } & \text { British thermal unit } \\ \text { gal } & \text { gallon(s) } \\ \text { gge } & \text { gallon gasoline equivalent } \\ \text { kg } & \text { kilogram(s) } \\ \text { kWh } & \text { kilowatt-hour(s) } \\ \text { lb } & \text { pound(s) } \\ \text { mi } & \text { mile(s) } \\ \text { MMbpd } & \begin{array}{l}\text { million barrels per day } \\ \text { million Btu } \\ \text { Mmt } \\ \text { mpg } \\ \text { mpgge }\end{array} \\ \text { million metric tons } \\ \text { mile(s) per gallon } \\ \text { miles per gallon gasoline equivalent }\end{array}$




\section{ACKNOWLEDGMENTS}

The authors are grateful for technical and financial support for this project.

Technical targets and input for the No Program and Program Success cases came from the expert opinions of technology managers at the U.S. Department of Energy. Gurpreet Singh, Ken Howden, Roland Gravel, and Leo Breton gave input regarding the Advanced Combustion Engines and Fuels program. Brian Cunningham, Susan Rogers, and Steven Boyd gave input for the Electrification program. Sarah Ollila, Felix Wu, and Will Joost gave input related to the Materials Technology program. Dimitrios Papageorgopoulos, Jesse Adams, Ned Stetson, Fred Joseck, and John Stevens gave input related to Fuel Cell Technologies Office targets.

Vehicles were simulated in Autonomie by the team at Argonne National Laboratory: Ehsan Islam, Namdoo Kim, Ayman Moawad, and Aymeric Rousseau. Light-duty vehicle choice modeling support came from Rebecca Levinson from Sandia National Laboratories, and Zhenhong Lin and Changzheng Liu of Oak Ridge National Laboratory. Oil security projections were provided by Shawn Ou and Zhenhong Lin of Oak Ridge National Laboratory.

Support and guidance by Vehicle Technologies Office (VTO) and Fuel Cell Technologies Office (FCTO) managers - Rachael Nealer and Jacob Ward of the Vehicle Technologies Office and Fred Joseck and John Stevens of the Fuel Cell Technologies Officewere essential for completing this analysis. This activity was supported in part by an American Association for the Advancement of Science, Science \& Technology Policy Fellow serving at the U.S. Department of Energy, Office of Energy Efficiency and Renewable Energy, Vehicle Technologies Office. 


\title{
VEHICLE TECHNOLOGIES AND FUEL CELL TECHNOLOGIES OFFICE RESEARCH AND DEVELOPMENT PROGRAMS: PROSPECTIVE BENEFITS ASSESSMENT REPORT FOR FISCAL YEAR 2018
}

by

\author{
T.S. Stephens, A. Birky, and D. Gohlke
}

\begin{abstract}
Under a diverse set of programs, the Vehicle Technologies and Fuel Cell Technologies Offices of the U.S. Department of Energy's Office of Energy Efficiency and Renewable Energy invest in early-stage research of advanced batteries and electrification, engines and fuels, materials, and energy-efficient mobility systems; hydrogen production, delivery, and storage; and fuel cell technologies. This report documents the estimated benefits of successful development and implementation of advanced vehicle technologies. It presents a comparison of a scenario with completely successful implementation of Vehicle Technologies Office (VTO) and Fuel Cell Technologies Office (FCTO) technologies (the Program Success case) to a future in which there is no contribution after Fiscal Year 2017 by the VTO or FCTO to these technologies (the No Program case). Benefits were attributed to individual program technology areas, which included FCTO research and development and the VTO programs of electrification, advanced combustion engines and fuels, and materials technology.

Projections for the Program Success case indicate that by 2035, the average fuel economy of on-road, light-duty vehicle stock could be $24 \%$ to $30 \%$ higher than in the No Program case, while fuel economy for on-road medium- and heavy-duty vehicle stock could be as much as $13 \%$ higher. The resulting petroleum savings in 2035 were estimated to be as high as 1.9 million barrels of oil per day, and reductions in greenhouse gas emissions were estimated to be as high as 320 million metric tons of carbon dioxide equivalent per year. Projections of light-duty vehicle adoption indicate that although advanced-technology vehicles may be somewhat more expensive to purchase, the fuel savings result in a net reduction of consumer cost. In 2035, reductions in annual fuel expenditures for vehicles (both light- and heavy-duty) are projected to range from $\$ 86$ billion to $\$ 109$ billion (2015\$), while the projected increase in new vehicle expenditures in the same year ranges from $\$ 6$ billion to $\$ 24$ billion (2015\$).
\end{abstract}


This page intentionally left blank. 


\section{EXECUTIVE SUMMARY}

Under the U.S. Department of Energy's (DOE's) Office of Energy Efficiency and Renewable Energy (EERE), the Vehicle Technologies Office (VTO) and Fuel Cell Technologies Office (FCTO) invest in research of technologies and innovations, including advanced batteries and electrification, engines and fuels, materials, and energy-efficient mobility systems; hydrogen production, delivery, and storage; and fuel cells. This report documents the estimated benefits of successfully developing and implementing these technologies (a "Program Success" case) relative to a base case (the "No Program" case). The Program Success case represents the future with successful implementation of VTO and FCTO technologies. The No Program case represents a future in which there is no contribution after Fiscal Year (FY) 2017 by VTO or FCTO to these technologies.

Projections for the Program Success case indicate that by 2035, the average fuel economy of on-road, light-duty vehicle stock could be $24 \%$ to $30 \%$ higher than in the No Program case. In addition, average on-road medium- and heavy-duty vehicle stock fuel economies in the same year could be as much as $13 \%$ higher. The resulting petroleum savings in 2035 were estimated to be as high as 1.9 million barrels per day, and reductions in greenhouse gas (GHG) emissions were estimated to be as high as 320 million metric tons of carbon dioxide equivalent $\left(\mathrm{CO}_{2}\right.$-eq) per year. Such petroleum reductions result in significant reductions in fuel expenditure for both light- and heavy-duty vehicles, totaling approximately $\$ 100$ billion annually by 2035 .

Figure ES-1 shows the projected petroleum consumption in years 2035 and 2050 under both the No Program and Program Success cases, with uncertainty bars showing the range of projected values. This report documents a robust range of benefits by using four light-duty vehicle choice models to develop projections of future technology adoption and resulting petroleum use. Figure ES-1 also shows the range of projected cumulative petroleum savings since 2019 attributed to all VTO and FCTO technology programs.

VTO and FCTO technology is projected to improve fuel economy by $36 \%$ to $66 \%$ for new light-duty vehicles sold in 2035 , and by as much as $77 \%$ by 2050 , relative to improvements in the absence of DOE funding. Similarly, Program Success for new heavy-duty trucks would increase fuel efficiency by $24 \%$ by 2035 , and $28 \%$ by 2050 , relative to the No Program case. These increases are shown in Figure ES-2.

Projections of light-duty vehicle adoption indicate that although advanced-technology vehicles may be somewhat more expensive to purchase, the fuel savings result in a net reduction of consumer cost. In 2035, projections of a decrease in annual fuel expenditures for light-duty vehicles range from $\$ 62$ billion to $\$ 85$ billion (2015\$), while the projected increase in new lightduty vehicle expenditures in the same year ranges from $\$ 3$ billion to $\$ 21$ billion (2015\$), as shown in Figure ES-3. In addition, investments in technology for heavy-duty vehicles results in projected fuel savings of $\$ 24$ billion, while vehicle costs increase by $\$ 3$ billion. By 2050 , annual fuel savings for light- and heavy-duty vehicles reaches $\$ 156$ billion to $\$ 246$ billion, while vehicle purchases are projected to be $\$ 30$ billion to $\$ 35$ billion more expensive. Ranges in costs and savings for light duty vehicles represent the results of using multiple vehicle choice models to estimate the vehicle fleet. 

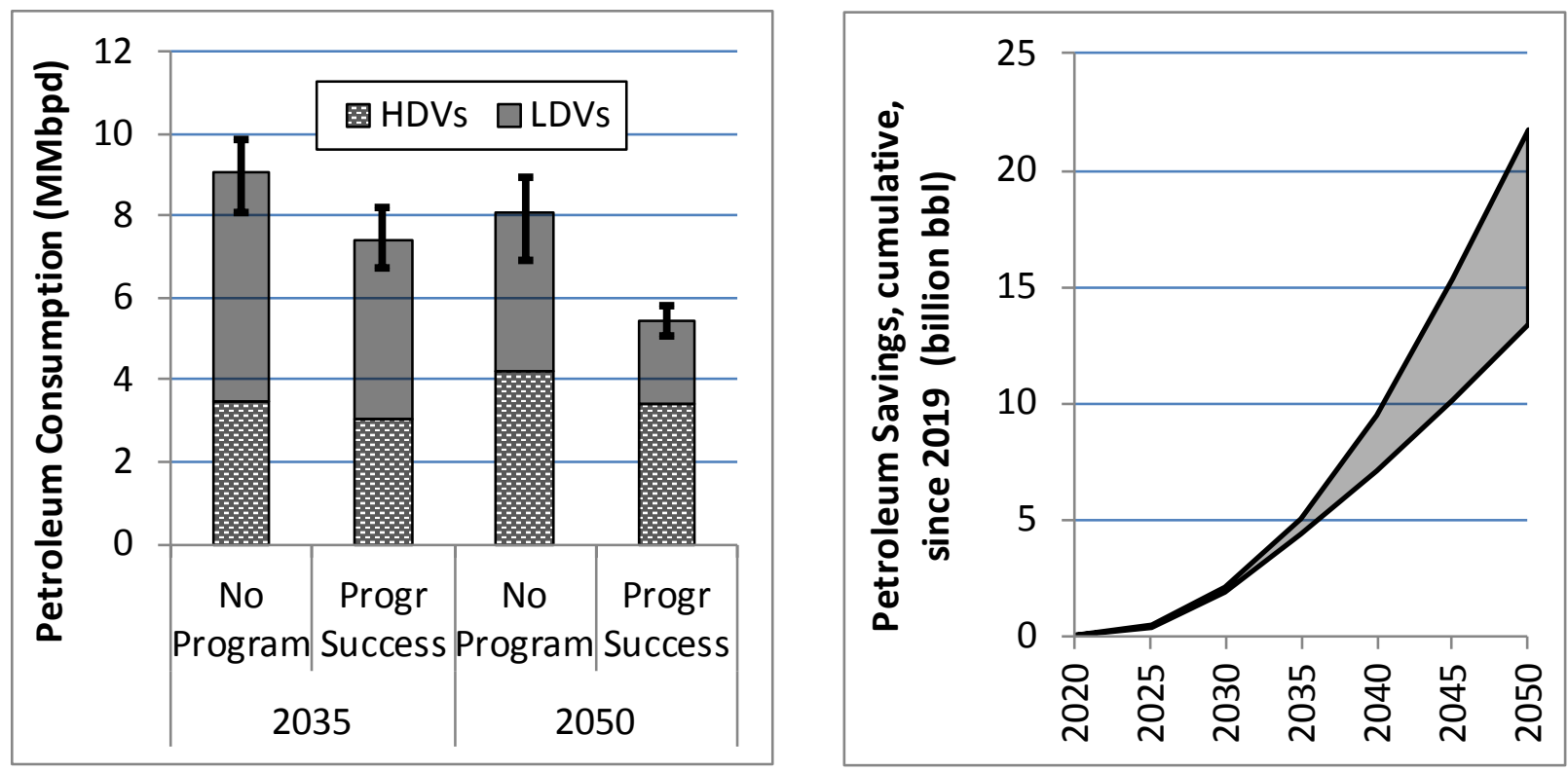

FIGURE ES-1 Projected On-road Petroleum Consumption under the No Program and Program Success Cases in 2035 and 2050 (left), and Projected Cumulative Petroleum Savings Attributed to All VTO and FCTO Technology Programs (right)
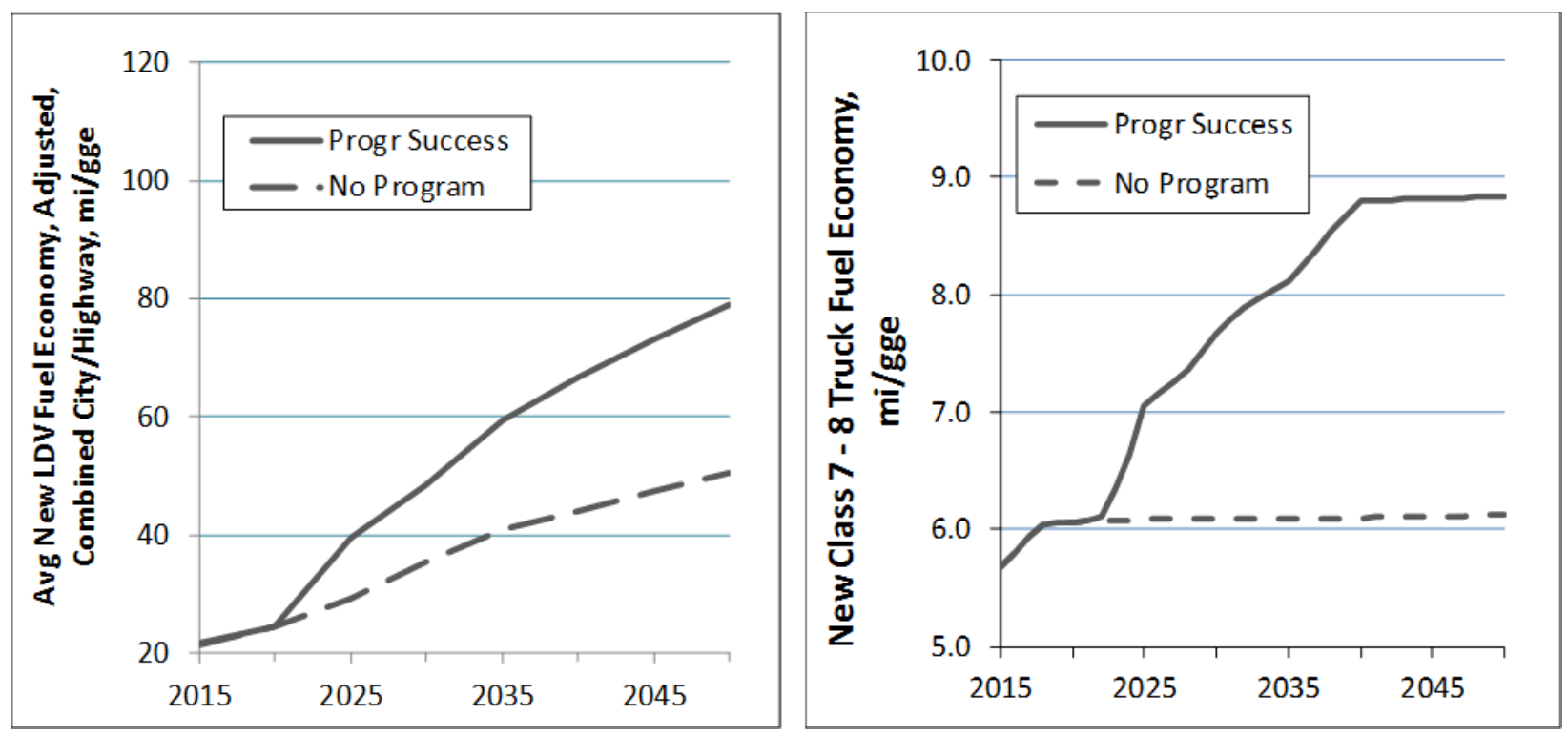

FIGURE ES-2 Fleet-averaged Fuel Efficiency through 2050 for Light-duty (left) and Class 7-8 Combination Unit (heavy-duty) Trucks (right) for the Program Success and No Program Cases 


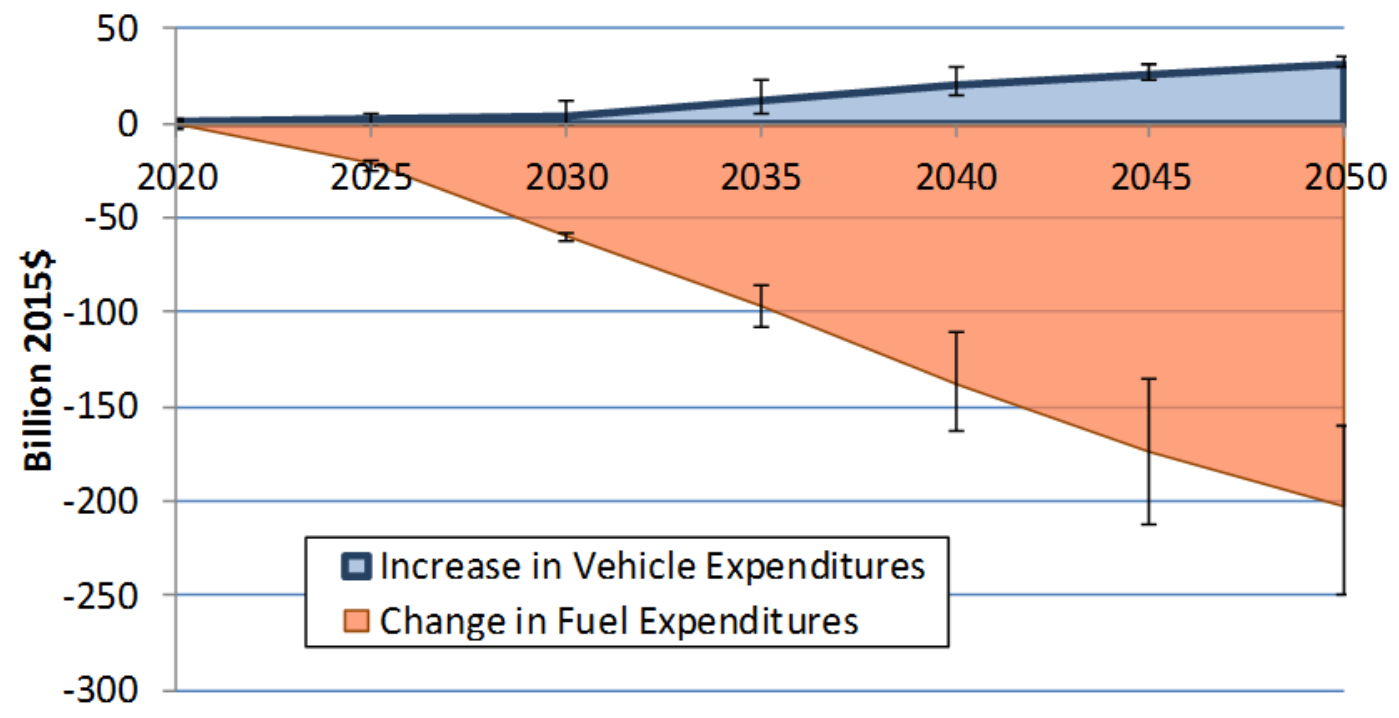

FIGURE ES-3 Difference in Annual National Consumer Costs of Vehicle Purchases and Fuel Costs for On-road Vehicles through 2050 for the No Program and Program Success Cases

Benefits were disaggregated by individual program technology areas, which included the FCTO program and the VTO research and development (R\&D) programs of Electrification, Advanced Combustion Engines and Fuels, and Materials Technology. Benefits to medium- and heavy duty vehicles were attributed to Advanced Combustion Engines and Fuels, the program which funds most of the heavy-duty technologies. Table ES-1 presents the ranges of projected petroleum savings and GHG reductions attributed to these programs. The estimated savings depend on market penetration projections that assume that those technologies closer to commercialization will ramp up more quickly than those that are in earlier stages of development such as fuel cells and hydrogen infrastructure.

TABLE ES-1 Projected Ranges of Petroleum Savings and Emissions Reductions in 2025, 2035, and 2050 by VTO and FCTO Technology Programs

\begin{tabular}{|c|c|c|c|c|c|c|}
\hline \multirow[b]{2}{*}{ Program Area } & \multicolumn{3}{|c|}{$\begin{array}{l}\text { Annual Petroleum Savings } \\
(\mathrm{MMbpd})\end{array}$} & \multicolumn{3}{|c|}{$\begin{array}{l}\text { Annual GHG Reduction } \\
\text { (million tons } \mathrm{CO}_{2} \text {-eq) }\end{array}$} \\
\hline & 2025 & 2035 & 2050 & 2025 & 2035 & 2050 \\
\hline Electrification & $0.03-0.19$ & $0.28-0.61$ & $0.34-1.44$ & $5-29$ & $57-123$ & $74-272$ \\
\hline $\begin{array}{l}\text { Advanced Combustion } \\
\text { Engines and Fuels }\end{array}$ & $0.25-0.32$ & $0.66-1.01$ & $0.85-1.01$ & $47-62$ & $122-194$ & $151-182$ \\
\hline Materials Technology & $0.02-0.03$ & $0.06-0.12$ & $0.06-0.08$ & $4-7$ & $11-24$ & $11-15$ \\
\hline Hydrogen Fuel Cells & $0.00-0.05$ & $0.11-0.45$ & $0.35-0.96$ & $0-6$ & $14-46$ & $59-148$ \\
\hline
\end{tabular}


This page intentionally left blank.

ES-4 


\section{INTRODUCTION AND PROGRAM OVERVIEW}

The U.S. Department of Energy's (DOE's) Office of Energy Efficiency and Renewable Energy (EERE) supports early-stage research and development (R\&D) of energy efficiency and renewable energy technologies that enhance energy affordability, reliability, and resilience and strengthen U.S. energy security, economic growth, and environmental quality. The Vehicle Technologies Office (VTO) and Fuel Cell Technologies Office (FCTO) are two offices under EERE's Sustainable Transportation pillar. VTO conducts R\&D to provide low-cost, reliable, and efficient energy for transportation of goods and people across America. FCTO has a comprehensive portfolio of activities that address the barriers facing the development and implementation of hydrogen and fuel cells, with the ultimate goals of decreasing our dependence on oil, reducing greenhouse gas (GHG) emissions, and enabling clean, reliable power generation through utilization of hydrogen for both transportation and stationary uses. This report quantifies the vehicle-level and national-level benefits of successful VTO and FCTO R\&D. The analysis in this report concludes that the prospective benefits of these R\&D activities will likely be significant as more fuel-efficient vehicles and no-petroleum vehicles are adopted for use in the U.S.

This report also describes scenarios for the implementation of VTO and FCTO technologies, as well as methods for estimating the benefits expected from successful adoption of these technologies. A number of analytic models were used, including advanced vehicle simulation-and-power-flow models that correlate the impacts of R\&D activities on future improvements in fuel economy due to traditional and alternative drivetrain technologies. Other models are used to estimate how more efficient vehicles and alternative fuel vehicles penetrate the on-road stock, and to quantify the resulting reductions in energy use and GHG emissions. This analysis links VTO and FCTO program goals to estimated benefits, as shown in Figure 1-1, which also indicates some of the models used for each step in the process. Methods and assumptions are described in Section 2 and the appendices.

The analyses documented here were made assuming that the VTO and FCTO budget levels will remain at recent historical levels. The technology development plans and milestones for each VTO program and for the FCTO program are presented in Section 1, with the estimated petroleum savings and GHG reductions attributable to each program. Section 2 details the methodology of this benefits analysis. A baseline case, "No Program," against which to measure VTO and FCTO program benefits and a "Program Success" case are described for light-duty vehicles (LDVs) and for heavy trucks (HTs). In Section 3, the benefits of the VTO and FCTO programs to the entire U.S. fleet, in terms of reductions in energy use and GHG emissions, and some of the economic implications of these reductions are discussed. Section 4 explores the benefits attributable to VTO and FCTO R\&D programs and key activities for LDVs and HTs. Section 5 summarizes key results from the report. References used in support of this document are provided in Section 6.

Deeper technical information is available in the appendices. Appendix A compares the No Program and Program Success cases with projections from DOE's Energy Information Administration (EIA). Appendix B examines LDV model inputs and outputs, describes four 


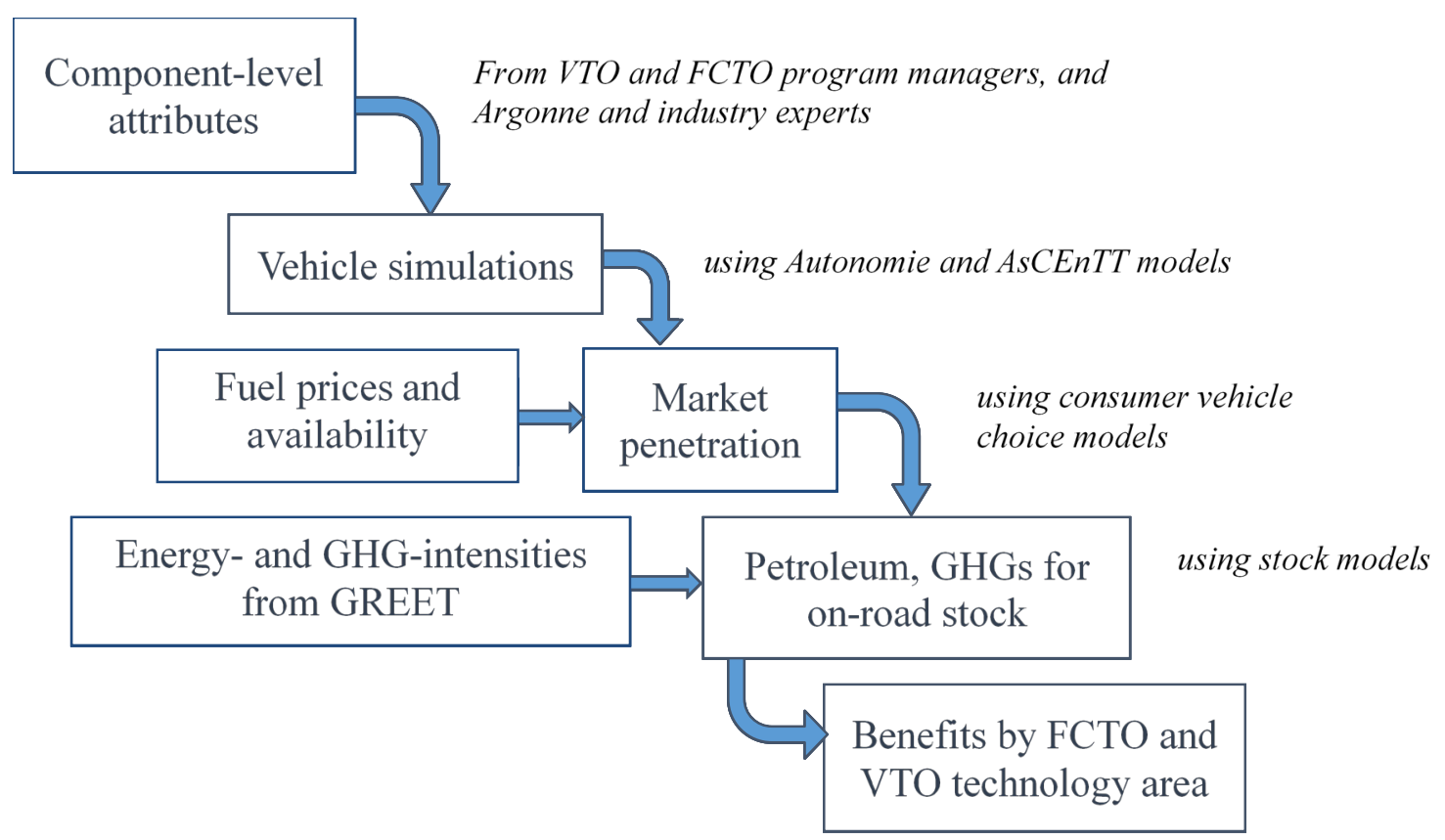

FIGURE 1-1 General Approach and Information Flow in the Benefits Analysis

vehicle choice models, and compares their projections for market penetrations and fleet fuel economy. Appendix C examines technology penetration in HTs. Appendix D explores the variation in consumer choice modeling and how this affects projections of oil security and consumer costs.

\subsection{OFFICE OF ENERGY EFFICIENCY AND RENEWABLE ENERGY SUSTAINABLE TRANSPORTATION PROGRAMS}

Under the EERE at DOE, the Sustainable Transportation Office comprises the VTO, FCTO, and the Bioenergy Technologies Office (BETO), as shown in Figure 1-2.

\subsubsection{Vehicle Technologies Office}

VTO funds early-stage, high-risk research to generate knowledge upon which industry can develop and implement innovative energy technologies for the efficient, reliable, and secure transportation of people and goods across America. As such:

- $\quad R \& D$ focuses on reducing cost, improving the energy-related performance, and minimizing emissions of a mix of medium- and long-term vehicle technologies, including advanced batteries, electrification technologies, lightweight and propulsion materials, advanced combustion engines and fuels, and energy-efficient mobility technologies and systems. 


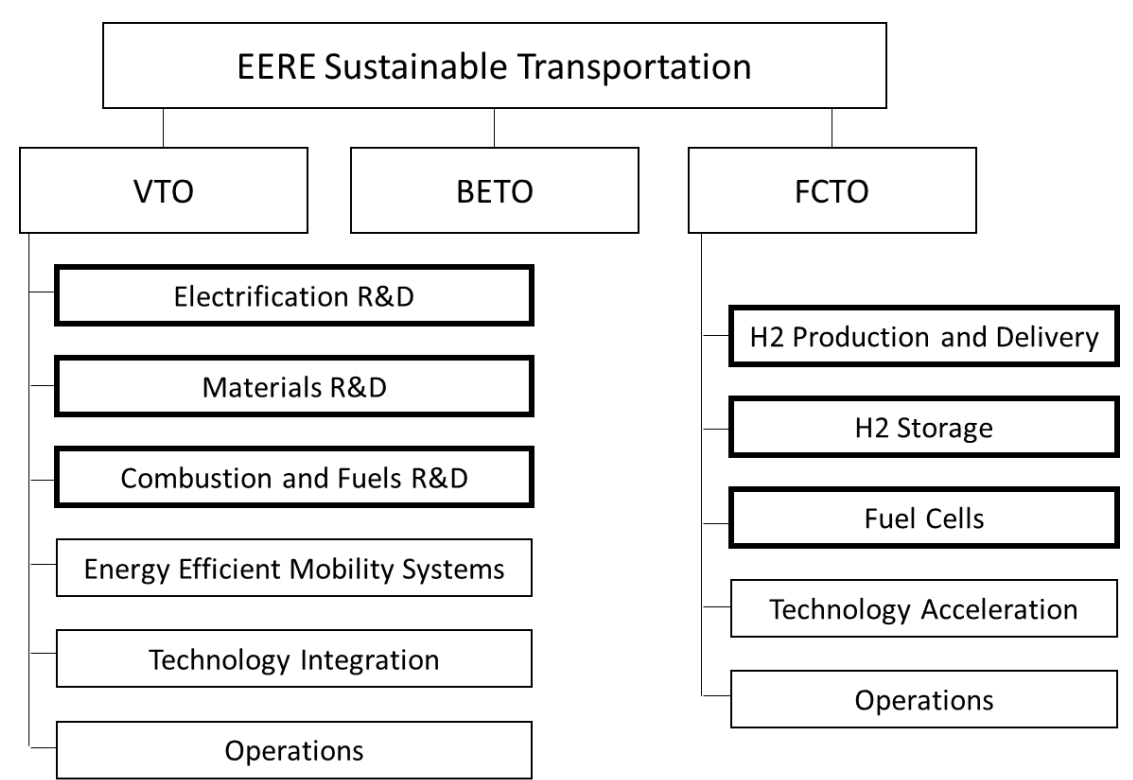

\section{FIGURE 1-2 Organization of Programs in EERE's VTO and FCTO (R\&D outputs from programs in boxes with bold borders are explored in detail in this report.)}

- Modeling, evaluation, and analysis provide objective, publicly available data to identify the most appropriate federal investments and pathways for technology improvements, along with lessons learned for cost-effective future integration.

- Technology integration provides data, tools, and resources to help consumers and businesses understand their options for saving money on their transportation energy costs.

Figure 1-2 and Section 1.2 detail the technical R\&D programs in VTO that provided inputs to this analysis. In addition, VTO includes programs for Energy Efficient Mobility Systems (EEMS), Technology Integration, and Analysis. Recognizing the fundamental disruption in transportation that is occurring due to new technologies emerging across the transportation system, and the potentially dramatic energy implications, the VTO EEMS program supports R\&D to address system-level questions to advance a maximum-mobility, minimum-energy future. EEMS includes the Systems and Modeling for Accelerated Research in Transportation (SMART) Mobility Consortium, a multi-year effort at five of the DOE national laboratories to research and deliver new data, analysis, and modeling tools to understand the energy implications of connectivity and automation, multi-modal transport of people and goods, urban mobility, advanced fueling infrastructure, and mobility decisions (Sarkar \& Ward, 2016). EEMS is working with the U.S. Department of Transportation (DOT) Smart City Challenge finalist cities and others to examine the energy impacts of mobility systems. Living labs test new ideas, collect data, and best practices to inform research on energy efficiency technologies and systems. 
The Technology Integration program includes a portfolio of activities that provide data, tools, and resources to help consumers and businesses understand their options for saving money on their transportation energy costs. The Data and Systems Research activity supports a broad technology portfolio that includes alternative fuels (e.g., biofuels, electricity, hydrogen, natural gas, and propane), EEMS and technologies, and other efficient advanced technologies that can reduce transportation energy costs for businesses and consumers. Data and Systems Research includes living lab activities that evaluate technology solutions under real-world conditions and generate data and lessons learned to inform future research needs. It also includes projects to disseminate data, information, and insight, as well as online tools and technical assistance to cities and regions working to implement alternative fuel and energy efficient mobility technologies and systems. Key to the success of VTO efforts is the nationwide network of local Clean Cities coalitions that provide a boots-on-the-ground approach and significantly extend the reach of VTO efforts. Advanced Vehicle Competitions activity provide hands-on, real-world experience to university students in the area of advanced vehicle technologies and designs. With a focus on science, technology, engineering, and math, VTO's Advanced Vehicle Competitions support the development of a workforce trained in advanced vehicle technologies. The Legislative and Rulemaking activity implements the statutorily directed State and Alternative Fuel Provider Regulatory program, as well as alternative fuel designations, and other legislated requirements, including reports and rulemaking, analyses of impacts of other regulatory and pending legislative activities, and the implementation of legislative changes to the Energy Policy Act (EPAct) fleet activities as they occur.

Strategic public-private research partnerships with industry (e.g., United States Driving Research and Innovation for Vehicle efficiency and Energy [U.S. DRIVE] and 21st Century Truck Partnerships) leverage technical expertise, prevent duplication, accelerate progress, and ensure public funding remains focused on the most critical barriers to technology commercialization. Strategic public-private partnerships with end-users and other key stakeholders (e.g., Clean Cities and the National Clean Fleets Partnership) focus on overcoming market barriers and catalyzing private sector action to enable the widespread use of advancedtechnology vehicles.

VTO supports the planning, execution, and communication of technological, societal, economic, and interdisciplinary analyses to inform overall VTO program planning and key technology investment decisions. The analysis activities support the planning and execution of mission-critical technology, economic, and interdisciplinary analyses to inform and prioritize VTO technology investments and research portfolio planning. Work, analyses, and publications support essential vehicle data, modeling and simulation, and integrated and applied analysis activities, using the unique capabilities, analytical tools, and expertise resident in the national laboratory system. 


\subsubsection{Fuel Cell Technologies Office}

Hydrogen fuel and fuel cells have the potential to advance energy security and reduce emissions of GHGs and criteria pollutants by improving energy efficiency, enabling alternative fuel sources, and spurring domestic production of clean energy technologies. Widespread use of hydrogen and fuel cells can have a major impact toward achieving EERE goals of expanding the adoption of sustainable, domestically powered transportation alternatives; improving the efficiency of energy use; stimulating the growth of domestic clean energy manufacturing; and enabling the integration of clean energy into a reliable, resilient, and more efficient electricity grid.

FCTO's portfolio includes both fuel cell and hydrogen fuel R\&D, with an emphasis on renewable production pathways and optimal methods for delivery and storage of hydrogen to help meet cost and performance goals. Improving cost, performance, and durability of hydrogen fuel cells is necessary for commercialization. Meeting hydrogen storage targets will require R\&D to develop low-cost, high- performance composites, high-strength materials, and packaging conformability. Cost reduction of at-scale technologies is the key challenge in the production and delivery of hydrogen, using a portfolio of technologies that are scalable and that meet industrial performance and safety requirements (DOE, 2015). Specific R\&D targets are presented in Section 1.2.4.

Beyond R\&D, technology acceleration is a core component of FCTO. The Technology Validation program demonstrates, tests, and validates hydrogen and fuel cell technologies and uses the results to provide feedback to FCTO R\&D activities and determine when technologies should be moved to the market transformation phase. The purpose of the Market Transformation program is to spur market introduction by demonstrating pre-commercial technologies in realworld applications. By doing so, this program helps to identify and overcome market barriers and to reduce the life-cycle costs of fuel cell power through technical and non-technical solutions. Market Transformation activities provide financial and technical assistance for the use of hydrogen and fuel cell systems in early market applications. Key goals are achieving sales volumes that will enable cost reductions through economies of scale; supporting the development of a domestic industry; and providing feedback to testing programs, manufacturers, and potential technology users. The Safety, Codes and Standards program supports R\&D needed to define requirements and close gaps in safety, codes, and standards to enable the safe use and handling of hydrogen and fuel cell technologies (DOE, 2017b).

FCTO has also addressed a number of nontechnical factors, such as user confidence, ease of financing, and refueling infrastructure logistics, particularly for fuel cell vehicles (FCVs). Public awareness of FCTO technologies is enhanced by activities such as support of partnerships like H2USA, a public-private collaboration focused on the widespread commercial adoption of FCVs. As in VTO, the Systems Analysis program supports the decision-making of the FCTO through greater understanding of technology gaps, options, and risks. The goal of the Systems Analysis program is to provide system-level analysis to support hydrogen and fuel cell technology development and technology readiness. Analysis is also conducted to assess crosscutting issues, such as integration of hydrogen and fuel cells with the electric grid for energy storage and hydrogen infrastructure development (DOE, 2017b). 


\subsection{TRANSPORTATION R\&D PROGRAMS}

\subsubsection{Electrification R\&D}

The VTO Electrification R\&D program supports research of the low-cost, high-energy batteries and low-cost, efficient electric drive technologies and charging systems needed to produce efficient plug-in electric vehicles (PEVs) (including all-electric vehicles and plug-in hybrid electric vehicles [PHEVs]). Activities also include R\&D of advanced thermal management technologies and advanced materials for electric drive technologies.

Battery R\&D focuses on the technologies necessary to reduce modeled high-volume battery costs from $\$ 300 / \mathrm{kWh}$ in 2014 to $\$ 125 / \mathrm{kWh}$ by 2022 by funding early-stage research programs with partners in academia, at national laboratories, and in industry (DOE, 2017d). These technologies include high-energy and high-power materials and systems that promise to significantly reduce the cost, weight, and volume of PEV batteries.

The focus of the Electric Drive, Grid, and Charging R\&D subprogram is on researching technologies and innovations to reduce the cost, significantly increase the power density, and improve the reliability of power electronics, electric motors, and other electric propulsion components. The electric drive cost target for 2020 is $\$ 8 / \mathrm{kW}$ ( $\$ 440$ for a $55-\mathrm{kW}$ system), a $50 \%$ reduction from the 2012 cost of $\$ 16 / \mathrm{kW}$ (\$880/system) (U.S. DRIVE, 2013). R\&D is focused on power electronics and electric motor innovations using advanced, low-cost materials, technologies, and topologies to develop motors, inverters, chargers, and DC/DC converters for electric drive vehicles. The subprogram will continue subcomponent R\&D of high-temperature capacitors, high-power, high-density packaging of power semiconductors, and non-rare earth magnetic materials.

\subsubsection{Advanced Combustion Systems and Fuels R\&D}

The VTO Advanced Combustion Systems and Fuels R\&D program supports research of advanced engine technologies and optimized fuel properties to improve thermal efficiency, reduce exhaust emission, and develop technologies that reduce parasitic losses to decrease petroleum use in U.S. highway transportation.

The Advanced Combustion Systems and Fuels R\&D program supports research to significantly increase the efficiency of next-generation internal combustion engines (ICEs) that will be co-optimized with advanced fuels, fully integrating high-performance combustion and fuels R\&D. The program will conduct research on fuel properties where the ultimate goal is cost-effective, performance-tailored blendstocks, including bio-derived, synthetic, and petroleum-based blendstocks to enable high-performance, efficient engines. Co-optimization of engines and fuels as an integrated system will enable better control of future engines operating on future fuel formulations at peak efficiency for a higher portion of the drive cycles. Increasing the efficiency of ICEs is one of the most cost-effective approaches to reducing petroleum consumption of new vehicles in the near- to mid-term, including in conventional (Conv), hybrid, 
and PHEVs. Co-optimization of higher-efficiency engines and high-performance fuels utilizing the fundamental knowledge and new understanding created by this subprogram has the potential to improve light-duty fuel economy by $55 \%$ ( $40 \%$ from advanced engine research and up to $15 \%$ from co-optimization with fuels) by 2030 compared to 2009 gasoline vehicles, and to increase Class 8 truck engine efficiency by 35\% compared to a 2009 baseline (DOE, 2017a; DOE 2016a). The SuperTruck II initiative builds on the earlier VTO SuperTruck initiative with a target of improved freight-hauling efficiency by greater than 100\% over a 2009 baseline, while being cost-effective and having comparable performance (DOE, 2016b). The knowledge generated by this program will increase energy efficiency and improve the fuel economy of passenger and commercial vehicles entering the market.

\subsubsection{Materials Technology R\&D}

The VTO Materials Technology program supports vehicle lightweighting and improved propulsion efficiency through the discovery, development, and utilization of materials and enabling technologies for light- and heavy-duty vehicles. The Materials Technology program seeks to accomplish these technical objectives through research programs with academia, national laboratories, and industry. Weight reduction R\&D emphasizes the glider, which includes the body, chassis, and interior of the vehicle. A wide range of lightweight materials are considered, such as advanced high-strength steels, aluminum alloys, magnesium alloys, carbon fiber composites, and multi-material systems with performance and manufacturability that greatly exceed today's technologies. VTO research addresses materials and manufacturing challenges spanning from extraction to assembly, with an emphasis on establishing tools, capabilities, and material standards for light- and heavy-duty vehicles.

Propulsion materials R\&D supports research to develop higher performance materials that can withstand increasingly extreme environments and address the future properties needs of a variety of relevant high- efficiency powertrain types, sizes, fueling concepts, and combustion modes. The activity will apply advanced characterization and multi-scale computational materials methods, including high-performance computing, to accelerate innovations of cuttingedge structural and after-treatment materials for cleaner, more efficient powertrains. Goals for cost and performance targets are for material technology to enable a $25 \%$ weight reduction at less than \$5/lb saved by 2025 for LDVs, including body, chassis, and interior against a 2012 baseline (DOE, 2017c).

\subsubsection{Hydrogen and Fuel Cells Technologies R\&D}

Fuel cells enable highly efficient use of energy and have the potential for zero emissions when powered by renewable fuels or hydrogen produced in tandem with carbon capture and storage. FCTO R\&D includes hydrogen production and delivery, hydrogen storage, and fuel cells research. The Hydrogen Production program supports R\&D of technologies that will enable the long-term viability of hydrogen as an energy carrier for a diverse range of end-use applications, while the Hydrogen Delivery program addresses all hydrogen transmission and distribution activities from the point of production to the point of dispensing (DOE, 2017b). 
Ultimate targets for total cost of hydrogen fuel are below $\$ 4 / \mathrm{kg}$, apportioned as less than $\$ 2 / \mathrm{kg}$ for production, and less than $\$ 2 / \mathrm{kg}$ for delivery and dispensing.

The Fuel Cells program supports research, development, and demonstration (RD\&D) of fuel cell technologies for transportation applications, as well as stationary and early market applications, with a primary focus on reducing cost and improving durability (DOE, 2017b). FCTO aims to have fuel cells with peak system efficiency of $70 \%$ and a specific power density of $850 \mathrm{~W} / \mathrm{kg}$, at a price of $\$ 30 / \mathrm{kW}$. To reach these goals, the catalyst-specific power should improve to $8 \mathrm{~kW}$ per gram of platinum group metals. These fuel cells should also be sufficiently durable to operate for 8,000 hours in an automotive drive cycle.

The Hydrogen Storage program supports R\&D of materials and technologies for compact, lightweight, and inexpensive storage of hydrogen (DOE, 2017b). Hydrogen storage inside the vehicle aims to double the energy density of hydrogen storage by 2050 , while reducing the cost by more than $40 \%$. These correspond to ultimate goals of gravimetric and volumetric storage densities of $2.5 \mathrm{~kg} \mathrm{H}_{2} / \mathrm{kg}$ system and $2.3 \mathrm{~kg} \mathrm{H}_{2} / \mathrm{L}$ system, at $\$ 8 / \mathrm{kWh}(\$ 266 / \mathrm{kg} \mathrm{H}$ ) when produced at volume. 


\section{TRANSLATING PROGRAM GOALS INTO MODEL INPUT}

The analysis of advanced technologies to estimate their benefits was based on a threestep, market-based approach. First, the average fuel economy and incremental costs of new vehicles that incorporate DOE-supported technologies were estimated. Second, consumer choice models were used to estimate the market shares of these platforms in the future. Finally, the projected fuel economies and market shares were used as inputs to the VISION model (used for LDVs) and the HDStock model (used for HTs), which projects future on-road vehicle stock and estimates fuel consumption and GHG emissions. From these, the fuel savings and GHG emission reductions were estimated and attributed to VTO and FCTO technologies. Each of these steps is described below, first for LDVs in Section 2.1, then for HTs in Section 2.2. The overall methodology for benefits analysis is similar to that used previously for the VTO programs, formerly called the Government Performance and Results Act (GPRA) report (e.g., Stephens et al., 2014).

For both LDVs and HTs, two cases were developed:

- The No Program case, which assumes that there is no technology improvement or cost reduction beyond 2018 due to the VTO and FCTO programs; and

- The Program Success case, which assumes that there are future technology improvements and cost reductions that meet VTO and FCTO program goals.

The economic and environmental benefits were taken to be the difference in the fuel use and GHG emissions between these two cases. The No Program case was developed to represent future vehicle technology, fuel use, and GHG emissions without the effects of technology improvements brought about by the VTO and FCTO programs. The No Program and Program Success cases for light-duty and heavy-duty vehicles are described in the following sections.

The DOE EIA's Annual Energy Outlook (AEO) is the official DOE-wide projection and analysis of future U.S. energy supplies, demands, and prices. Inputs from AEO 2016 were used for fuel prices, vehicle travel, and vehicle ownership in this analysis (EIA, 2016). However, the AEO Reference Case assumes current policies remain in effect until they sunset. Projections made for the AEO Reference Case thus incorporate assumptions about the market success of technologies historically supported by VTO and FCTO. A more appropriate baseline case for comparing LDVs and HTs was constructed by projecting the diminishing technological progress over time that would be expected to occur without VTO- and FCTO-supported R\&D. Appendix A compares the projections from AEO 2016 with the No Program and Program Success cases discussed here. 


\subsection{LDV ANALYSIS}

\subsubsection{LDV Attributes}

For LDVs, parameters describing vehicle component performance, manufacturing costs, and other attributes were estimated for 2010, 2015, 2020, 2025, 2030, and 2045 based on input from VTO and FCTO analysts and program managers and Argonne National Laboratory (Argonne) vehicle technology experts. For the No Program case, a baseline based on simulations of future vehicles was developed by assuming that only incremental technology improvements would occur without support from the VTO and FCTO programs. For the Program Success case, starting assumptions about vehicle component characteristics were based on VTO and FCTO program targets and relevant vehicle data available in the Autonomie library, a database used with the Autonomie toolkit (Argonne, 2017). These starting assumptions were used in the Autonomie toolkit (Argonne, 2017) to simulate vehicles in five classes-compact car, midsize car, small sport utility vehicle (SUV), midsize SUV, and pickup truck-with each one having the following types of drivetrains using the specified fuel:

- Conv spark-ignition (SI), gasoline;

- Conv compression-ignition (CI), diesel;

- Hybrid electric vehicle (HEV), gasoline;

- Plug-in hybrid electric, SI engines with nominal charge-depleting (CD) ranges of 25 and $50 \mathrm{mi}$ (PHEV25, PHEV50), gasoline and electricity;

- FCV, hydrogen; and

- Battery electric vehicle (BEV), with batteries sized for ranges of 100, 200, and $300 \mathrm{mi}$ (BEV100, BEV200, and BEV300), electricity.

For each of these powertrain architectures, the Autonomie model was used to simulate future vehicles, appropriately sized to offer sufficient power, given the weight of the glider (chassis, body, and interior components) and drivability requirements. This was done for each technology scenario to estimate each vehicle's fuel economy on U.S. Environmental Protection Agency (EPA) city and highway driving schedules. The incremental costs associated with the advanced powertrains were calculated by using a combination of direct inputs from VTO and FCTO for advanced technologies and costs estimated by Ricardo Engineering of Van Buren, Michigan, for near-commercial technologies. Specifically, EERE technology targets were used to estimate costs and performance for the Program Success case for batteries, power electronics and electric motors, fuel cells, and on-board hydrogen storage; cost models developed by the Argonne Autonomie group and by Ricardo Engineering were used for estimating costs for other components. 
Vehicle retail price equivalent was estimated by applying a factor of $150 \%$ to the vehicle manufacturing cost, based on reviews of automotive manufacturing indirect costs (Rogozhin et al., 2010; Vyas et al., 2000). Prices were estimated for the base trim level, and all component price models assumed fully learned, high-production-level costs. Further details will be documented in a forthcoming report (Islam et al., 2017). This methodology is essentially the same as used in previous benefits analyses, as described in Moawad et al. (2016).

Future LDVs were not assumed a priori to meet EPA/National Highway Transportation Safety Administration standards for GHG emissions and Corporate Average Fuel Economy (CAFE) for 2017 through 2025. Sales-weighted average fuel economy values for the new car and light truck fleets were calculated after sales shares were estimated and compared with CAFE standards; however, regulatory flexibilities such as trading or banking of credits were not accounted for. Average fuel economies projected by the vehicle choice models depended on sales shares of the various vehicle types. In most No Program projections, and in year 2020 of the Program Success case values fell short of CAFE standards. However, in nearly all projections for the Program Success case in 2025, values met or exceeded the standards. Note that VTO and FCTO technologies were assumed not to influence vehicle efficiency until 5 years after R\&D targets were assumed to be met, as discussed below. The vehicle attributes assumed for 2020 were the same in the Program Success case as in the No Program case. A comparison of the No Program and Program Success cases with federal fuel economy standards using EIA projections is presented in Appendix A.

The objective of this analysis was not to assess how advanced vehicle technologies might be applied in order to meet future fuel economy or GHG standards, but to assess the influence of technologies independent of the influence of standards. Therefore, automakers' strategic decisions regarding technology adoption were not explicitly modeled; rather, the consumer choice models were used to represent consumer demand.

Vehicles simulated with these component attributes were assumed to be representative of vehicles available in showrooms 5 years later-in 2015, 2020, 2025, 2030, 2035, and 2050. Attributes in vehicles in showrooms in 2015 and 2020 were the same for both the No Program and Program Success cases, since the benefits being analyzed were those accruing after 2018. Attributes of vehicles in showrooms in 2025, 2030, 2035, and 2050 in the Program Success case reflected the improved efficiency and lower cost that are expected from completely successful achievement of VTO and FCTO program goals and commercialization of these technologies.

\subsubsection{LDV Market Penetration Modeling}

Outputs of the Autonomie modeling were used with fuel prices as inputs to the vehicle choice models in the second step of LDV modeling. Owing to the large uncertainty of future markets for advanced technology vehicles, multiple projections of market shares of LDVs were developed using different vehicle choice models. Four models under development by VTO were used to give four sets of market projections for the No Program and Program Success cases: 
- Light-Duty Alternative Vehicle Energy Transitions (LAVE-Trans) model, developed by Oak Ridge National Laboratory (ORNL) (Liu, 2015; NRC, 2013)

- LVCFlex model, developed by Energetics, Incorporated (Birky, 2015)

- Market Acceptance of Advanced Automotive Technologies (MA3T) model, developed by ORNL (Lin and Greene, 2010, 2011; Lin, 2015)

- ParaChoice model, developed by Sandia National Laboratories (SNL) (Manley et al., 2015)

Comparisons of sales and stock shares across each of these four models is presented in Appendix B. In the LVCFlex and ParaChoice models, the total LDV annual sales were assumed to be the same as in the AEO 2016 Reference Case extrapolated to 2050 (a linear extrapolation based on the average slope in years 2035 to 2040). Total LDV sales were estimated by the $\mathrm{MA}^{3} \mathrm{~T}$ and LAVE-Trans models, but these were close to the AEO Reference Case projections. Future energy consumption and GHG emissions by LDVs for both the No Program and Program Success cases were projected for the four vehicle choice models using sales shares calculated in the earlier steps using Argonne's VISION model, 2016 version (Zhou and Vyas, 2014).

The VISION model is an accounting spreadsheet that calculates output metrics of interest on a national scale. Results from vehicle choice models with multiple car and light truck size classes were aggregated to give sales-weighted average values of fuel economy and sales share by technology for cars and light trucks. For each drivetrain type, VISION applies a fuel economy adjustment factor to convert combined city/highway test-cycle fuel economy values (supplied by Autonomie) to on-road fuel economy values. These factors range from 0.7 to 0.85 , depending on the drivetrain type, and are based on factors used by the EIA in the AEO or on EPArecommended "mileage-based" equations (EPA, 2006). The distance driven by LDVs (annual vehicle miles traveled, or VMT per vehicle per year) were based on AEO 2016 but was assumed to be somewhat dependent on the cost per mile, with an elasticity of demand for travel of about -0.1 , the default value in the VISION model (Zhou and Vyas, 2014).

Full fuel cycle GHG emission coefficients for fuels and electricity from the Argonne GREET (Greenhouse Gases, Regulated Emissions, and Energy Use in Transportation) model (2015 version) were used to estimate GHG emissions (Argonne, 2016), using the AEO 2016 Reference Case electricity generation mix. For the No Program case, hydrogen was assumed to be produced by steam methane reforming (SMR). The upstream energy (full fuel-cycle energy per unit of energy of hydrogen delivered, not including the embodied energy of the hydrogen) and well-to-tank GHG-intensity were estimated by the FCTO Analysis Team and these values are shown in Table 2-1. For the Program Success case, hydrogen was assumed to be produced by a combination of methane reforming and electrolysis using a mix of conventional and renewable electricity. The fraction of hydrogen produced by SMR and the energy- and GHG-intensities of the hydrogen produced by this mix were estimated by the FCTO Analysis Team and are given in Table 2-1. 
TABLE 2-1 Upstream Energy- and GHG-Intensities of Hydrogen in the No Program and Program Success Cases

\begin{tabular}{|c|c|c|c|}
\hline Case & 2020 & 2035 & 2050 \\
\hline \multicolumn{4}{|l|}{ No Program } \\
\hline$\%$ SMR & 100 & 100 & 100 \\
\hline Upstream energy, Btu/Btu $\mathrm{H}_{2}$ & 0.867 & 0.844 & 0.837 \\
\hline $\begin{array}{l}\text { GHG-intensity, well-to-tank } \\
\left(\text { Mmt GHG/quad } \mathrm{H}_{2}\right)\end{array}$ & 121.4 & 118.9 & 117.6 \\
\hline \multicolumn{4}{|l|}{ Program Success } \\
\hline \%SMR (remainder electrolysis) & 83.3 & 75 & 66.7 \\
\hline Upstream energy, Btu/Btu $\mathrm{H}_{2}$ & 0.862 & 0.826 & 0.811 \\
\hline GHG-intensity (Mmt GHG/quad $\mathrm{H}_{2}$ ) & 105.0 & 94.5 & 85.1 \\
\hline
\end{tabular}

\subsubsection{Fuel Savings Due to LDV Technology Improvement}

From the VISION results for LDVs, the total petroleum savings and GHG reduction by LDVs attributable to VTO and FCTO technologies were measured as the differences between the Program Success and No Program projections of petroleum use and GHG emissions by the total light-duty on-road fleet.

These totals were disaggregated (i.e., separated) into contributions from VTO subprogram and FCTO subprograms. Petroleum savings included those due to:

- Improvements in the fuel efficiency of each drivetrain type; and

- Increases in the shares of vehicles in the on-road stock with drivetrains that consume less, or no, petroleum-based fuel.

The petroleum saved in a given year from fuel efficiency improvements was calculated for drivetrain types that consume gasoline or diesel (gasoline ICE, diesel ICE, HEV, and PHEV). The differences between No Program and Program Success in petroleum used annually by vehicles of each drivetrain type were multiplied by the number of such vehicles on the road in that year. Energy efficiency improvements to BEVs and FCVs did not lead directly to petroleum reduction; they did, however, contribute to increased stock share of these vehicles, as described below.

Petroleum savings due to fuel economy improvements for Conv SI, Conv CI, HEV, and PHEV were attributed to VTO program technology areas by estimating the decrease in fuel consumption per mile in advanced vehicles due to improvements in technologies in each of the programs. This disaggregation is described in detail in Section 4.1. Additional fuel savings result from changes in the shares of the on-road stock of vehicles that consume less gasoline and diesel. These shares were higher in the Program Success case due to lower vehicle purchase prices and better fuel economy. 
Projected vehicle stocks were ordered from lowest petroleum consumption to highest: Conv SI, Conv CI, HEV, PHEV, BEV, and FCV. Considering the petroleum consumed by the on-road stock of vehicles in this order allows attribution of petroleum savings both to improvements in the fuel efficiencies of each drivetrain type and to substitution or replacement of one technology by another. This can be graphically represented by plotting vehicle sales along one axis, and average fuel economy on the other axis. As a representative example, Figure 2-1 shows the average annual amount of petroleum-based fuel consumed per car for each drivetrain technology, plotted against the cumulative number of cars in the on-road stock by drivetrain technology in the above order (Conv SI, Conv CI, HEV, PHEV, BEV, and FCV), as modeled by $\mathrm{MA}^{3} \mathrm{~T}$ for the No Program and Program Success cases in year 2035. The area under the curve for each drivetrain type (shown in different colors) is proportional to the average amount of petroleum-based fuel consumed by the on-road stock of vehicles of that type, since the height of each area is the petroleum consumed annually per car, and the width of each area is the number of cars on the road in that year. Cars that consume no gasoline or diesel are shown as segments along the $\mathrm{x}$-axis, with the length of the segment indicating the number of these vehicles in the on-road stock.

Figure 2-1 shows that the Program Success case has lower petroleum consumption by each vehicle type; lower stocks of Conv SI, Conv CI, and PHEV25 cars; and increased stock of other vehicle types. Figure 2-1 shows projections from the $\mathrm{MA}^{3} \mathrm{~T}$ model as an example. Analogous plots were made to analyze the petroleum savings from projections from the LVCFlex, LAVE-Trans, and ParaChoice models, as well, based on market penetration shares presented in Section B.2 of Appendix B.

Figure 2-2 shows the difference in fuel consumption under the No Program and Program Success cases. The shaded area indicates the amount of petroleum-based fuel saved by cars in 2035 that is attributable to VTO and FCTO technologies.
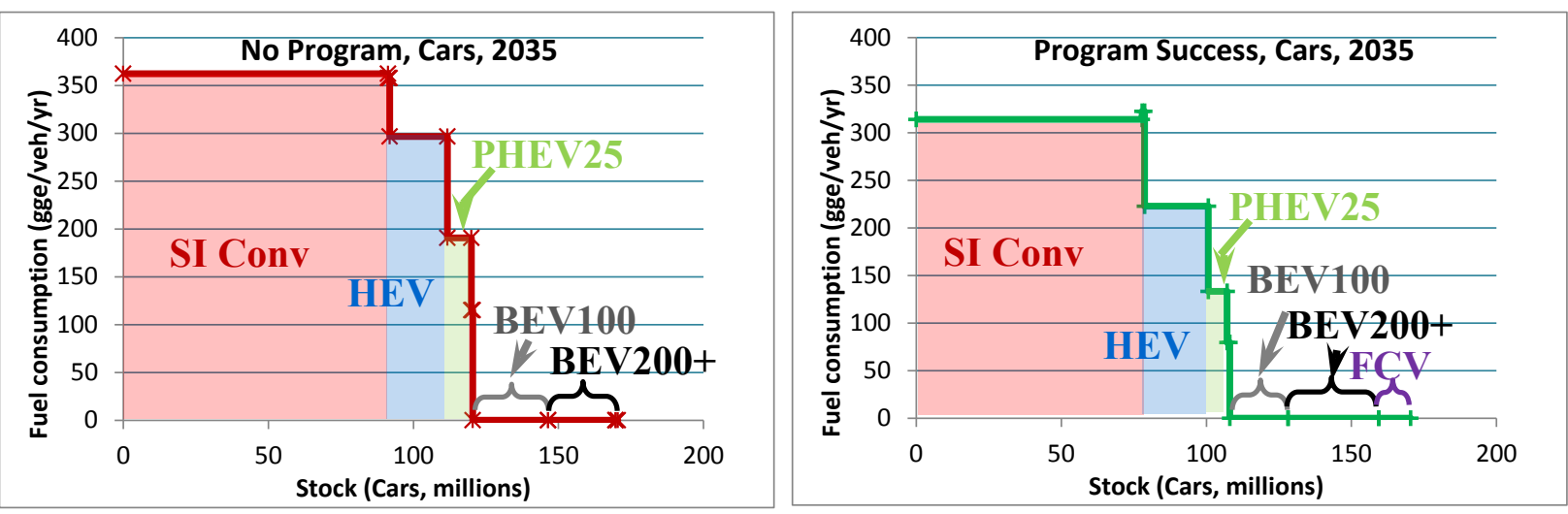

FIGURE 2-1 Example Average Annual Petroleum-based Fuel Consumption per Car in 2035 for the No Program (left) and Program Success (right) Cases, Based on Market Share Modeled by $\mathrm{MA}^{3} \mathrm{~T}$ (Petroleum consumption is plotted against the cumulative number of cars in the on-road stock. Shaded areas indicate the amount of petroleum consumed by cars of each drivetrain type in 2035.) 


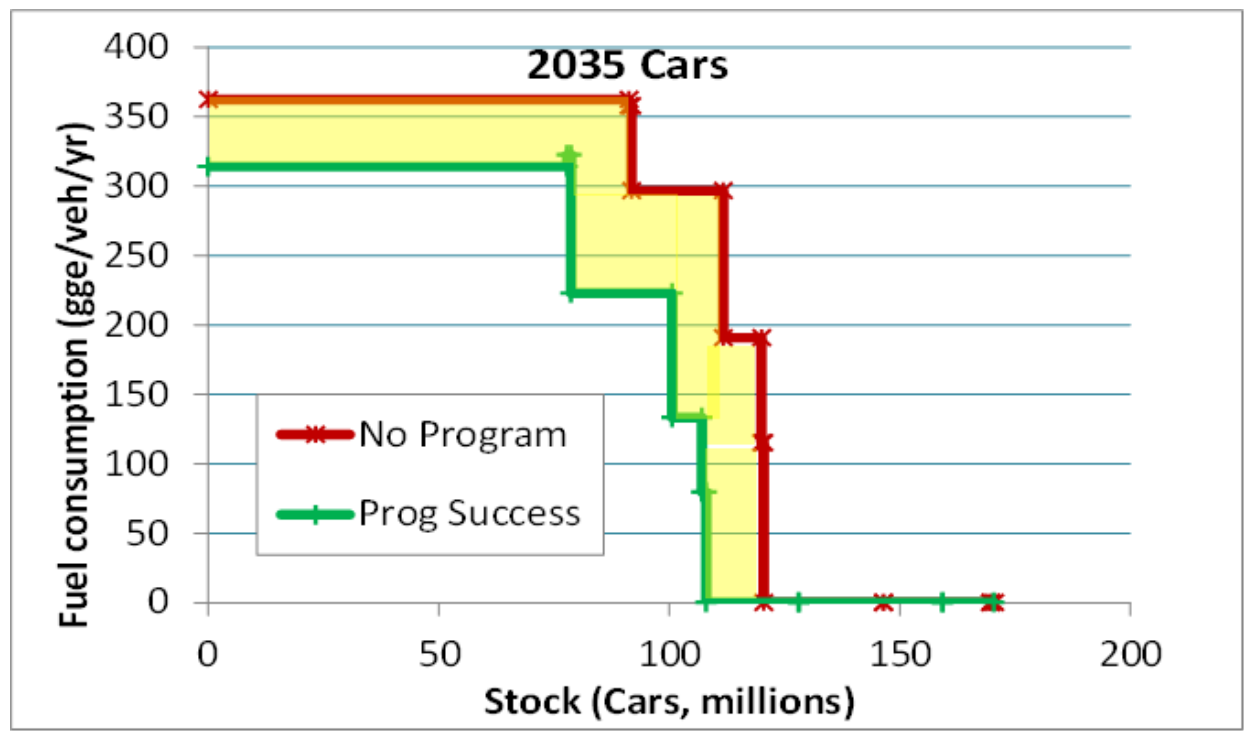

FIGURE 2-2 Average Annual Petroleum-based Fuel Consumption per Car in 2035 for the No Program (red) and Program Success (green) Cases, Based on Market Share Projected by the MA ${ }^{3}$ T Model (The shaded area indicates the amount of petroleum-based fuel saved by cars in 2035 in the Program Success case over the No Program case.)

\subsection{HEAVY TRUCK ANALYSIS}

As with LDV, the analysis of HT benefits from VTO technologies was a four-step process, in which (1) a baseline (No Program) case was developed, (2) fuel economy values and incremental costs of new vehicles with DOE-supported technologies were estimated, (3) market penetration of advanced technology vehicles was projected for Program Success vs. No Program, and (4) the projected fuel savings and GHG reductions were calculated as the differences between the two cases. Sections 2.2.1 through 2.2.3 report on each step of the benefits analysis for HTs. It was assumed that very few HTs would be FCVs; thus savings were attributed to VTO programs only.

\subsubsection{Heavy Truck Baseline}

The No Program case for medium- and heavy-duty vehicles was developed by adjusting the AEO 2016 Reference Case fuel economy values for new medium- and heavy-duty vehicles (or collectively, "heavy trucks," HT) beginning after 2018. The adjustments removed the fuel economy improvements attributed to the projected market penetration of VTO-funded advanced vehicle technologies. Using 2018 as the base year for the analysis ensures that the baseline No Program case meets the Phase 1 fuel consumption standards for commercial vehicles (EPA and NHTSA, 2011a). For the AEO Reference Case, the EIA provided estimates of the contributions of individual component technologies to truck fuel economy and market penetrations. The EIA modeled the technology market penetrations at a finer level of 
disaggregation than presented in the AEO output tables. Technology penetrations were analyzed in subclasses consistent with the EPA/NHTSA (National Highway Transportation Safety Administration) fuel consumption rules (EPA and NHTSA, 2011a, 2011b):

- Class 7 and 8 tractor sleeper cabs

- Class 7 and 8 tractor day cabs

- Class 7 and 8 vocational trucks

- Class 4-6 vocational

- Class 3 pickup, van, and vocational

"Vocational" as used in the above list was adopted from EPA/NHTSA and refers to all trucks that are not tractors or pickups. These include van- or box-type trucks as well as vehicles such as cement mixers, refuse haulers, dump trucks, and utility vehicles.

Consistent with prior analyses of benefits due to VTO and FCTO programs (e.g., Stephens et al., 2016; Stephens et al., 2014), this analysis considers only technologies developed for diesel trucks in weight Classes 4-8. As a result, the sales distribution and fuel economy of Class 4-8 gasoline trucks and all Class 3 trucks in the Program Success case remain the same as in the No Program case. While VTO-funded research for both light- and heavy-duty vehicles is likely to have spillovers that improve the fuel economy of the omitted gasoline and diesel vehicles, this impact is estimated to be relatively small compared to the fuel savings for Class 4-8 diesel trucks. This assumption is based on the fact that these diesel trucks consume much more fuel than the vehicles that were not considered. The AEO Reference Case projects that the trucks covered by this analysis (Class 4-8 diesel) will be responsible for $85 \%$ of Class 3-8 fuel consumption in 2020, after the Phase 1 Rule is fully implemented (EIA, 2016). In addition, medium-duty trucks in general, and gasoline trucks especially, are driven fewer miles annually and have a higher baseline fuel economy compared to larger, diesel trucks. Therefore, fuel cost savings accrue fairly slowly, which extends the payback period for investment in advanced technologies, resulting in lower market adoption rates and lower fleet fuel savings.

Contributions of individual VTO-supported technologies to the new fleet fuel economies in the AEO 2016 Reference Case were based on base year vehicle fuel economies and technology market penetrations for HT subclasses, as documented in AEO's input files and penetration tables. Fuel-cell-powered trucks were not considered in this analysis, consistent with the AEO Reference Case. Further, no benefits are claimed for the market penetration of natural gas and propane trucks found in the AEO Reference Case, and the Program Success case does not estimate additional penetration of these vehicles as a result of VTO funding.

Finally, representative baseline vehicles were simulated in the Energetics Incorporated Assessment of Cycle Energy of Truck Technologies model (AsCEnTT) using inputs for vehicle and engine characteristics consistent with EPA/NHTSA fuel economy standards. Most inputs were derived from the regulatory impact assessment and associated documentation (EPA and NHTSA, 2011a, 2011b; EPA, 2011a, 2011b). Where input values were not available, Energetics Incorporated relied on prior analyses to determine reasonable ranges and adjusted values within these ranges to obtain results consistent with EPA Greenhouse Gas Emissions Model (GEM) fuel consumption results. The AsCEnTT model projected the fuel economy of representative vehicles on the EPA-specified duty cycles. The baseline case for HTs is detailed in Birky (2017). 


\subsubsection{Heavy Truck Advanced Technology Modeling}

Modeling for HT Program Success followed a process flow similar to that for LDVs. Ensuring consistency with VTO program research areas and goals, Energetics Incorporated defined advanced vehicle platforms using input on technology approaches and benefits from VTO program managers, the SuperTruck program (TAE, 2012), and prior years' benefits analyses (Stephens et al., 2016). The following heavy vehicle classes and technology platforms were included:

- Class 4-6 diesel delivery

- Baseline Conv diesel CI

- Advanced Conv diesel CI, low

- Advanced Conv diesel CI, high

- Mild hybrid diesel-electric CI

- Class 8 combination unit (CU)

- Baseline Conv diesel CI

- Advanced Conv diesel CI, low

- Advanced Conv diesel CI, high

- Class 7 and 8 single unit (SU)

- Baseline Conv diesel CI

- Advanced Conv diesel CI, low

- Advanced Conv diesel CI, high

- Mild hybrid diesel-electric CI

Technology characterizations - model parameters describing performance and costwere developed for the advanced conventional, low platforms representing application of current and near-term technologies. Technology characterizations also were developed for the advanced conventional, high truck platforms representing the VTO program goals and phase-in of component technologies. Program goals were assumed to be achieved using the technological approaches of SuperTruck industry teams (TAE, 2012) and the National Research Council (NRC, 2010). As detailed in Birky (2017), inputs were specified for the following attributes:

- Base engine maximum thermal efficiency,

- Engine friction and parasitic loss coefficients,

- Waste heat recovery strategy and performance,

- Coefficient of aerodynamic drag,

- Aerodynamic profile,

- Coefficient of rolling friction,

- Transmission type and efficiency,

- Truck empty weight, and

- Hybridization system size. 
Component costs relative to the baseline truck were estimated using cost estimates from the NRC (2010) and regulatory impact assessments and supporting documentation (EPA and NHTSA, 2011a, 2011b, ; EPA, 2011a, 2011b; Schubert et al., 2015).

The advanced conventional low platform was included to capture the commercialization and adoption of the most cost-effective component technologies. While the performance of this platform falls below the DOE vehicle system level goal, it represents real-world strategies and provides an option for vehicle operators with annual mileage below the segment average.

The advanced conventional high diesel and hybrid diesel platforms are two possible approaches to meeting the VTO program goals and are consistent with the development efforts of the SuperTruck industry partners and the market development expectations of the 21st Century Truck Partnership members. SuperTruck II initiatives extend for 4 to 5 years; however, commercialization of the technologies developed to achieve them is likely to occur gradually, with some lag time following demonstration. Initial commercialization of the advanced conventional, low, platform is assumed to occur between 2018 and 2025, and all other platforms are introduced beginning in 2025.

The fuel economies of the various configurations were estimated using the AsCEnTT model. These estimates, along with incremental cost estimates, were then used in the mediumand heavy-duty commercial vehicle fuel consumptions standards. These estimates were then aggregated to the weight classifications used in the AEO. Fuel economy and incremental cost estimates were then used in the market penetration analysis.

Further details of the technologies, incremental cost estimates, and fuel economy improvements for each HT platform and technology package modeled are given in Birky (2017).

\subsubsection{Heavy Truck Market Penetration and Stock Modeling}

In the second phase of the HT analysis, the fuel economy improvements and estimated costs from AsCEnTT modeling were used in the TRUCK market penetration model (Argonne, 2015 ) to project market penetration of the advanced platforms for 2015 through 2050 . TRUCK projects market acceptance by comparing incremental costs and the value of fuel savings with buyer preferences for different payback periods. Since fuel-efficient technology is more costeffective for trucks with higher annual mileage, the payback algorithm is applied to multiple mileage cohorts rather than assuming the fleet-averaged mileage for all trucks. TRUCK then reports market share as a fraction of total miles driven by trucks of a particular model year in the first year of ownership. As for LDVs, fuel prices for HT market penetration analyses were taken from the AEO 2016 Reference Case, extrapolated to 2050. No elasticity of travel demand was assumed for HTs, since these are primarily commercial vehicles with fuel costs passed on to the customers, with little effect on the volume of commercial vehicle travel (Winebrake et al., 2015a, 2015b). 
For the third and final step of the HT benefits analysis, fuel use by HTs in the Program Success case was compared with that in the baseline No Program case. Since the VISION model currently is not configured to analyze all the heavy-vehicle platforms modeled for the HT analysis, information from the latest AEO and the associated model input files, including total truck sales, age-specific average annual mileage, and scrappage rates, were applied in an additional spreadsheet tool, HDStock, which tracks the stock of heavy vehicles. Fuel use by these trucks was calculated first by assuming the simulated fuel economies and TRUCK market penetrations, and then by assuming the baseline No Program fuel economy for all trucks. The difference between these two calculations provides a projection of energy and GHG emission savings attributable to the VTO program. The resulting projections of market penetration by advanced technology HTs and the resulting average fuel economy are discussed in Appendix C. 
This page intentionally left blank. 


\section{OVERALL BENEFITS OF VTO AND FCTO R\&D}

Reductions in energy use and GHG emissions attributable to VTO and FCTO program technologies were projected for the entire U.S. fleet (LDVs and HTs) as described in this report. Table 3-1 quantifies the cumulative energy and emissions savings projected to occur after 2018, energy and emissions reduction rates in each year, and the economic implications projected through 2050. Ranges in Table 3-1 represent national-scale impacts from each fleet as derived from each LDV choice model.

Reductions in oil consumption and GHG emissions in LDVs were estimated using four different LDV consumer choice models, while only one set of projections was made for HTs. Values for LDVs are therefore shown as ranges, which show considerable uncertainty because of the wide range of market penetration projected for advanced-technology LDVs under both No Program and Program Success. Since the projected market penetration of advanced technology vehicles differed among LDV consumer choice models, the resulting petroleum use projections were also different.

Section 3.1 describes the benefits realized due to VTO/FCTO technologies relative to petroleum consumption. Section 3.2 examines the economic benefits to the end-consumer based on reduced petroleum consumption. Section 3.3 looks at environmental benefits due to VTO and FCTO technologies. Together, these benefits demonstrate that successful VTO and FCTO programs will significantly reduce oil consumption and oil dependence, consumer energy expenditures, and GHG emissions. Moreover, these programs offer American drivers benefits not captured in Table 3-1, including increased mobility, reduced pollution, and reduced exposure to potential oil price shocks. The benefits of continuing to invest government resources in advanced vehicle and fuel cell technologies would have significant economic value in the U.S. transportation sector; help consumers and businesses save money; and increase the use of secure, domestic energy sources.

As shown in Table 3-1, the Program Success case reduces total fuel use relative to the No Program case. Petroleum is greatly reduced, in particular, for LDVs, as shown in Figure 3-1. Due to the growth in electric vehicles and fuel cell electric vehicles over the time examined, hydrogen and electricity use each increase in both the No Program and Program Success cases, relative to today. The Program Success case uses more hydrogen than the No Program case, due to the increase in FCVs. The Program Success case uses less electricity than the No Program case for three of the four LDV vehicle choice models, due to improvements in energy efficiency of BEVs and PHEVs. 


\begin{tabular}{|c|c|c|c|c|}
\hline \multirow[b]{2}{*}{ Metric } & \multicolumn{4}{|c|}{ Year } \\
\hline & 2025 & 2030 & 2035 & 2050 \\
\hline \multicolumn{5}{|l|}{ Oil savings, cumulative (billion bbl) ${ }^{\mathrm{a}}$} \\
\hline LDVs & $0.3-0.4$ & $1.6-1.8$ & $3.4-4.1$ & $9.0-17.3$ \\
\hline HTs & 0.04 & 0.3 & 0.9 & 4.4 \\
\hline Total & $0.4-0.5$ & $1.9-2.2$ & $4.4-5.0$ & $13.4-21.7$ \\
\hline \multicolumn{5}{|l|}{ Oil savings rate, $(\text { million bpd })^{\mathrm{a}}$} \\
\hline LDVs & 0.4 & $0.8-1.0$ & $0.9-1.5$ & $1.0-2.7$ \\
\hline HTs & 0.06 & 0.2 & 0.4 & 0.8 \\
\hline Total & $0.4-0.5$ & $1.1-1.2$ & $1.3-1.9$ & $1.8-3.5$ \\
\hline $\begin{array}{l}\text { Primary energy savings, cumulative } \\
\text { (quads) })^{\mathrm{a}}\end{array}$ & $2-3$ & $13-14$ & $30-31$ & $91-117$ \\
\hline Primary energy savings, annual (quads/yr) ${ }^{\mathrm{a}}$ & $1.1-1.2$ & $2.7-2.8$ & $3.5-4.3$ & $4.4-6.3$ \\
\hline \multicolumn{5}{|l|}{ New vehicle mpg improvement (percent) ${ }^{\mathrm{b}}$} \\
\hline LDVs & $32-48 \%$ & $36-48 \%$ & $36-66 \%$ & $43-77 \%$ \\
\hline HTs & $12 \%$ & $19 \%$ & $24 \%$ & $28 \%$ \\
\hline \multicolumn{5}{|l|}{ On-road stock mpg improvement (percent) ${ }^{\mathrm{b}}$} \\
\hline LDVs & $6-7 \%$ & $16-18 \%$ & $24-30 \%$ & $38-68 \%$ \\
\hline HTs & $2 \%$ & $7 \%$ & $13 \%$ & $23 \%$ \\
\hline \multicolumn{5}{|l|}{ 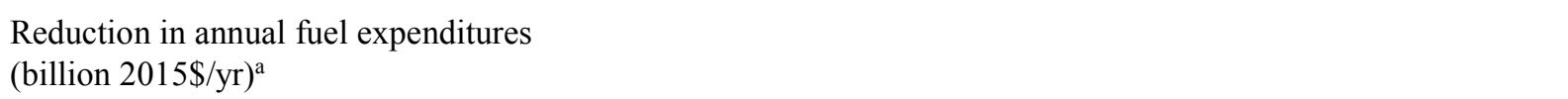 } \\
\hline LDVs & $15-21$ & $44-49$ & $62-85$ & $94-184$ \\
\hline HTs & 3 & 12 & 24 & 63 \\
\hline Total & $18-24$ & $56-61$ & $85-108$ & $156-246$ \\
\hline \multicolumn{5}{|l|}{$\begin{array}{l}\text { Increase in annual expenditures for new } \\
\text { vehicle purchases (billion } 2015 \$ / y r)^{\mathrm{a}}\end{array}$} \\
\hline LDVs & $-2-+3$ & $-3-+10$ & $3-21$ & $27-32$ \\
\hline HTs & 1 & 2 & 3 & 3 \\
\hline Total & $-1-+4$ & $-1-+12$ & $6-24$ & $30-35$ \\
\hline Oil security savings (billion $2015 \$ / y r)^{\mathrm{a}}$ & $6-7$ & $19-22$ & $30-44$ & c \\
\hline $\begin{array}{l}\text { GHG emissions reduction, cumulative } \\
\left.\text { (million tons } \mathrm{CO}_{2} \text {-eq) }\right)^{\mathrm{a}}\end{array}$ & $177-205$ & $947-1,000$ & $2,190-2,320$ & $6,860-9,130$ \\
\hline \multicolumn{5}{|l|}{$\begin{array}{l}\text { GHG emissions reduction, annual } \\
\left.\text { (million tons } \mathrm{CO}_{2}-\mathrm{eq} / \mathrm{yr}\right)^{\mathrm{a}}\end{array}$} \\
\hline LDVs & $67-77$ & $159-163$ & $186-251$ & $215-389$ \\
\hline HTs & 10 & 40 & 71 & 138 \\
\hline Total & $77-87$ & 199-203 & $257-322$ & $353-527$ \\
\hline
\end{tabular}

a "Reductions" and "savings" were calculated as the difference between the results from the Program Success case (i.e., in which requested DOE funding for this technology is received and the program is successful) and the results from the baseline (No Program) case (i.e., in which there is no future DOE funding for this technology). Negative reduction values reflect increases. All cumulative metrics are based on results beginning in 2019 .

b Improvement relative to baseline (No Program) fleet in the same year.

c AEO 2016 only projects through 2040; thus oil security savings are not available for 2050 . 

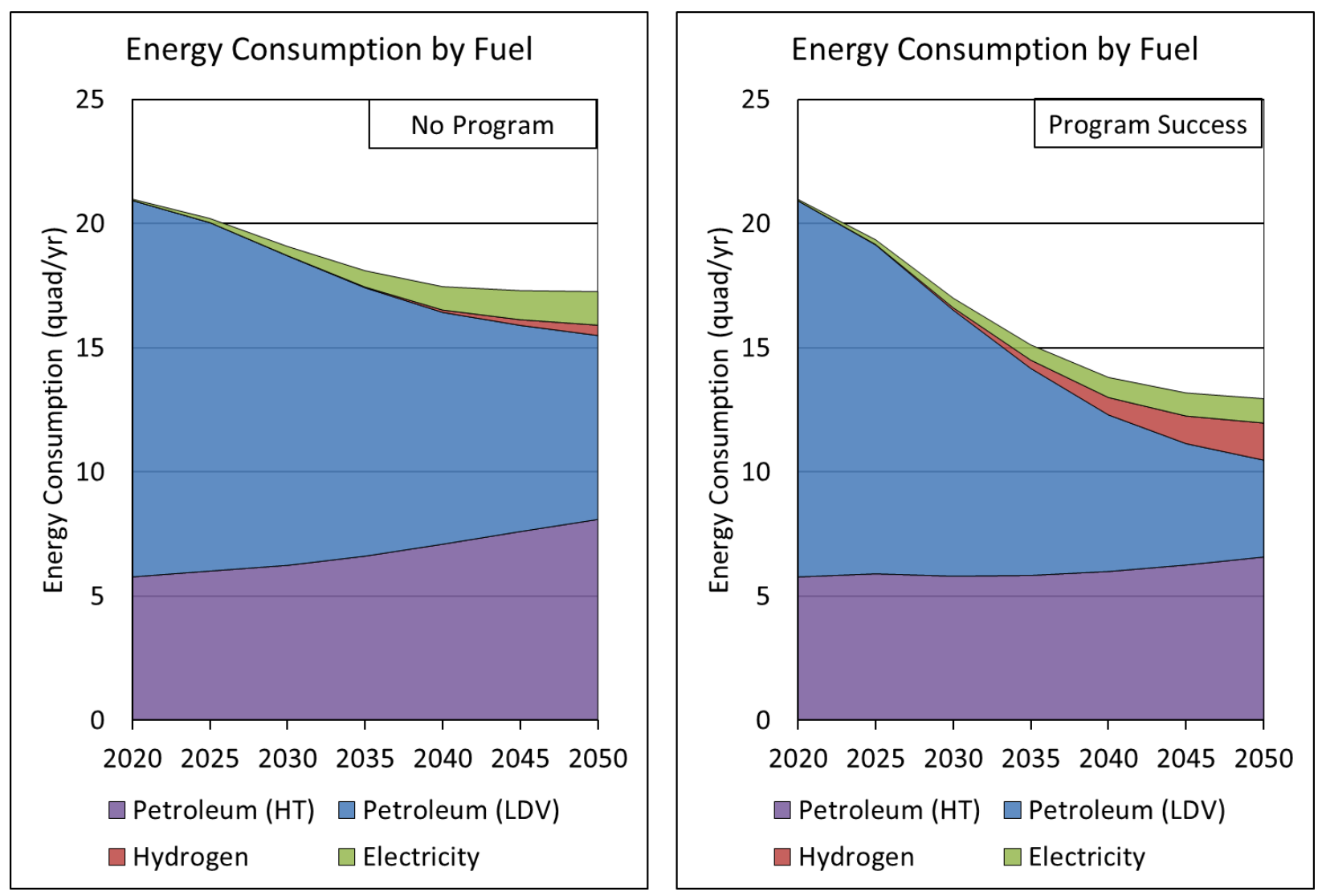

FIGURE 3-1 On-road Fuel Consumption by Fuel Type through 2050 for the No Program and Program Success Cases

\subsection{PETROLEUM BENEFITS}

\subsubsection{Petroleum Reduction}

The projected reductions in oil use from successful VTO and FCTO programs are significant: up to 1.9 million barrels per day (MMbpd) in 2035 and 3.5 MMbpd in 2050. The oil savings projected for 2035 amount to as much as $10 \%$ of the total U.S. petroleum consumption in the same year as projected in the AEO 2016 Reference Case. The U.S. transportation sector is oil intensive, with $92 \%$ of the energy used by the sector coming from petroleum in 2015 . Transportation-sector petroleum consumption represented $70 \%$ of total U.S. petroleum consumption (Davis et al., 2016).

Figure 3-2 shows the total petroleum savings by all VTO and FCTO programs in 2035 and 2050 and the total cumulative petroleum savings since 2019. Gains are slow until 2025, but increase rapidly after 2025 due to the time it takes for technology to reach the market. VTO and FCTO fund research across a broad spectrum of commercialization, but much of the R\&D is at early stages, with technology readiness levels (TRLs) between 2 and 5 . 

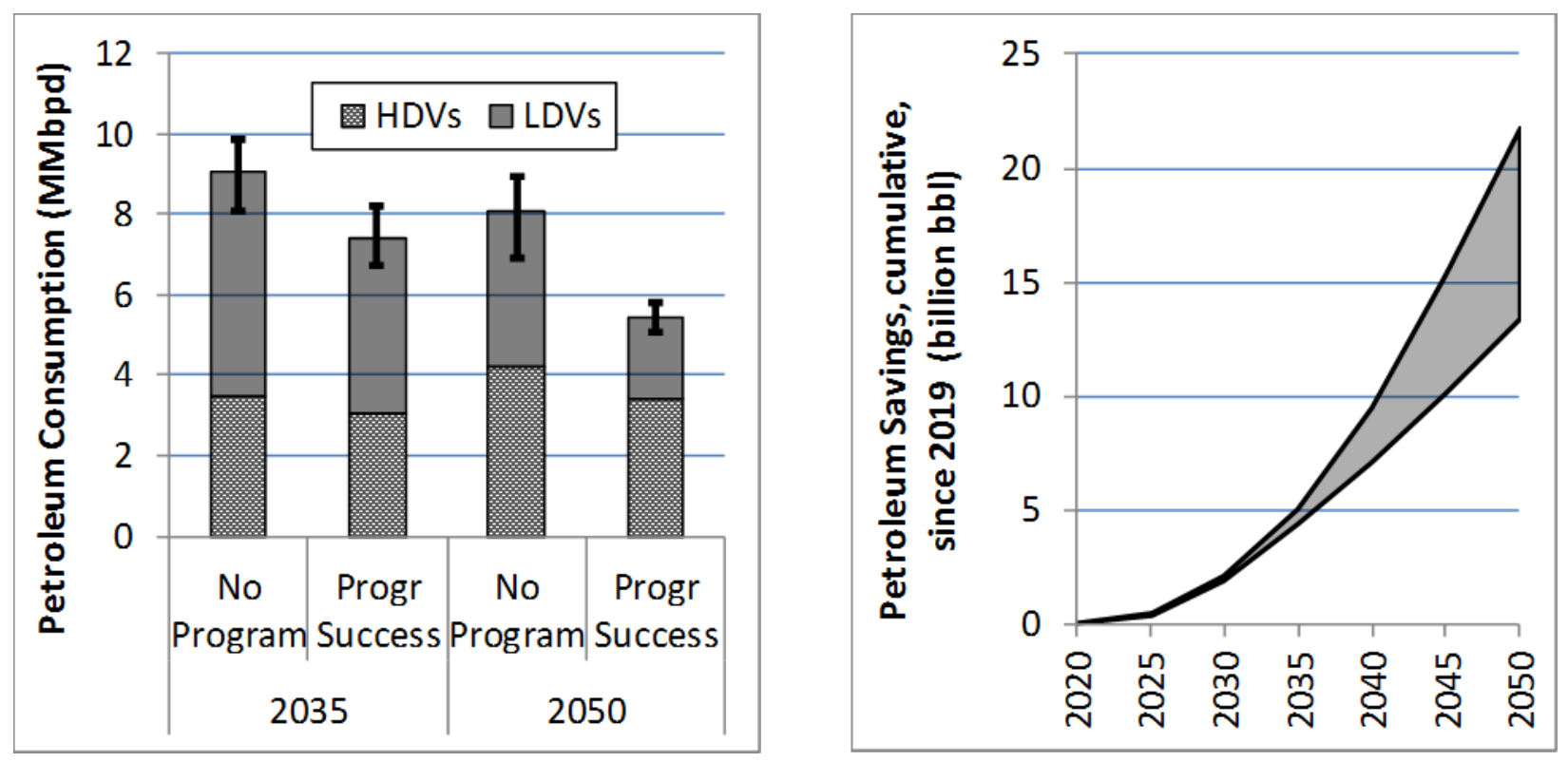

FIGURE 3-2 Projected On-road Petroleum Consumption under the No Program and Program Success Cases in 2035 and 2050 (left) and Projected Cumulative Petroleum Savings Attributed to All VTO and FCTO Technology Programs (right) (Uncertainty bars represent the ranges of estimates from different vehicle choice models.)

In 2025, the estimated petroleum reduction for LDV is $0.36-0.43 \mathrm{MMbpd}$; in 2035, the estimated petroleum reduction is $0.91-1.53 \mathrm{MMbpd}$; and in 2050, the estimated petroleum reduction reaches $0.99-2.70 \mathrm{MMbpd}$. To put these estimated reductions in petroleum use in context, in 2014, LDVs in the U.S. consumed 8.2 MMbpd of petroleum (Davis et al., 2016). Petroleum savings in million barrels per day have the energy content of $1 \mathrm{MMbpd}=1.916$ quadrillion Btu/yr (based on 125,000 Btu/gal and $42 \mathrm{gal} / \mathrm{barrel}$ ).

Reductions in petroleum usage by HT due to VTO technologies are expected to grow from $0.06 \mathrm{MMbpd}$ in 2025, to $0.40 \mathrm{MMbpd}$ in 2035, to $0.79 \mathrm{MMbpd}$ by 2050. To put this in context, medium- and heavy-duty trucks in the U.S. consumed 2.9 MMbpd of petroleum in 2014 (Davis et al., 2016).

Program Success is estimated to reduce cumulative petroleum consumption by both LDV and HT between 2019 and 2050 by 13.4 to 21.7 billion barrels, representing $13 \%$ to $19 \%$ of cumulative consumption in the No Program case. 


\subsubsection{Oil Security}

Oil security is important to the U.S. even with increased domestic oil production. An economic value can be assigned to oil security that reflects the potential reduction (as a consequence of the VTO and FCTO programs) in damage done to the U.S. economy by oil supply disruptions. The benefits that can be measured monetarily are:

- Transfer of wealth - the quantity of oil imports at the higher price, multiplied by the difference between the actual price of oil and what the price would have been in a competitive (or undisrupted) market.

- Economic surplus losses - deadweight losses that accompany changes in prices and the amounts of oil supplied.

- Macroeconomic disruption costs - costs that occur when sudden changes in oil price cause economic dislocations that result in temporary underemployment and misallocation of resources, and thereby a loss of gross domestic product (GDP) beyond what the higher price level alone would induce. Disruption costs result from job destruction and creation, and they cause a temporary period of increased unemployment and lost productivity.

Oil security costs for No Program and Program Success were estimated from the total oil consumption projected using the Oil Security Metrics Model (OSMM) at ORNL (Greene et al., 2014). Reductions in oil security costs calculated for the projections of oil consumption were made using the LDVs projections of the four consumer choice models-ParaChoice, $\mathrm{MA}^{3} \mathrm{~T}$, LAVE-Trans, and LVCFlex - as described in Appendix B, and the HT projections were made using the TRUCK and AsCEnTT models, as described in Appendix C.

Figure 3-3 shows the projected oil security cost reductions for Program Success. Oil security cost reductions increase as oil savings increase. The cost reductions per year range from $\$ 42$ billion to $\$ 75$ billion in 2040 , represented with gray lines. The mean value, $\$ 58$ billion, represents about $0.1 \%$ of the GDP as projected by the AEO Reference Case. Projections are uncertain, and oil security costs can range much higher depending on unforeseeable global oil market conditions. Confidence intervals are plotted for each of the projections in Figure 3-3 and in Figures D-1 through D-4 in Appendix D.

Reducing oil dependence protects the U.S. economy from these uncertain costs. Oil dependence decreases as individual vehicle powertrains become more efficient. Dependency on oil decreases further as consumers move from conventional ICE vehicles to plug-in vehicles powered by both electricity and petroleum and to FCVs powered by hydrogen produced from a variety of primary energy sources. 


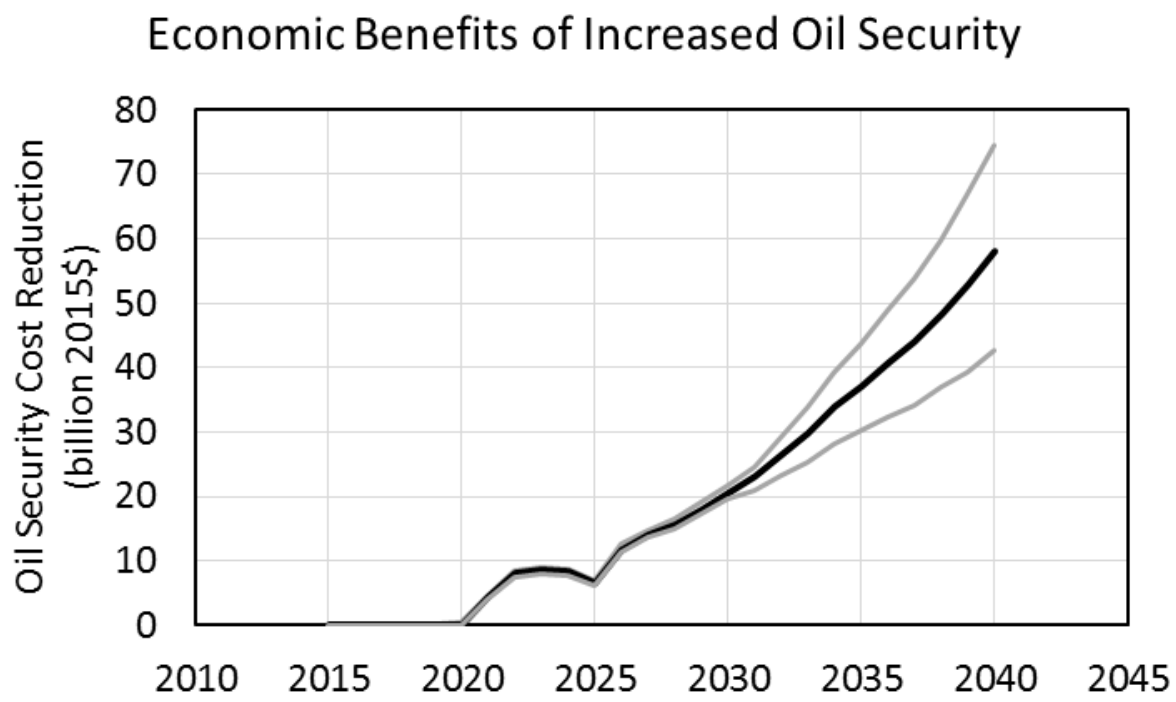

FIGURE 3-3 Estimated Reduction in Annual Oil Security Costs from the Oil Security Metrics Model

\subsection{ECONOMIC BENEFITS}

\subsubsection{Consumer Fuel Economy}

Fuel economy for consumers and businesses is improved through successful implementation of VTO and FCTO technology. Improving fuel economy offers benefits to consumers, who pay lower prices for fuel and transportation-dependent commodities. Figure 3-4 shows projected fuel economy for LDVs and HTs. Fuel economy is explored in greater depth at both the vehicle and fleet level in Appendix B for LDVs and in Appendix C for HTs.

The fuel economy improvements shown in Figure 3-4 and in Table 3-1 are large, with adjusted, combined city/highway fuel economy of new LDVs potentially increasing by as much as $62 \%$ by 2035 (from the No Program case), implying greatly reduced consumer spending on fuel. Likewise, large improvements in HT fuel economy (over a 20\% increase in new HT fuel economy by 2035) imply savings in goods transported by truck. In addition to these savings, increased average U.S. fuel economy means that vehicle drivers use fuel more efficiently, depending less on large amounts of petroleum fuel. 

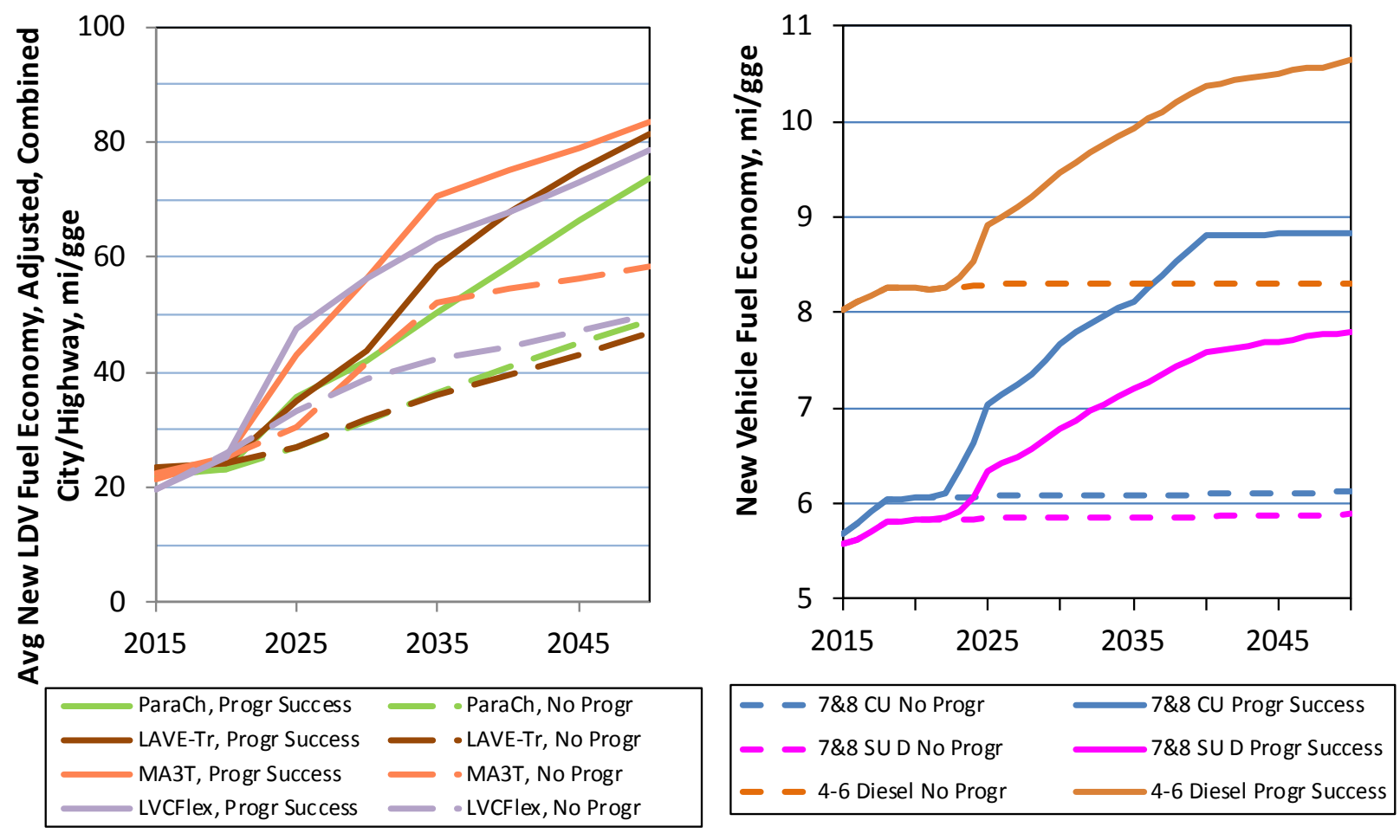

FIGURE 3-4 Fleet-averaged Fuel Efficiency through 2050 for Light-duty (left) and Heavy-duty Vehicles (right) for the Program Success and No Program Cases

\subsubsection{LDV Levelized Cost of Driving}

The levelized cost of driving (LCD) is a measure of typical consumer expenditures per mile driven for a vehicle and the fuel purchased over a period of interest. The LCD was calculated for the drivetrains simulated for years 2025 and 2035 for the No Program and Program Success cases. The LCD is calculated as the ratio of the sum of the vehicle price and the present value of fuel consumed during operation, to the miles driven in that timeframe.

where

$$
L C D=\frac{P_{V e h}+P V\left(C_{\text {Fuel }}\right)}{\sum_{i=1}^{N}(V M T / y r)_{i}}
$$

$P_{V e h}=$ Vehicle retail price equivalent, $P V\left(C_{F u e l, i}\right)=$ Present value of fuel costs over $N$ years,

$N=$ Ownership period, and

$(V M T / y r)_{i}=$ Annual distance driven in year $i$

The LCD was calculated from the estimated retail price equivalent for each vehicle, and the estimated fuel expenditures over the miles driven over the period of vehicle ownership. Here, the period considered was 5 years. Based on the 2009 National Household Travel Survey, it was 
assumed that a vehicle would be driven an average of 13,500 mi per year during the first 5 years. Fuel expenditures were discounted at 7\% annually, intermediate between the high discount rates (often over 20\%) at which some vehicle consumers discount future fuel savings (Greene, 2010; Greene et al., 2013), and a low discount rate (near zero) appropriate for discounting of social costs (OMB, 1992). LCDs reported here do not include costs such as depreciation (or resale value), operation costs such as maintenance and repair, or other costs such as taxes and fees. Most of these costs are assumed to be similar for different drivetrain types, except for perhaps depreciation, maintenance, and repair. However, insufficient data are available to estimate reliable values for depreciation, maintenance, and repair costs for all the drivetrain types considered here, particularly PEVs and FCVs (Zhou et al., 2016).

The LCD estimated for midsize cars in 2025 is shown in Figure 3-5, and for 2035 in Figure 3-6. Several drivetrains were analyzed, in $2015 \$$ per mile. A discount rate of $7 \%$ with a 5 -year ownership period and an annual distance driven of 13,500 mi were assumed. The figures show the LCD of the Program Success case as colored bars, with each component labeled. The LCD for the No Program case is displayed as a cross above each bar, showing that Program Success LCD values are consistently lower than for the other cases, particularly for more advanced powertrains such as FCVs and BEVs.

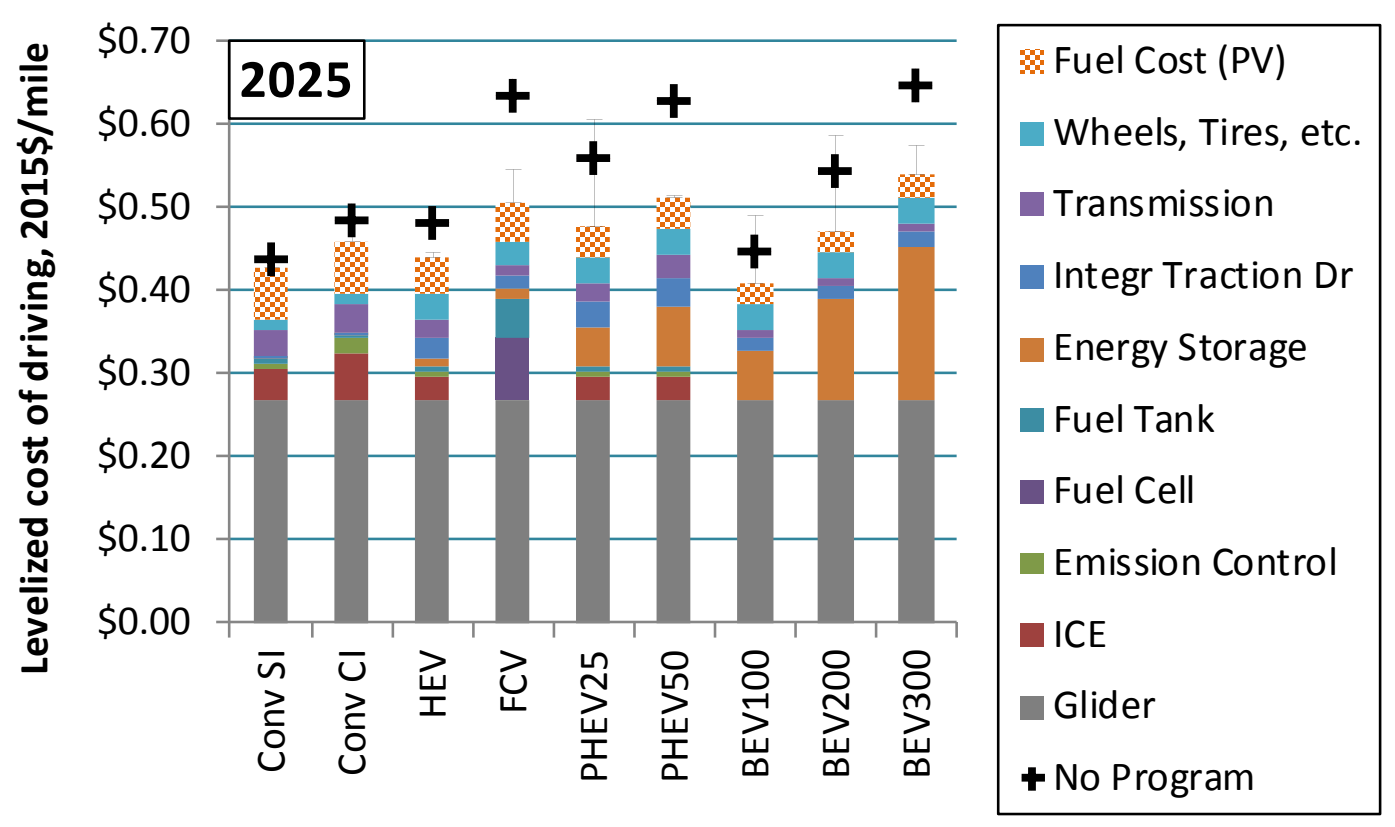

FIGURE 3-5 Projected Levelized Cost of Driving of LDVs (midsize cars) in 2025 (The bars show the LCDs of Program Success, and the crosses above each bar represent the LCDs of No Program. PVs of fuel costs are shown assuming a $7 \%$ discount rate.) 


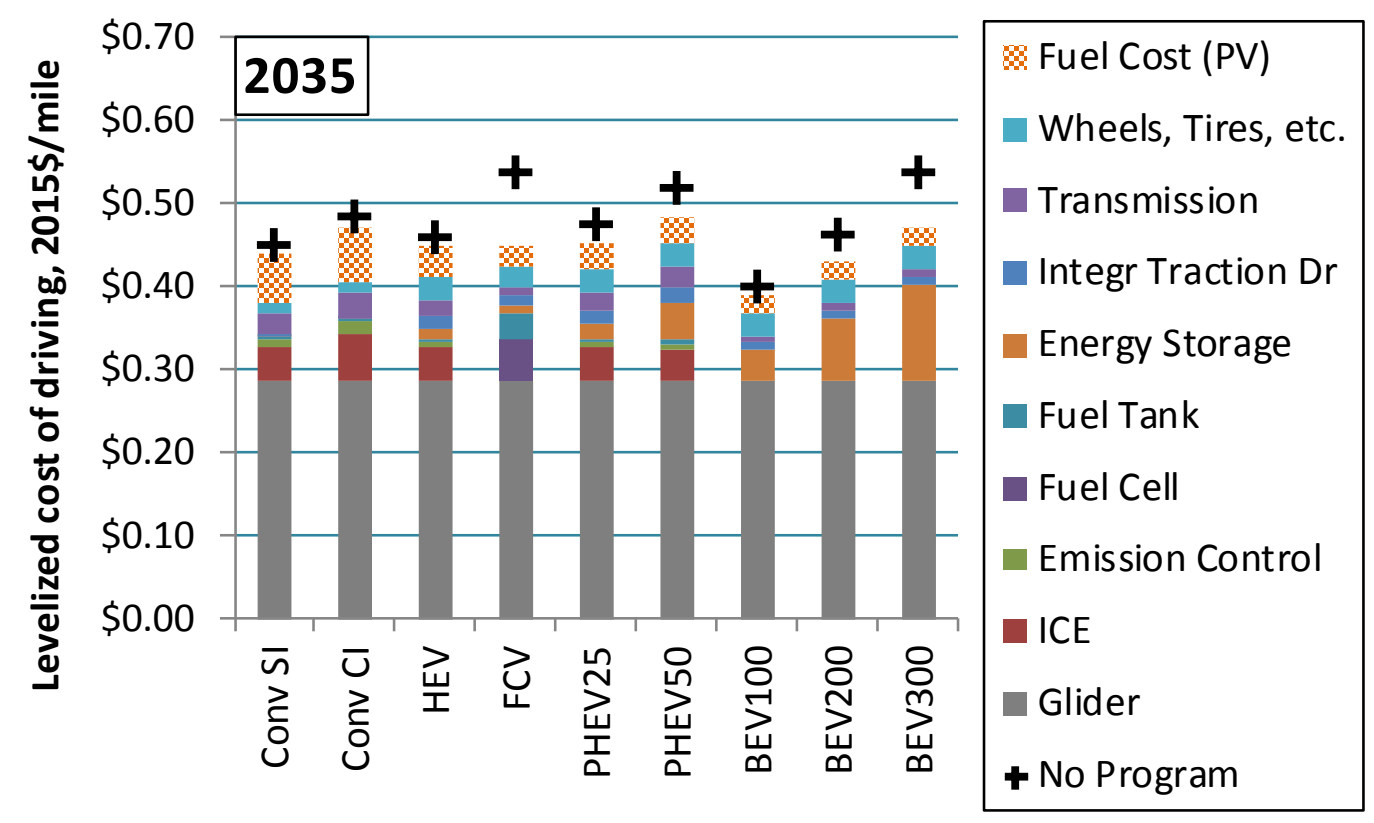

FIGURE 3-6 Projected Levelized Cost of Driving of LDVs (midsize cars) in 2035 (The bars show the LCDs of Program Success, and the crosses above each bar represent the LCDs of No Program. PVs of fuel costs are shown assuming a $7 \%$ discount rate.)

\subsubsection{National-Level Vehicle Expenditures}

Projections of LDV adoption indicate that although advanced-technology vehicles may be somewhat more expensive at purchase, the fuel savings are likely more than twice the increase in expenditures on new vehicles. For example, projections of reductions in annual fuel expenditures for LDVs in 2035 range from $\$ 62$ billion to $\$ 85$ billion (2015\$), while the projected increase in new LDV expenditures in the same year ranges from $\$ 3$ billion to $\$ 21$ billion (2015\$). These fuel expenditure savings and increased new vehicle costs are shown in Figure 3-7. As more advanced-technology vehicles penetrate the market, vehicles become more expensive; however, the value of the fuel saved is much larger than the increase in spending on new vehicles. Uncertainty bars in Figure 3-7 represent the ranges of projections across different vehicle choice models. 


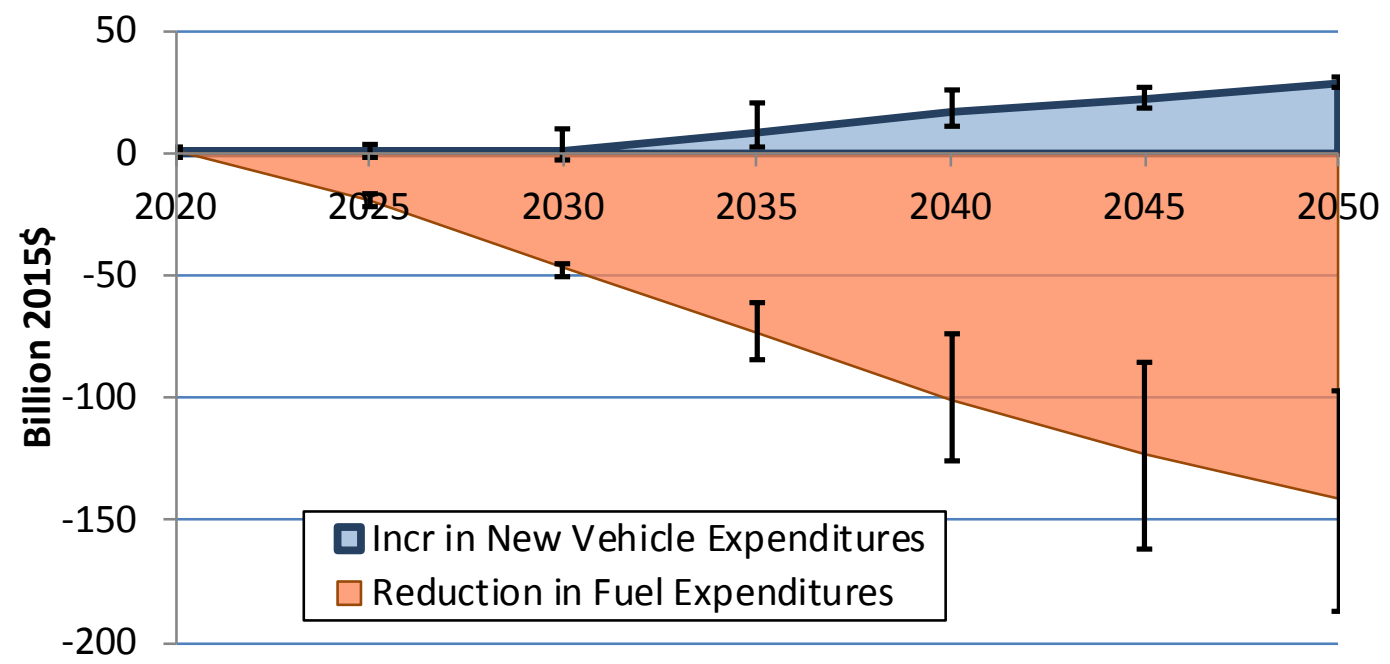

FIGURE 3-7 Differences in Annual National Consumer Expenditures for Vehicle Purchases and Fuel for LDVs through 2050 between the No Program and Program Success Cases (Uncertainty bars represent ranges of estimates for expenditures coming from different vehicle choice models.)

Similar trends are projected for medium- and heavy-duty vehicles. Projected increases in annual new vehicle expenditures for Class 4-6 trucks and reductions in annual fuel expenditures by the on-road stocks of these trucks are shown in Figure 3-8. Total increases in expenditures for new vehicle purchases and reductions in annual fuel expenditures are given in Table 3-1.

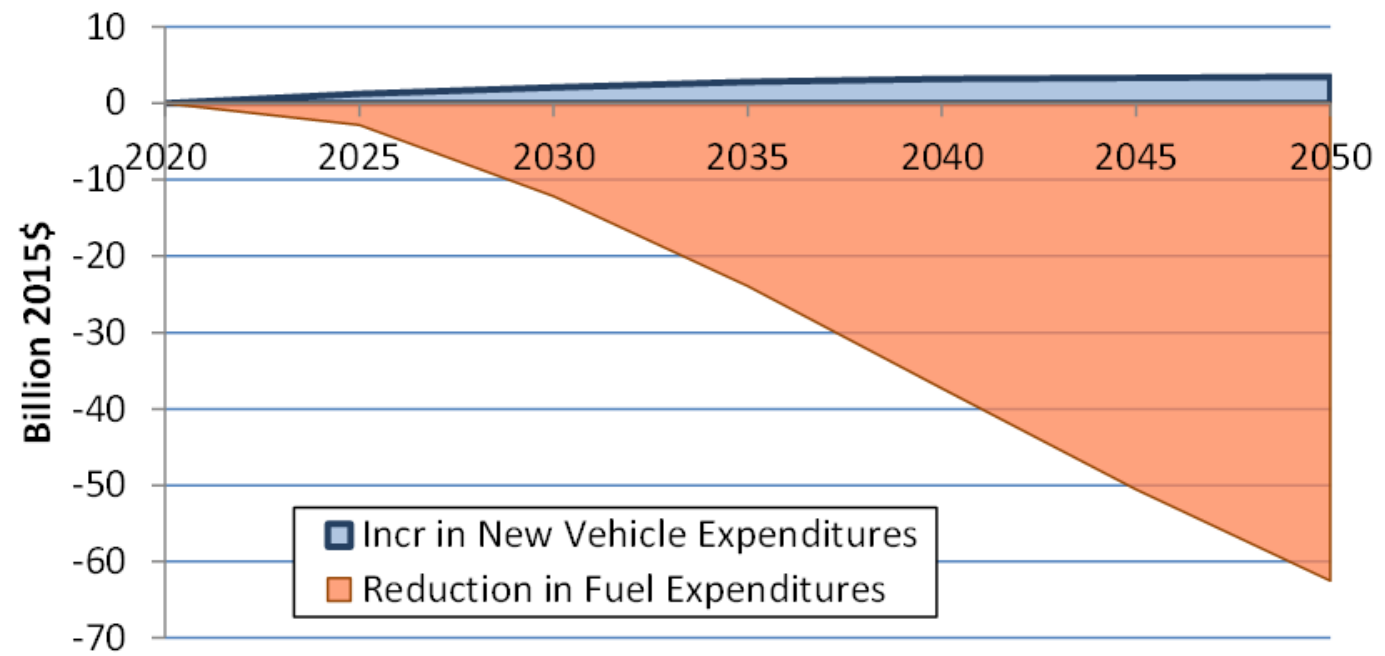

FIGURE 3-8 Differences in Annual National Costs of Vehicle Purchases and Fuel for Medium- and Heavy-duty Vehicles through 2050 between the No Program and Program Success Cases (The lack of uncertainty bars is due to using a single model for estimating the medium- and heavy-duty vehicles, though uncertainty in the projection still exists.) 


\subsection{ENVIRONMENTAL BENEFITS}

\subsubsection{Reductions in GHG Emissions}

The ranges of projected reductions in GHG emissions in 2035 and 2050, for all VTO and FCTO research programs, are shown in Figure 3-9, along with the range of cumulative GHG emission reductions since 2019. Again, since different LDV choice models gave different GHG projections, ranges are shown. Emission reductions were estimated based on the projected changes in fuel used (including gasoline, diesel, electricity, and hydrogen) and the GHG-intensity of each fuel, as described in Section 2, Appendix B, and Appendix C. Although there is uncertainty in these projections, it is clear that successful implementation of VTO and FCTO technologies can significantly reduce petroleum consumption and GHG emissions.

The estimated annual GHG emission benefit in 2035 is up to 322 million metric tons (Mmt) of $\mathrm{CO}_{2}$-eq, as shown in Table 3-1 and Figure 3-9. These GHG reductions are substantial and will help the nation move toward a lower GHG total in 2035. By 2050, GHG reductions can be more than $500 \mathrm{Mmt}$ of $\mathrm{CO}_{2}$-eq per year. Compared with a national 2005 baseline of 7,379 Mmt (EPA, 2016), this is potentially a 7\% reduction attributable to VTO and FCTO. The cumulative reduction in GHG emissions between 2019 and 2050 due to Program Success is estimated to be 6,860 to $9,130 \mathrm{Mmt} \mathrm{CO}_{2}$-eq, which is $12 \%$ to $16 \%$ of the No Program cumulative emissions of 55,700 $\mathrm{Mmt} \mathrm{CO}_{2}$-eq.

Various dollar values have been placed on a ton of $\mathrm{CO}_{2}$ (IWG, 2013). Assuming $\mathrm{CO}_{2}$ values ranging from $\$ 10$ to $\$ 100$ per metric ton, these estimated carbon reductions would range in value from $\$ 3$ billion to $\$ 32$ billion per year (not discounted).
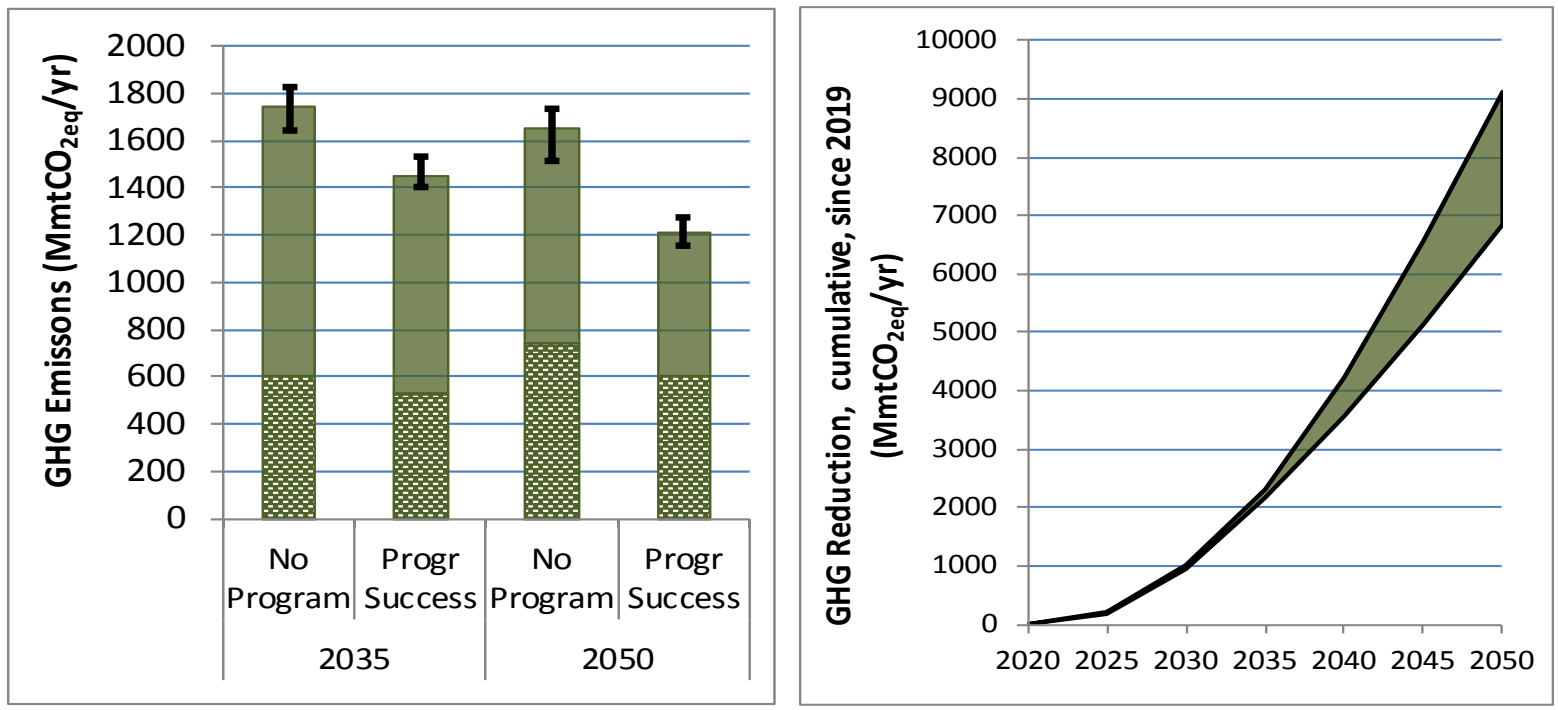

FIGURE 3-9 Projected GHG Emissions under the No Program and Program Success Cases in 2035 and 2050 (left) and Projected Cumulative GHG Reductions Attributed to All VTO and FCTO Technology Program since 2019 (right) 
This page intentionally left blank. 


\section{DISAGGREGATION OF BENEFITS BY TECHNOLOGY AREA}

Section 3 described the benefits due to R\&D funded by the VTO and FCTO. These benefits can be disaggregated to the program level, for electrification, advanced combustion engines and fuels, materials, and fuel cells. Section 4.1 describes the methodology to disaggregate program benefits for LDVs, and Section 4.2 does the same for HTs. Section 4.3 summarizes the benefits attributable to each VTO and FCTO program for petroleum reduction and GHG abatement.

\subsection{ATTRIBUTION OF LDV BENEFITS TO TECHNOLOGY AREAS}

As discussed in Section 2.1.3, two factors contribute to petroleum savings: (1) more efficient drivetrains and (2) substituting cars with more efficient drivetrains for cars with less efficient drivetrains (stock changes). Petroleum savings projections were disaggregated by powertrain in order to estimate the contribution of each of the two factors and to attribute the savings to specific VTO and FCTO technologies. Petroleum savings from efficiency improvements were further disaggregated into contributions by each of the four EERE technology areas (Advanced Combustion Engines and Fuels, Electrification, Advanced Materials, and Fuel Cell Technologies). Petroleum savings from changes in stocks of drivetrain technologies were attributed to each of these areas based on assumptions about which drivetrains substitute for others.

Figure 2-2 in Section 2.1.3 shows the difference in petroleum usage between the No Program and Program Success cases. Figure 4-1 shows the petroleum savings from efficiency improvements as cross-hatched, and the savings due to changes in stocks as shaded (pale yellow). As shown in Figure 4-1, for cars in 2035, the petroleum savings from changes in drivetrain stocks were nearly all due to replacement of Conv SI and Conv CI vehicles by HEVs and PHEVs, and replacement of PHEVs by BEVs (areas shown in yellow). The petroleum savings from these replacements were therefore attributed to the Electrification program.

The decrease in the amount of fuel consumed per mile resulting from reduced friction was attributed to the Advanced Combustion Engines and Fuels program. A 10\% reduction in engine friction was assumed to lower fuel consumption by $0.3 \%$, and a $10 \%$ reduction in drivetrain frictional losses was assumed to lower fuel consumption by $0.5 \%$, on the basis of power flows in vehicle simulations (EPA and DOE, 2011). A reduction in engine and drivetrain friction was assumed to increase from zero in 2015 to $10 \%$ in 2020 , to increase from $10 \%$ in 2020 to $15 \%$ by 2035 , and to remain at $15 \%$ through 2050 . As opposed to other DOE technologies, which were assumed to be implemented only in new vehicles, friction reduction was assumed for both new and used vehicles. 


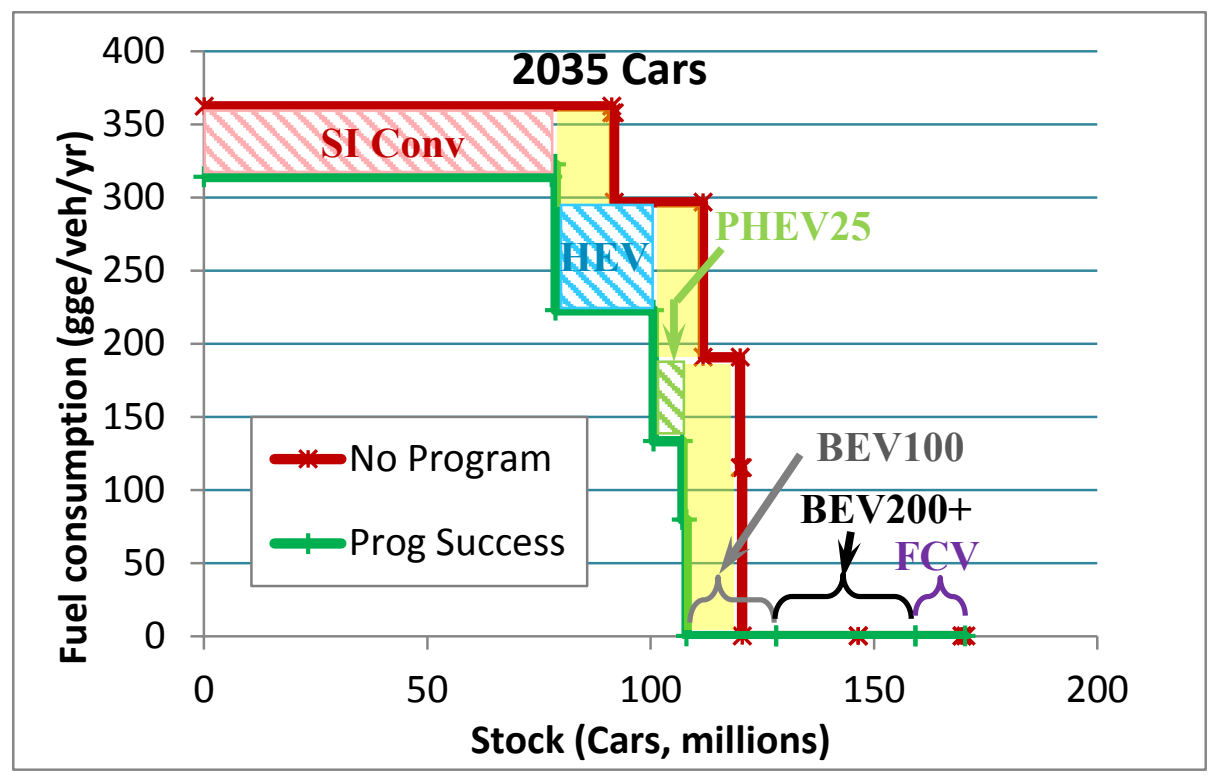

FIGURE 4-1 Average Annual Petroleum-based Fuel Consumption in Cars in 2035 for the No Program (red) and Program Success (green) Cases, with Savings Due to Drivetrain Efficiency Improvements (shown as cross-hatched areas), and Those Due to Changes in the Stock Shares of Drivetrain Technologies (shaded) Disaggregated

Improved efficiency of traditional SI and CI combustion engines through electrification was attributed to the Advanced Combustion Engines and Fuels program. A side analysis was performed using $\mathrm{MA}^{3} \mathrm{~T}$ to estimate the general market uptake of micro hybrid engines and turbocharging. For both the Program Success and No Program cases, 12-Volt micro hybrids were considered the default SI and CI vehicles beginning in 2025 (lab year 2020). In 2030 (lab year 2025), turbocharging was defined as standard on Conv SI vehicles in both cases.

The differences in vehicle weights in Autonomie simulations for the Program Success and No Program cases were used to estimate the fuel saved by lightweighting. For HEVs and PHEVs, changes in the masses of batteries and PEEM (power electronics and electric motors) were not considered part of lightweighting because the lower weights of these components were attributable to the batteries and electric drive technologies used. It was assumed that the percentage decrease in fuel consumption per mile was proportional to the percentage decrease in vehicle mass (excluding battery and PEEM mass).

For Conv SI and CI vehicles, a proportionality constant of 0.5 was applied (i.e., a $10 \%$ mass reduction corresponds to a 5\% reduction in fuel consumption). This constant is based on the analytical results of a number of studies showing that a $10 \%$ decrease in mass with engine downsizing at constant performance gives approximately a $6.5 \%$ decrease in fuel consumption per mile, while without downsizing, the decrease is 3.5\% (Kim and Wallington, 2013; Bandivadekar et al., 2008; Pagerit et al., 2006). Here, an intermediate value of 5\% was used to estimate the portion of the fuel economy benefit attributable to the Materials program, under the assumption that the remainder of the benefit was due to engine downsizing attributable to the 
Advanced Combustion Engines and Fuels program. For HEVs, a value of $4.5 \%$ was used on the basis of previous vehicle simulations (Pagerit et al., 2006; Moawad and Rousseau, 2012). For PHEVs, it was assumed that the value was slightly less than for HEVs, and 4\% was used.

Lower fuel consumption per mile due to reductions in rolling resistance and aerodynamic resistance were estimated but were not attributed to the VTO programs for LDVs, because none of these programs supports the reduction of rolling resistance or aerodynamic resistance in LDVs. In general, these fuel savings were small compared with the contributions of VTO technologies.

For Conv SI and CI vehicles, the remainder of the petroleum savings was attributed to improvements in engine combustion efficiency (Advanced Combustion Engine and Fuels program). For HEVs and PHEVs, $70 \%$ of the remainder of fuel savings was attributed to improvements in engine combustion efficiency, and 30\% was attributed to the battery and electric drive technologies used. The value of $70 \%$ was arrived at because comparisons of fuel economies of HEVs and similar Conv SI vehicles indicate that HEVs consume approximately $70 \%$ of the fuel per mile that similar Conv SI vehicles do; that is, hybridization gives a $30 \%$ reduction in fuel consumption per mile. This same percentage was used for PHEVs, as well, assuming that hybridization benefits the fuel economy of PHEVs operating in CD similarly to HEVs.

In addition to fuel saved from improved efficiency, petroleum was saved by replacement of less efficient powertrains by powertrains that consume less or no petroleum. The petroleum saved by this replacement was attributed to VTO and FCTO programs by examining changes in the on-road stocks of different drivetrain types and by assuming that more advanced technology vehicles replaced more mature technologies. As described in Appendix B, as advanced powertrain options improve in cost and performance, they are projected to gain market share and displace more mature technologies. Technology replacement was assumed to be in the following order: Conv SI, Conv CI, HEV, PHEV, BEV, and FCV, which is the order in which they gain market share in the market penetration projections in most cases analyzed here. This order is consistent with the current maturity of the technologies (Conv SI being the most mature and FCV being the most advanced). Fuel savings attributed to FCVs were estimated by an alternative method assuming FCV replaced a mix of non-FCVs, as described below.

Because of uncertainty in future markets and the assumed order in which petroleum savings from drivetrain substitution were assigned, petroleum savings attributable to VTO and FCTO technologies were strongly dependent on projected market penetration of these vehicle types. Therefore, the attribution methodology was modified to assign petroleum savings to the FCTO program in proportion to the increase in vehicle-miles traveled (VMT) by FCVs in the Program Success case over the No Program case, assuming the increase represented miles traveled by FCVs replacing miles traveled by non-FCVs. That is, the petroleum saved by each mile traveled by a FCV is the average petroleum consumed by non-FCVs. For cars, this is the ratio of petroleum consumed by all cars to the VMT by all cars except FC cars: 


$$
\text { average fuel per mile, non } F C \text { cars }=\left(\frac{P_{\text {Tot Cars }}^{\text {PrgSucc }}}{V M T_{\text {Tot Cars }}^{\text {PrgSucc }}-V M T_{F C \text { Cars }}^{\text {PrgSucc }}}\right)
$$

and analogously for light trucks:

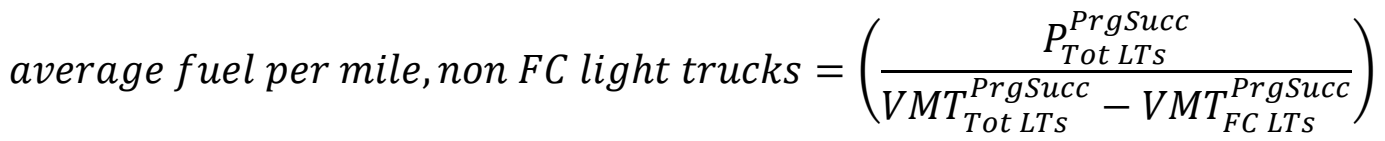

The fuel consumed per mile was estimated using quantities from the Program Success case, since vehicles in this case have benefitted from VTO technologies; the intent here is to isolate the benefits of FCTO technologies.

Using this method, the petroleum saved by $\mathrm{FC}$ cars, $\triangle P_{F C}$ Cars, was estimated by multiplying the fuel used per mile by non-FC cars by the vehicle miles replaced by FC cars:

$$
\Delta P_{F C \text { Cars }}=\left(\frac{P_{\text {Tot Cars }}^{\text {PrgSucc }}}{V M T_{\text {Tot Cars }}^{\text {PrgSucC }}-V M T_{F C \text { Cars }}^{\text {PrgSucC }}}\right)\left(V M T_{F C \text { Cars }}^{\text {PrgSucc }}-V M T_{F C \text { Cars }}^{\text {NoPrg }}\right)
$$

and that saved by FC light trucks, $\triangle P_{F C L T S}$, was estimated analogously:

$$
\Delta P_{F C \text { LTS }}=\left(\frac{P_{\text {Tot LTS }}^{\text {PrgSucc }}}{V M T_{\text {Tot Cars }}^{\text {PrgSucc }}-V M T_{F C \text { LTS }}^{\text {PrgSucc }}}\right)\left(V M T_{F C L T S}^{\text {Prgsucc }}-V M T_{F C ~ L T S}^{\text {NoPrg }}\right)
$$

and the total saved by FCVs, $\triangle P_{F C V s}$, is the sum:

$$
\Delta P_{F C V S}=\Delta P_{F C \text { Cars }}+\Delta P_{F C L T S}
$$

where

$P_{\text {Tot Cars }}^{\text {PrgSucc }}=$ Total petroleum consumed by all cars in Program Success,

$P_{\text {Tot LTs }}^{\text {PrgSucc }}=$ Total petroleum consumed by all LTs in Program Success,

$V M T_{\text {Tot } \text { Cars }}^{\text {PrgSucc }}=$ Total VMT by all cars in Program Success,

$V M T_{\text {Tot } L T s}^{\text {Prgsucc }}=$ Total VMT by all light trucks (LTs) in Program Success,

$V M T_{F C \text { Cars }}^{\text {PrgSucc }}=$ VMT by FC cars in Program Success,

$V M T_{F C \text { Cars }}^{\text {NoPrg }}=$ VMT by FC cars in No Program,

$V M T_{\text {Tot LTS }}^{\text {PrgSucc }}=$ VMT by FC LTs in Program Success, and

$V M T_{\text {Tot LTS }}^{\text {NoPrg }}=$ VMT by FC LTs in No Program. 
Thus, fuel savings attributable to FCTO technologies were assumed to be proportional to the increase in VMT by FCVs and to the average fuel consumed per mile by vehicles replaced by FCVs.

As with petroleum savings, GHG reductions were calculated as the difference in GHG emissions between the No Program and Program Success cases. GHG reductions were attributed to VTO and FCTO programs on the basis of the petroleum savings attributed to each of these, taking into account the GHG intensity of gasoline and diesel, as well as the estimated changes in electricity and hydrogen consumption and their GHG intensities. GHG intensities were taken from the GREET model for gasoline, diesel, and electricity, assuming the same electricity generation mix as in the AEO 2016 Reference Case. In Program Success, hydrogen was assumed to be produced by methane reforming and electrolysis with some fraction of renewable electricity as given in Table 2-1.

\subsubsection{Gaps in LDV Program Disaggregation}

Attributing the aggregate benefits of VTO and FCTO success to each program is difficult. Many of the benefits of DOE research are economic, reducing costs to purchase and operate the vehicles; and the potential changes in market shares are not examined by individual technology at the program level. In addition, lightweighting can work synergistically with both improvements in ICE vehicles, FCVs, and electric vehicles to maximize benefits. By reducing the mass of the glider, the load on the drivetrain is reduced, thereby improving efficiency. However, the powertrain itself can also be downsized due to this reduced load, which can reduce costs and potentially increase the market share of alternative drivetrains.

In this way, lightweighting can act as an enabling technology. Some of the benefits from electrification and fuel cells should be attributed to materials research due to their increased market share. These benefits are difficult to quantify because the LDV vehicle choice models are run on whole vehicles with benefits from all programs, and are not included in this analysis.

\subsection{ATTRIBUTION OF HT BENEFITS TO TECHNOLOGY AREAS}

The AsCEnTT results were used to assess the relative contribution of each of the following technology types to fuel economy improvements:

- Engine efficiency, thermal management, and transmission

- Base engine thermal efficiency (engine design and combustion process improvements)

- Fuel injector advances, fuel and oil pump improvements

- Waste heat recovery (turbocompounding and organic Rankine cycle) 
- Improved lubricants and engine friction reduction

- Aerodynamics and rolling friction

- Coefficient of drag reductions through incorporation of fairings, dynamic gap closure, use of cameras instead of mirrors, and complete tractor and trailer redesign

- Profile reductions through dynamic height adjustment and tractor and trailer redesign

- Advances in low-rolling-resistance single wide-based tires

- Advanced Materials

- Mass reduction

- Hybridization

- Other, such as auxiliary and accessory improvements, including electrification (applies to auxiliaries not included in brake thermal efficiency measurements).

Note that aerodynamics and rolling friction are not specifically DOE-sponsored technology subprograms, but are significant elements of the SuperTruck industry team strategies. The contributions of current cost-effective aerodynamic and rolling friction technologies to the AEO fuel economies were included in the No Program case, so only benefits from improvements beyond these were attributed to the VTO program. The vehicle platforms analyzed for the Program Success case included fuel economy improvements attributable to aggressive reductions in aerodynamic drag and rolling friction that are expected from the SuperTruck II research initiative. Example strategies that might be used to achieve these reductions include dynamic ride-height and/or trailer gap adjustment and complete tractor and trailer redesign.

Idle reduction was not considered, since this is becoming a mature technology, and although this technology can save significant fuel (Gaines et al., 2006), little benefit from idle reduction was assumed to be attributable to VTO technology programs for years after 2019.

The AsCEnTT model predicted power losses by vehicle component, which were used to calculate fuel consumption by technology type. The fuel consumption by technology area for each advanced vehicle was compared with the base vehicle to find the reduction in duty cycle average gallons per mile attributable to each technology area. Further details are reported in Birky (2017). 


\subsubsection{Gaps in HT Program Disaggregation}

Changes in fuel economy from mass reduction were not estimated. As with LDVs, many of the benefits of lightweighting are economic, rather than improved efficiency. Rather, the decrease in mass was assumed to offset the added weight of other energy-saving technologies such as aerodynamic devices, waste heat recovery systems, and hybrid electric components. Any additional mass reductions for tractors (combination units) were assumed to be offset by increasing cargo weight, resulting in higher freight efficiency (ton-miles per gallon) rather than fuel efficiency (miles per gallon). The AsCEnTT results therefore include fuel consumption reductions attributable to weight reduction within the aerodynamic and waste heat recovery benefits.

This analysis has not estimated the benefits of any heavy vehicle elements beyond VTO or spillovers from non-vehicle research, specifically those attributable to FCTO. Fuel-cellpowered trucks were not considered in this analysis, though it is possible to power both mediumduty and heavy-duty vehicles with fuel cells. While these programs were outside the scope of this analysis in earlier years, efforts are ongoing to integrate the benefits analysis for VTO and FCTO for heavy trucks. In order to more comprehensively credit DOE for the impact of proposed R\&D budgets, efforts will continue to incorporate fuel cell research, Class 4-8 gasoline vehicles, and all Class 3 vehicles into future analysis.

\subsection{SUMMARY OF FUEL SAVINGS BY TECHNOLOGY AREA}

The petroleum savings projected to result from VTO and FCTO programs by vehicles of all types was estimated by adding up the fuel saved by the vehicles with the relevant technologies on the road in a given year. Total petroleum savings were attributed to each program area using the methodology described in Section 2. Multiple projections of market shares of vehicles by drivetrain technology were used to develop ranges for LDV petroleum savings.

Table 4-1 shows the estimated ranges of reductions in petroleum-based fuel consumption by the U.S. fleet of LDVs in MMbpd in 2025, 2035, and 2050, by technology area. In 2025, the estimated petroleum reduction across all programs for LDV is $0.4 \mathrm{MMbpd}$; in 2035, the estimated petroleum reduction is $1.0-1.6 \mathrm{MMbpd}$; and in 2050, the estimated petroleum reduction reaches 1.0-2.7 MMbpd. In earlier years, benefits from advanced combustion systems and fuels are responsible for most of the petroleum reduction. As market shares for EVs and FCVs increase, more benefits are attributed to electrification and FCTO research. Totals are different from the sum of the reductions because the minimum and maximum reductions in each technology area are from different projections. Also, the small amount of petroleum savings resulting from improvements in aerodynamic drag and rolling resistance are not currently included in the VTO portfolio of projects applicable to LDVs. 
TABLE 4-1 Projected Reductions in Oil Consumption by the U.S. LDV Fleet Attributable to EERE, by Technology Area (MMbpd)

\begin{tabular}{lccc}
\hline & \multicolumn{3}{c}{ MMbpd } \\
\cline { 2 - 4 } & 2025 & 2035 & 2050 \\
\cline { 2 - 4 } \multicolumn{1}{c}{ EERE Transportation Technology Area } & & & \\
Batteries and electric drive & $0.03-0.19$ & $0.28-0.61$ & $0.34-1.44$ \\
Advanced combustion systems and fuels & $0.19-0.27$ & $0.26-0.61$ & $0.06-0.22$ \\
Materials & $0.02-0.03$ & $0.06-0.12$ & $0.06-0.08$ \\
Fuel cells & $0.00-0.05$ & $0.11-0.45$ & $0.35-0.96$ \\
Non-EERE vehicle changes & $0.01-0.02$ & $0.04-0.08$ & $0.04-0.08$ \\
Total LDV Fleet Petroleum Use Reduction & $0.37-0.44$ & $0.96-1.60$ & $1.05-2.74$ \\
\hline
\end{tabular}

Table 4-2 shows the estimated reductions in fuel consumption in 2025, 2035, and 2050 by medium- and heavy-duty trucks, including Classes $4-8$. Total reductions in petroleum usage by HT due to VTO technologies are expected to grow from $0.06 \mathrm{MMbpd}$ in 2025, to $0.40 \mathrm{MMbpd}$ in 2035, to $0.79 \mathrm{MMbpd}$ by 2050. The technologies listed in Table 4-2 correspond to the technologies being developed and demonstrated under VTO activities such as the SuperTruck initiative and the 21 st Century Truck Partnership. Reductions attributable to engine and drivetrain efficiency and friction reduction are combined in the table. For heavy- and medium-duty trucks (HTs, including size Classes 4-8), reductions in fuel consumption due to improvements in aerodynamics and rolling resistance are also shown. No petroleum savings for HTs were attributable to the FCTO program.

TABLE 4-2 Projected Reductions in Petroleum Consumption by the U.S. Fleet of Medium- and Heavy-duty Trucks (Classes 4-8) Attributable to VTO, by Technology Area (MMbpd)

\begin{tabular}{|c|c|c|c|}
\hline \multirow[b]{2}{*}{ VTO Technology } & \multicolumn{3}{|c|}{ MMbpd } \\
\hline & 2025 & 2035 & 2050 \\
\hline Advanced combustion engine & 0.038 & 0.275 & 0.541 \\
\hline Fuels technology & 0.003 & 0.019 & 0.031 \\
\hline Advanced materials ${ }^{\mathrm{a}}$ & 0.000 & 0.002 & 0.004 \\
\hline Batteries and electric drive & 0.000 & 0.001 & 0.004 \\
\hline Transmission and drivetrain & 0.001 & 0.005 & 0.011 \\
\hline Aerodynamic and rolling friction ${ }^{\mathrm{b}}$ & 0.014 & 0.095 & 0.186 \\
\hline Idle reduction, non-hybrid ${ }^{c}$ & 0.000 & 0.000 & 0.000 \\
\hline Other (accessories and auxiliaries) & 0.001 & 0.006 & 0.011 \\
\hline Total HT Fleet Petroleum Use Reduction & 0.057 & 0.403 & 0.788 \\
\hline \multicolumn{4}{|c|}{ a Includes only the estimated fraction of rolling resistance benefit due to mass reduction. } \\
\hline \multicolumn{4}{|l|}{ b Drag used for deceleration is removed. } \\
\hline c Benefit from idle reduction was not att & & & \\
\hline
\end{tabular}


The projected reductions in petroleum consumption in 2025, 2035, and 2050 by technology area are shown in Figure 4-2. In Figure 4-2, LDV savings are equal to those from Table 4-1, while most of the HT fuel savings are part of "ACE \& Lubes," since the majority of VTO R\&D applicable to HTs are funded under the Advanced Combustion Systems and Fuels $\mathrm{R} \& \mathrm{D}$ program. The differences between vehicle choice models are represented by individual dots on the y-axis.

Projected reductions in GHG emissions are presented for each VTO and FCTO program in Figure 4-3 for 2025, 2035, and 2050. Projected GHG reduction by LDV varies somewhat depending on the LDV choice model used to project market shares; therefore ranges of projected reductions are shown. As with projected petroleum savings, the projected GHG reductions attributable to electrification and FCVs are sensitive to the projected market penetration by plugins and FCVs; therefore the uncertainty in GHG reductions is large, particularly for 2050. However, the reductions are significant for all four sets of projections.

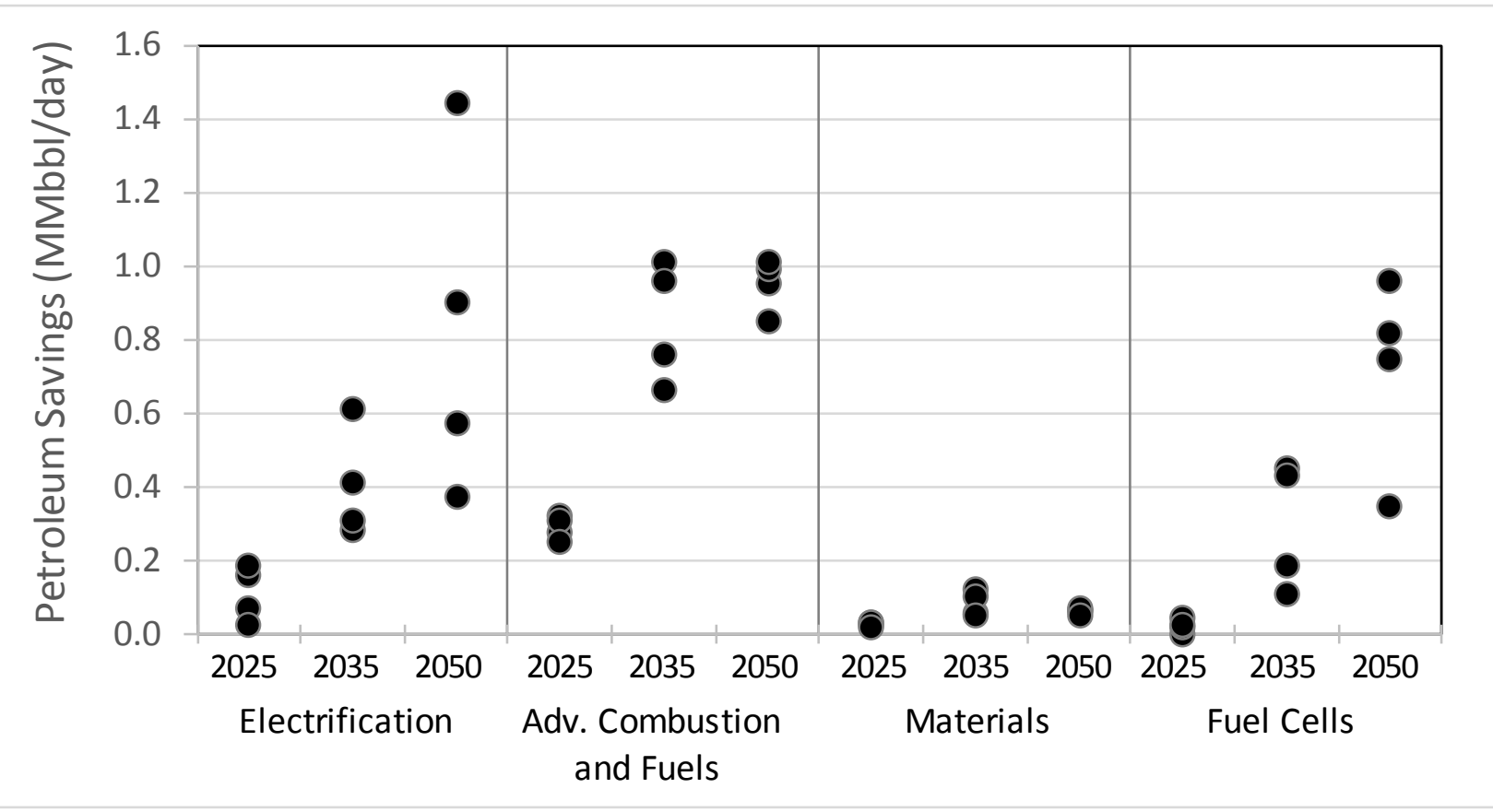

FIGURE 4-2 Projected Petroleum Savings in 2025, 2035, and 2050 Attributable to VTO and FCTO Technology Programs 


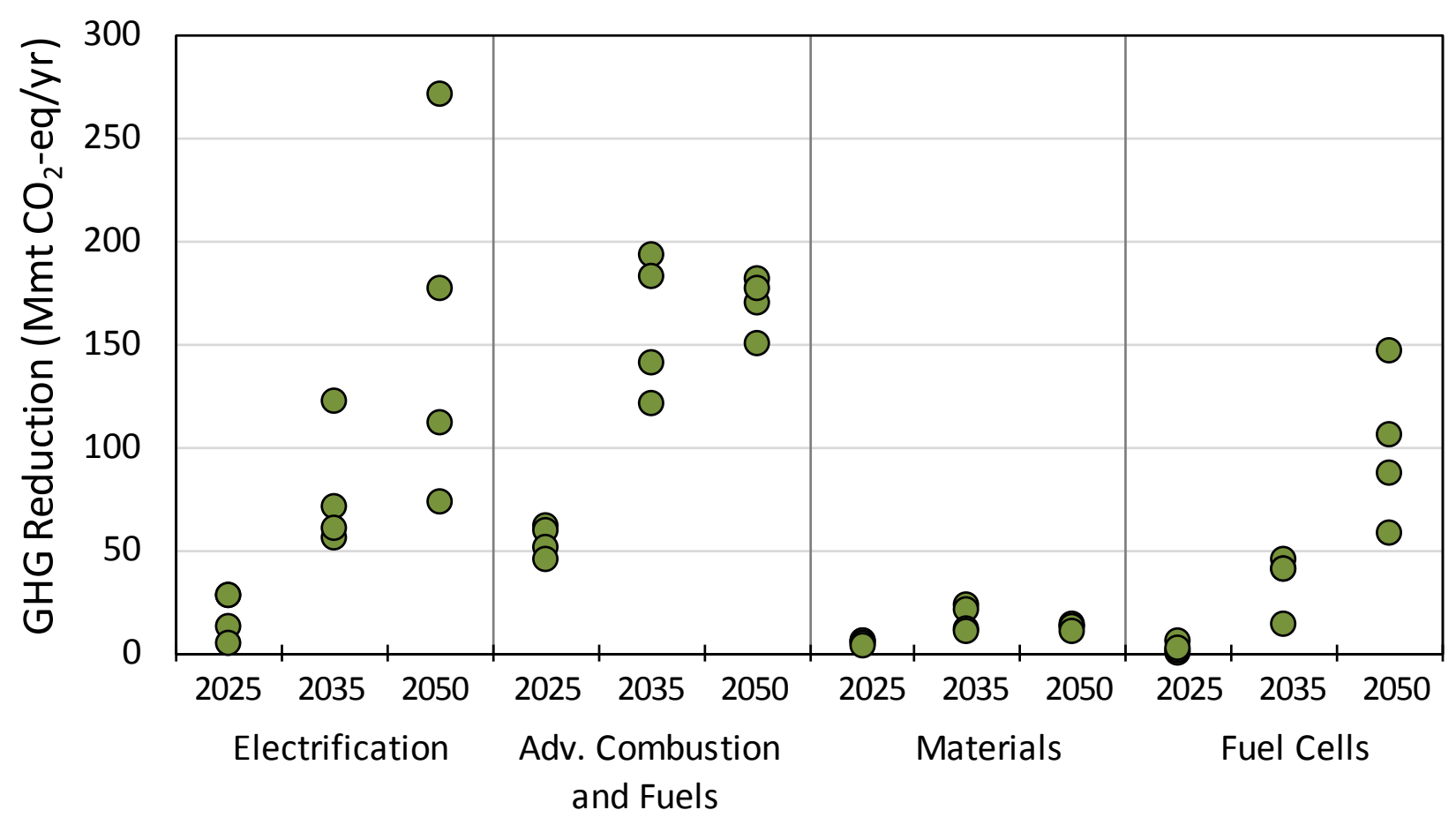

FIGURE 4-3 Projected Reductions in GHG Emissions in 2025, 2035, and 2050 Attributable to VTO and FCTO Technology Programs

Results from Figures 4-2 and 4-3 are also presented in Table 4-3, which shows total benefits for both LDV and HT disaggregated by program, attributing HT fuel savings to Combustion and Fuels.

TABLE 4-3 Projected Ranges of Petroleum Savings and Emissions Reductions in 2025, 2035, and 2050 Attributable to VTO and FCTO Technology Programs

\begin{tabular}{|c|c|c|c|c|c|c|}
\hline \multirow[b]{2}{*}{ Program Area } & \multicolumn{3}{|c|}{$\begin{array}{l}\text { Annual Petroleum Savings } \\
\text { (MMbpd) }\end{array}$} & \multicolumn{3}{|c|}{$\begin{array}{l}\text { Annual GHG Reduction } \\
\text { (million tons } \mathrm{CO}_{2} \text {-eq) }\end{array}$} \\
\hline & 2025 & 2035 & 2050 & 2025 & 2035 & 2050 \\
\hline Electrification & $0.03-0.19$ & $0.28-0.61$ & $0.34-1.44$ & $5-29$ & $57-123$ & $74-272$ \\
\hline $\begin{array}{l}\text { Combustion Engines } \\
\text { and Fuels }\end{array}$ & $0.25-0.32$ & $0.66-1.01$ & $0.85-1.01$ & $47-62$ & $122-194$ & $151-182$ \\
\hline Materials Technology & $0.02-0.03$ & $0.06-0.12$ & $0.06-0.08$ & $4-7$ & $11-24$ & $11-15$ \\
\hline Hydrogen Fuel Cells & $0.00-0.05$ & $0.11-0.45$ & $0.35-0.96$ & $0-6$ & $14-46$ & $59-148$ \\
\hline
\end{tabular}




\section{CONCLUSIONS}

New technologies whose development is supported by VTO and FCTO can be used to improve the vehicles that will be manufactured over the coming decades, from both a costeffectiveness and fuel economy perspective. Research in advanced vehicle and fuel cell technologies could have significant economic value in the U.S. transportation sector; help consumers and businesses save money; and increase the use of secure, domestic energy sources. Comparing the estimated benefits of successfully developing and implementing these technologies (a Program Success case) relative to the base case (the No Program case), quantifies the benefits of this government investment.

Projections for the Program Success case indicate that by 2035, the average fuel economy of on-road, LDV stock could be $24 \%$ to $30 \%$ higher than in the No Program case. In addition, average on-road medium- and heavy-duty vehicle stock fuel economies in the same year could be as much as $13 \%$ higher. The resulting petroleum savings in 2035 were estimated to be as high as $1.9 \mathrm{MMbpd}$, and reductions in GHG emissions were estimated to be as high as $320 \mathrm{Mmt}$ of $\mathrm{CO}_{2}$-eq per year. Such petroleum reductions result in significant reductions in fuel expenditure for both light- and heavy-duty vehicles, totaling approximately $\$ 100$ billion annually by 2035 .

By 2050, these benefits compound, resulting in large aggregate benefits. A cumulative reduction of up to 22 billion barrels of oil, saving a total of nearly 120 quads of energy use, is possible with successful development of VTO and FCTO technologies. By comparison, these values are greater than the total U.S. petroleum consumption and U.S. energy usage in 2015, respectively (Davis et al., 2016). This improvement in technology could save the U.S. consumer more than $\$ 200$ billion in 2050 .

Disaggregating these benefits by individual technology areas - electrification, advanced combustion systems and fuels, materials technology, and hydrogen and fuel cells technologieshighlights the need for research across all vehicle components. Energy savings attributable to each of these areas will increase through 2035. From 2035 to 2050, the benefits from research on electrification and hydrogen fuel cells are estimated to increase in LDVs, while advanced combustion and fuels technologies will improve medium- and heavy-duty trucks. The estimated savings depend on market penetration projections that assume that those technologies closer to commercialization will ramp up more quickly than those that are in earlier stages of development such as fuel cells and hydrogen infrastructure. 
This page intentionally left blank. 


\section{REFERENCES}

Argonne (Argonne National Laboratory), 2015, TRUCK Heavy Vehicle Market Penetration Model, Argonne National Laboratory, Argonne, IL. Available at www.anl.gov/energysystems/project/truck-heavy-vehicle-market-penetration-model. Accessed Aug. 31, 2017.

Argonne, 2016, GREET Model: The Greenhouse Gases, Regulated Emissions, and Energy Use in Transportation Model, Argonne National Laboratory, Argonne, IL. Available at http://greet.es.anl.gov/. Accessed Aug. 31, 2017.

Argonne, 2017, Autonomie, Argonne National Laboratory, Argonne, IL. Available at http://www.autonomie.net/index.html. Accessed Aug. 31, 2017.

Bandivadekar, A., et al., 2008. On the Road in 2035: Reducing Transportation's Petroleum Consumption and GHG Emissions, Report No. LFEE 2008-05 RP, Laboratory for Energy and the Environment, Massachusetts Institute of Technology, Cambridge, Mass. Available at http://web.mit.edu/sloan-auto-lab/research/beforeh2/otr2035/. Accessed Aug. 31, 2017.

Birky, A., 2015, "Modeling for Light and Heavy Vehicle Market Analysis," presented at U.S. Department of Energy Vehicle Technologies Office Annual Merit Review and Peer Evaluation, Washington, D.C. Available at http://energy.gov/eere/vehicles/downloads/vehicletechnologies-office-merit-review-2015-modeling-light-and-heavy. Accessed Aug. 31, 2017.

Birky, A., 2017, "Heavy Vehicle Prospective Benefits Analysis Methodology,” memorandum from A. Birky (Energetics Incorporated) to T. Stephens (Argonne National Laboratory) and R. Nealer (U.S. Department of Energy).

Davis, S.C., S.W. Diegel, and R.G. Boundy, 2016, Transportation Energy Data Book, Edition 35, ORNL-6992, Oak Ridge National Laboratory, Oak Ridge, Tenn.

DOE (U.S. Department of Energy), 2015, Quadrennial Technology Review: An Assessment of Energy Technologies and Research Opportunities, U.S. Department of Energy, Washington, D.C. Available at https://energy.gov/under-secretary-science-and-energy/quadrennialtechnology-review-2015. Accessed Aug. 31, 2017.

DOE, 2016a, Co-Optimization of Fuels \& Engines for Tomorrow's Energy-Efficient Vehicles, DOE/GO-102016-4860, U.S. Department of Energy, Washington, D.C. Available at https://www.nrel.gov/docs/fy16osti/66146.pdf. Accessed Oct. 4, 2017.

DOE, 2016b, Energy Department Announces \$137 Million Investment in Commercial and Passenger Vehicle Efficiency, August 16, 2016. Available at https://energy.gov/articles/energydepartment-announces-137-million-investment-commercial-and-passenger-vehicle. Accessed Oct. 4, 2017. 
DOE, 2017a, Advanced Combustion Engines 2016 Annual Report, DOE/EE-1506, U.S. Department of Energy, Washington, D.C. Available at https://energy.gov/sites/prod/files/ 2017/08/f36/fy16_adv_comb_report_print.pdf. Accessed Oct. 4, 2017.

DOE, 2017b, DOE Hydrogen and Fuel Cells Program: 2016 Annual Progress Report, DOE/GO-102017-4891, U.S. Department of Energy, Washington, D.C. Available at https://www.hydrogen.energy.gov/annual_progress16.html. Accessed Aug. 31, 2017.

DOE, 2017c, Lighweight Materials 2016 Annual Report, DOE/EE-1533, U.S. Department of Energy, Washington, D.C. Available at https:/energy.gov/sites/prod/files/2017/11/ https://energy.gov/sites/prod/files/2017/11/f46/FY_2016_APR_Consolidated_Report_compliant102617.pdf. Accessed Nov. 13, 2017.

DOE, 2017d, FY 2016 Annual Progress Report for Advanced Batteries, DOE/EE-1531, U.S. Department of Energy, Washington, D.C. Available at https://energy.gov/sites/prod/files/ 2017/08/f36/ES_APR_16_v5b\%20-\%201\%20of\%204.pdf. Accessed Oct. 4, 2017.

EIA (Energy Information Administration), 2016, Annual Energy Outlook 2016: With Projections to 2040, DOE/EIA-0383(2016), Office of Integrated Analysis and Forecasting, Energy Information Administration, U.S. Department of Energy, Washington, D.C. Available at https://www.eia.gov/outlooks/aeo/pdf/0383(2016).pdf. Accessed Aug. 31, 2017.

EPA (U.S. Environmental Protection Agency), 2006, "Final Rule: Fuel Economy Labeling of Motor Vehicles: Revisions to Improve Calculation of Fuel Economy Estimates," Federal Register, Dec. 27. Available at www.federalregister.gov/articles/2006/12/27/06-9749/fueleconomy-labeling-of-motor-vehicles-revisions-to-improve-calculation-of-fuel-economyestimates. Accessed Aug. 31, 2017.

EPA, 2011a, Final Rulemaking to Establish Greenhouse Gas Emissions Standards and Fuel Efficiency Standards for Medium- and Heavy-Duty Engines and Vehicles, Regulatory Impact Analysis, EPA-420-R-11-901, Office of Transportation and Air Quality, U.S. Environmental Protection Agency and National Highway Traffic Safety Administration, U.S. Department of Transportation, Aug.

EPA, 2011b, Greenhouse Gas Emissions Model (GEM) User Guide, EPA-420-B-11-019, Assessment and Standards Division, Office of Transportation and Air Quality, U.S. Environmental Protection Agency, Aug.

EPA, 2016, Inventory of U.S. Greenhouse Gas Emissions and Sinks: 1990-2014, EPA-430-R16-002, U.S. Environmental Protection Agency, April. Available at https://www.epa.gov/ ghgemissions/inventory-us-greenhouse-gas-emissions-and-sinks-1990-2014. Accessed Aug. 31, 2017.

EPA and DOE, 2011, Where the Energy Goes: Gasoline Vehicles. Available at http://www.fueleconomy.gov/feg/atv.shtml. Accessed Aug. 31, 2017. 
EPA and NHTSA (National Highway Transportation Safety Administration), 2011a, "Final Rule: Greenhouse Gas Emissions Standards and Fuel Efficiency Standards for Medium- and Heavy-Duty Engines and Vehicles," Federal Register, Sept. 9. Available at www.federalregister.gov/articles/2011/09/15/2011-20740/greenhouse-gas-emissions-standardsand-fuel-efficiency-standards-for-medium--and-heavy-duty-engines. Accessed Aug. 31, 2017.

EPA and NHTSA, 2011b, Draft Joint Technical Support Document: Proposed Rulemaking for 2017-2025 Light-Duty Vehicle Greenhouse Gas Emission Standards and Corporate Average Fuel Economy Standards, EPA-420-D-11-901. Available at https://nepis.epa.gov/Exe/ ZyPDF.cgi/P100CV58.PDF?Dockey=P100CV58.PDF. Accessed Aug. 31, 2017.

Gaines, L., A. Vyas, and J. Anderson, 2006, "Estimation of Fuel Use by Idling Commercial Trucks," Transportation Research Record: Journal of the Transportation Research Board, 1983, 91-98.

Greene, D.L., 2010, How Consumers Value Fuel Economy: A Literature Review, EPA-410-10008, Environmental Protection Agency, Washington, D.C. Available at https://cfpub.epa.gov/si/ si_public_file_download.cfm?p_download_id=499454. Accessed Aug. 31, 2017.

Greene, D.L., D.H. Evans, and J. Hiestand, 2013, "Survey Evidence on the Willingness of U.S. Consumers to Pay for Automotive Fuel Economy," Energy Policy, 61, 1539-1550.

Greene, D.L., C. Liu, and P.N. Leiby, 2014, The Oil Security Metric Model: 2014 Update, ORNL/TM-2014/628, Oak Ridge National Laboratory, Oak Ridge, Tenn.

Islam, E., A. Moawad, N. Kim, and A. Rousseau, 2017, An Extensive Study on Sizing, Energy Consumption and Cost of Advanced Vehicle Technologies, ANL/ESD-17/17, Argonne National Laboratory, Argonne, IL (forthcoming).

IWG (Interagency Working Group on Social Cost of Carbon), 2013, Technical Support Document: Technical Update of the Social Cost of Carbon for Regulatory Impact Analysis under Executive Order 12866, May.

Kim, H.K., and T.J. Wallington, 2013, "Life Cycle Assessment of Vehicle Lightweighting: A Physics-Based Model of Mass-Induced Fuel Consumption," Environmental Science and Technology, 47, 14358-14366.

Lin, Z., 2015, $M A^{3} T$-Modeling Vehicle Market Dynamics with Consumer Segmentation, presented at U.S. Department of Energy Vehicle Technologies Office Annual Merit Review and Peer Evaluation, Washington, D.C., June 11. Available at https://energy.gov/eere/vehicles/ downloads/vehicle-technologies-office-merit-review-2015-ma3t-modeling-vehicle-market. Accessed Aug. 31, 2017. 
Lin, Z., and D.L. Greene, 2010, "A Plug-in Hybrid Consumer Choice Model with Detailed Market Segmentation," presented at Transportation Research Board 2010 Annual Meeting, TRB 89th Annual Meeting Compendium of Papers, Transportation Research Board, Washington, D.C. Available at http://pubsindex.trb.org/view.aspx?id=910112. Accessed Aug. 31, 2017.

Lin, Z., and D.L. Greene, 2011, "Promoting the Market for Plug-In Hybrid and Battery Electric Vehicles: The Role of Recharge Availability," Transportation Research Record, 2252, 49-56. Available at http://trrjournalonline.trb.org/doi/abs/10.3141/2252-07. Accessed Aug. 31, 2017.

Liu, C., 2015, Transportation Energy Transition Modeling and Analysis: The LAVE-Trans Model, presented at U.S. Department of Energy Vehicle Technologies Office Annual Merit Review and Peer Evaluation, Washington, D.C., June 11. Available at http://energy.gov/eere/ vehicles/downloads/vehicle-technologies-office-merit-review-2015-transportation-energy. Accessed Aug. 31, 2017.

Manley, D., R. Levinson, G. Barter, and T. West, 2015, ParaChoice: Parametric Vehicle Choice Modeling, presented at U.S. Department of Energy Vehicle Technologies Office Annual Merit Review and Peer Evaluation, Washington, D.C., June 11. Available at http://energy.gov/eere/ vehicles/downloads/vehicle-technologies-office-merit-review-2015-parachoice-parametricvehicle. Accessed Aug. 31, 2017.

Moawad, A., and A. Rousseau, 2012, Impact of Electric Drive Vehicle Technologies on Fuel Efficiency - Final Report, DOT HS 811 668, National Highway Traffic Safety Administration, Washington, D.C. Available at http://www.nhtsa.gov/staticfiles/rulemaking/pdf/cafe/ Effect_of_Electric_Drive_Vehicle_Technologies-811668.pdf. Accessed Dec. 3, 2015.

Moawad, A., N. Kim, N. Shidore, and A. Rousseau, 2016, Assessment of Vehicle Sizing, Energy Consumption and Cost through Large Scale Simulation of Advanced Vehicle Technologies, ANL/ESD-15/28, Argonne National Laboratory, Argonne, IL.

NRC (National Research Council), 2010, Technologies and Approaches to Reducing the Fuel Consumption of Medium- and Heavy-Duty Vehicles, National Academies Press, Washington, D.C. Available at www.nap.edu/catalog/12845/technologies-and-approaches-to-reducing-thefuel-consumption-of-medium-and-heavy-duty-vehicles. Accessed Aug. 31, 2017.

NRC, 2013, Transitions to Alternative Vehicles and Fuels, National Academies Press, Washington, D.C. Available at www.nap.edu/catalog/18264/transitions-to-alternative-vehiclesand-fuels. Accessed Aug. 31, 2017.

OMB (Office of Management and Budget), 1992, Guidelines and Discount Rates for BenefitCost Analysis of Federal Programs, Circular A-94 Revised, Office of Management and Budget, Washington, D.C. Available at www.whitehouse.gov/omb/circulars_a094/. Accessed Dec. 10, 2013. 
Pagerit, S., P. Sharer, and A. Rousseau, 2006, Fuel Economy Sensitivity to Vehicle Mass for Advanced Vehicle Powertrains, Paper 2006-01-0665, Society of Automotive Engineers, Washington, D.C. Available at http://papers.sae.org/2006-01-0665/.

Rogozhin, A., M. Gallaher, G. Helfand, and W. McManus, 2010, "Using Indirect Cost Multipliers to Estimate the Total Cost of Adding a New Technology in the Automobile Industry," International Journal of Production Economics 124, 360-368.

Sarkar, R., and J. Ward, 2016, "DOE SMART Mobility: Systems and Modeling for Accelerated Research in Transportation," pp. 39-52 in Road Vehicle Automation 3, Springer International Publishing.

Schubert, R., M. Chan, and K. Law, 2015, Commercial Medium- and Heavy-Duty Truck Fuel Efficiency Technology Cost Study, DOT HS 812 177, National Highway Traffic Safety Administration, Washington, D.C. Available at https://www.regulations.gov/ document?D=NHTSA-2014-0132-0008. Accessed Nov. 3, 2017.

Stephens T., A.K. Birky, and J. Ward, 2014, Vehicle Technologies Program Government Performance and Results Act (GPRA) Report for Fiscal Year 2015, ANL/ESD-14/3, Argonne National Laboratory, Argonne, IL. Available at www.osti.gov/scitech/biblio/1130740. Accessed March 30, 2017.

Stephens T., C.H. Taylor, J.S. Moore, and J. Ward, 2016, Vehicle Technologies and Fuel Cell Technologies Program Prospective Benefits Assessment Report for Fiscal Year 2016, ANL/ESD-16/2, Argonne National Laboratory, Argonne, IL. Available at http://www.osti.gov/ scitech/biblio/1250457-vehicle-technologies-fuel-cell-technologies-program-prospectivebenefits-assessment-report-fiscal-year. Accessed Jan. 26, 2017.

TAE (TA Engineering, Inc.), 2012, DOE SuperTruck Program Benefits Analysis, TA Engineering, Baltimore, Md., Dec. 20.

U.S. DRIVE (United States Driving Research and Innovation for Vehicle Efficiency and Energy Sustainability), 2013, "Electrical and Electronics Technical Team Roadmap," June. Available at https://www1.eere.energy.gov/vehiclesandfuels/pdfs/program/eett_roadmap_june2013.pdf.

Vyas, A., D. Santini, and R. Cuenca, 2000, Comparison of Indirect Cost Multipliers for Vehicle Manufacturing, Technical Memorandum, Argonne National Laboratory, Argonne, IL.

Winebrake, J.J., E.H. Green, B. Comer, C. Li, S. Froman, and M. Shelby, 2015a, "Fuel Price Elasticities in the U.S. Combination Trucking Sector," Transportation Research Part D 38, $166-177$.

Winebrake, J.J., E.H. Green, B. Comer, C. Li, S. Froman, and M. Shelby, 2015b, "Fuel Price Elasticities for Single-Unit Truck Operations in the United States," Transportation Research Part D 38, 178-187. 
Zhou, Y., and A. Vyas, 2014, VISION Model Description and User's Guide: Model Used to Estimate the Impacts of Highway Vehicle Technologies and Fuels on Energy Use and Carbon Emissions to 2100, ANL/ESD-14/1, Argonne National Laboratory, Argonne, IL, Jan. Available at http://www.osti.gov/scitech/biblio/1130301-vision-model-description-user-guide-model-usedestimate-impacts-highway-vehicle-technologies-fuels-energy-use-carbon-emissions. Accessed Aug. 31, 2017.

Zhou, Y., D. Santini, T. Stephens, and J. Ward, 2016, "Comparison of Value Retention of Plugin and Conventional Vehicles and Potential Contributing Factors," presented at Transportation Research Board 2016 Annual Meeting, TRB 95th Annual Meeting Compendium of Papers, Transportation Research Board, Washington, D.C. Available at http://docs.trb.org/prp/166732.pdf. Accessed Nov. 3, 2017. 


\section{APPENDIX A: COMPARISON WITH EIA PROJECTIONS AND FUEL ECONOMY STANDARDS}

As described in Section 2, neither the Program Success nor the No Program case is the same as the Annual Energy Outlook (AEO) 2016 Reference Case published by the Energy Information Administration (EIA). Also, neither scenario assumes that federal Corporate Average Fuel Economy (CAFE) or greenhouse gas (GHG) standards or the California Zero Emission Vehicle (ZEV) program are constraints on fuel economy or sales shares. It is useful to compare the light-duty-vehicle (LDV) projections of the two scenarios to those of the AEO Reference Case, since the AEO Reference Case does conform to the LDV CAFE and GHG standards as well as California's Clean Cars program, including ZEV sales requirements in California and nine other states (EIA, 2017). The current federal fuel economy standards are footprint-based, so the exact petroleum reduction and GHG abatement required for compliance are dependent on the mix of sales. The AEO 2016 Reference Case therefore represents one possible future in which these regulations are met. The projected petroleum consumption by LDVs in 2025 for the Program Success and No Program cases are compared with the AEO 2016 Reference Case in Figure A-1 (left). GHG emissions projections in the same year are also shown in Figure A-1 (right). Petroleum consumption and GHG emissions were calculated using VISION for each case.

As described in Section 2.1.2 and Appendix B, four different consumer choice models were used to develop projected market shares of different powertrain types of LDVs. These market shares differed between the different projections as did the resulting projected petroleum consumption. The uncertainty bars in Figure A-1 show the range of petroleum consumption and GHG emissions projected in 2025 in the No Program and Program Success cases, while the heights of the bars show the average values of the four projections. LDV petroleum consumption is shown in the tank-to-wheels consumption (no upstream energy); the GHG emissions shown, however, are for the full fuel cycle, as described in Section 2.1.2. AEO projections were taken from the VISION 2016 base case, which was calibrated to match the AEO Reference Case, though outputs differ from the AEO due to differences in accounting.

On average, in the No Program case, petroleum consumption and GHG emissions are somewhat higher than in the AEO Reference Case. In particular, values fall short of regulatory standards for cars and for light trucks in most No Program projections for 2025. This is not unexpected, since the AEO Reference Case is developed assuming U.S. Department of Energy (DOE) technology programs continue as planned, which is more optimistic than the assumptions underlying the No Program case. In addition, neither the Program Success nor the No Program case makes assumptions about strategies that automakers might take to reach compliance with the standards, including incentivized sales of more efficient vehicles or accumulation of offcycle credits, which are not directly accounted for here.

Even without accounting for these strategies, nearly all projections for Program Success in 2025 met or exceeded targets. The average petroleum consumption in the Program Success projections is somewhat lower than the AEO Reference Case, due at least in part to the higher adoption levels of advanced vehicles, in particular plug-in electric vehicles (PEVs). 

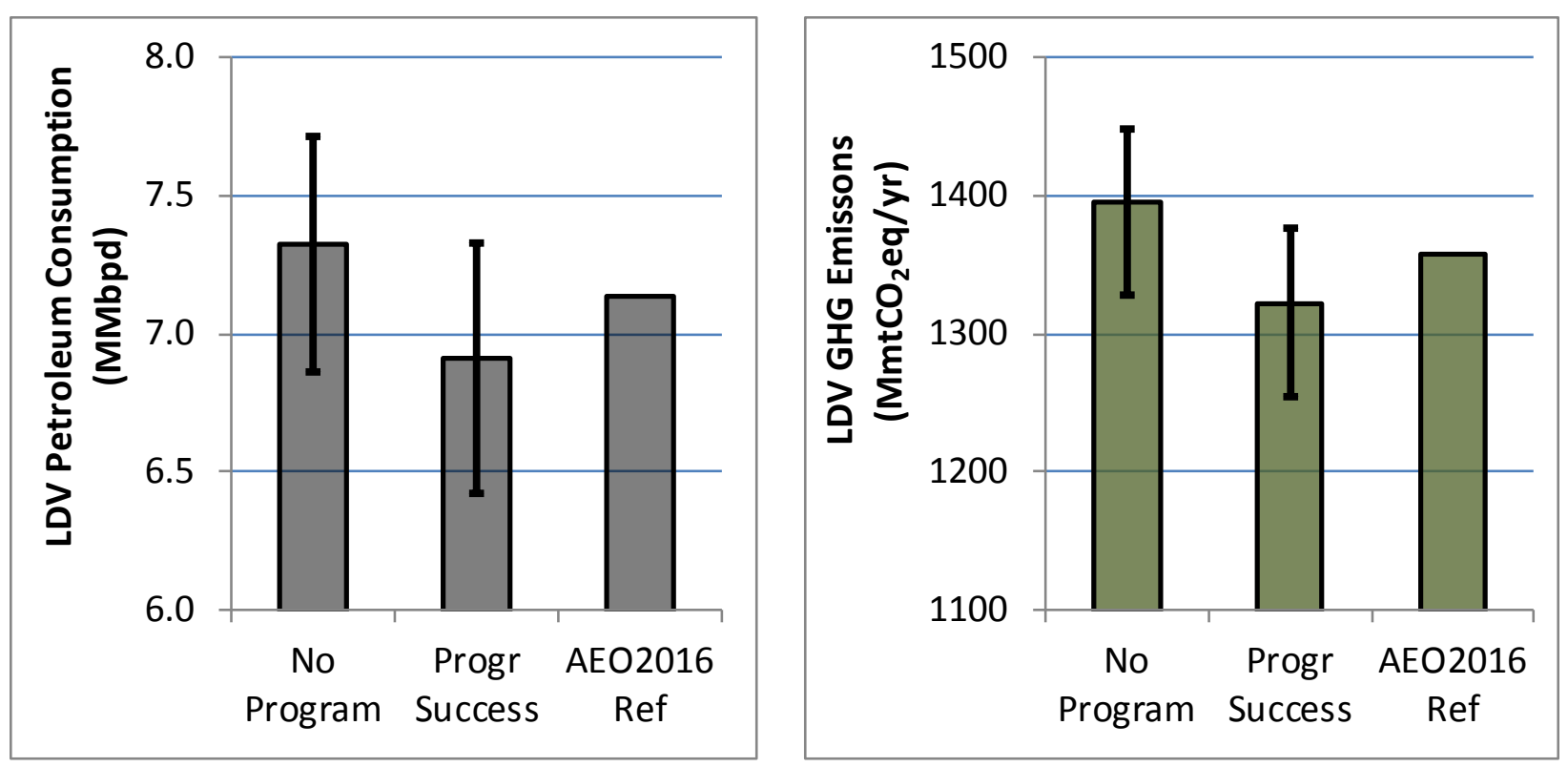

FIGURE A-1 Projected Petroleum Consumption (left) and GHG Emissions (right) by LDVs in 2025 under the No Program and Program Success Cases and by the AEO 2016 Reference Case

Neither the Program Success nor the No Program case reached the fuel economy of the AEO Reference Case in 2020. Note that Vehicle Technologies Office (VTO) and Fuel Cell Technologies Office (FCTO) technologies were assumed not to influence vehicle efficiency until 5 years after research and development (R\&D) targets were assumed to be met, as discussed in Section 2.1.1, and the vehicle attributes assumed for 2020 were the same in the Program Success case as in the No Program case. Figure A-2 shows the fleet-averaged fuel economy projected to 2025 for each LDV vehicle choice model compared to the AEO Reference Case. In general, the AEO Reference Case projects higher fleet-wide fuel economy in early years, while the Program Success case surpasses it in the early 2020s, and the No Program case eventually reaches the AEO Reference Case level.

The analysis here attributes the difference between the Program Success and No Program cases to DOE technologies. If it were assumed that the CAFE and GHG standards and ZEV sales requirements were all met in the No Program case, this would reduce the difference between the Program Success and No Program projections in some cases, thereby reducing the projected benefits, at least in the near term. Even so, since on average, roughly half of the difference between the Program Success case and the No Program case is above the AEO 2016 Reference Case, which satisfies policy considerations, at least this fraction is attributable to VTO and FCTO technologies. As noted before, the AEO Reference Case assumes current policies remain in effect until they sunset. Projections made for the AEO Reference Case thus incorporate assumptions about the market success of technologies historically supported by VTO and FCTO, and some of the benefit registered there is likely due to Energy Efficiency and Renewable Energy (EERE) technologies. DOE program targets are not designed to satisfy regulations, but to have benefits beyond those from regulatory compliance. 


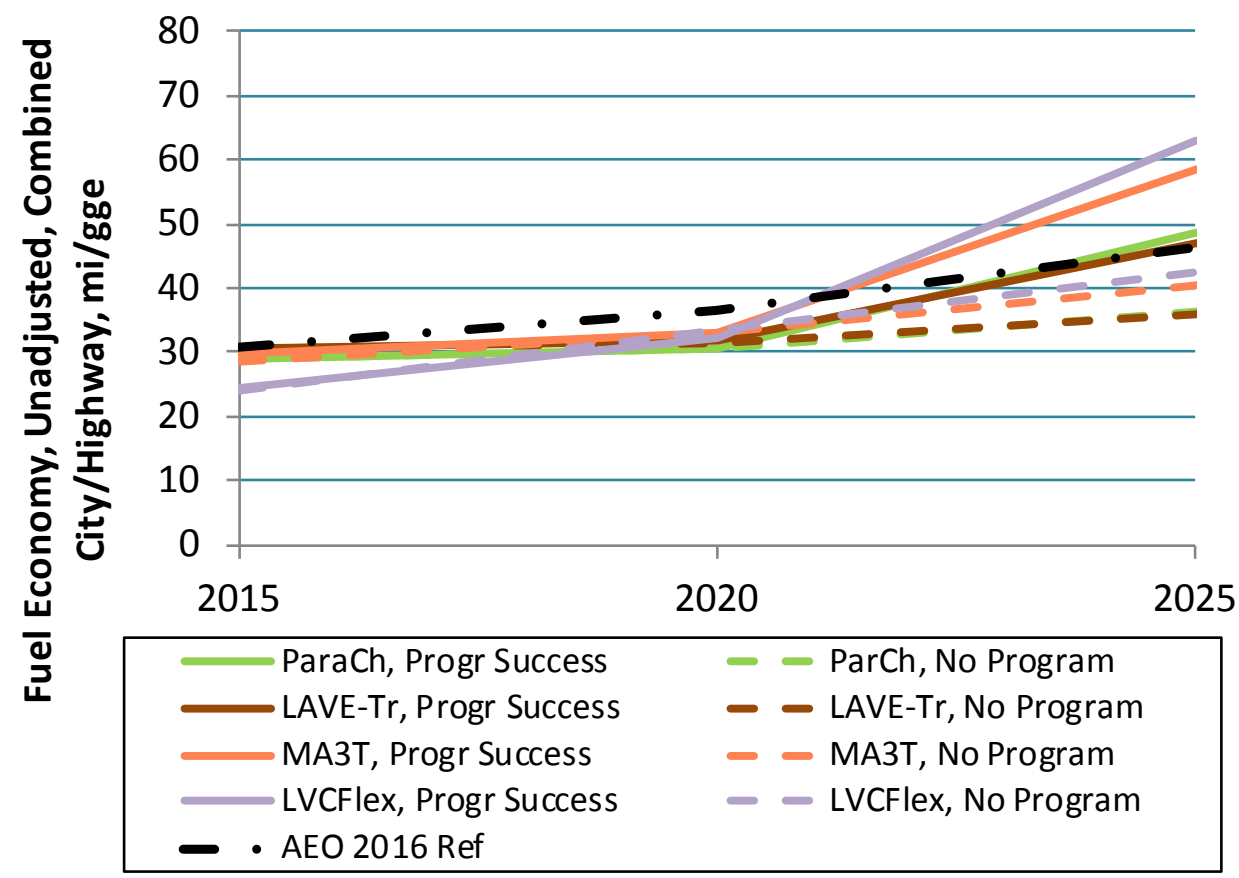

FIGURE A-2 Unadjusted, Combined City/Highway Fleet-averaged Fuel Economy of LDVs Projected under the No Program and Program Success Cases and by the AEO 2016 Reference Case

More significantly, continued increases in vehicle efficiency and advanced vehicle market penetration after 2025 are realized in the No Program case, with all vehicle choice models projecting that the fuel economy standards for 2025 are met and surpassed. Therefore, the benefits estimated for later years are insensitive to assumptions about compliance to standards. The bulk of the petroleum reduction attributed to VTO and FCTO technologies is projected to occur in later years, with more than $80 \%$ of the oil savings occurring after 2030 .

\section{REFERENCE}

EIA (Energy Information Administration), 2016, Annual Energy Outlook 2016: With Projections to 2040, DOE/EIA-0383(2016), Office of Integrated Analysis and Forecasting, Energy Information Administration, U.S. Department of Energy, Washington, D.C. Available at https://www.eia.gov/outlooks/aeo/pdf/0383(2016).pdf. Accessed Aug. 31, 2017. 
This page intentionally left blank. 


\section{APPENDIX B: LIGHT-DUTY VEHICLE MODEL INPUTS AND OUTPUTS}

\section{B.1 INPUTS OF LIGHT-DUTY VEHICLE (LDV) VEHICLE CHOICE MODELING}

Multiple projections give a range of possible outcomes and permits examination of the effects of these differences on fuel use and greenhouse gas (GHG) emissions. Each of these models was developed with different assumptions, and each represents the LDV market slightly differently:

- The Light-Duty Alternative Vehicle Energy Transition (LAVE-Trans) model gives sales shares for cars and light trucks, and represents two segments of consumers, early adopters and majority adopters, with the main difference being the value that consumers place on newness or maturity of technology. Early adopters more readily adopt vehicles with advanced technologies, such as plug-in vehicles and fuel cell vehicles, while majority adopters are averse to these vehicles. As more of these new vehicles are purchased, both the preference for them by early adopters and the aversion by majority adopters decrease. This phenomenon is calculated in LAVE-Trans, which tracks the on-road populations of these vehicles.

- The LVCFlex model is a simplified version of the vehicle choice component of the National Energy Modeling System used to develop the Annual Energy Outlook (AEO). LVCFlex models consumer choice in five size classes: small cars, large cars, small sport utility vehicles (SUVs), large SUVs, and pickups. Sales shares of each size class are specified by the user; in this case, the shares by size class and total vehicle sales were specified to be consistent with the AEO 2016 Reference Case (EIA, 2016).

- In the Market Acceptance of Advanced Automotive Technologies $\left(\mathrm{MA}^{3} \mathrm{~T}\right)$ model, consumers are segmented by attitude toward risk (early adopter, early majority, and late majority), driving pattern, population density, availability of electric charging at home and at work, and state of residence. Both the LAVETrans and $\mathrm{MA}^{3} \mathrm{~T}$ models estimate total light-duty sales and sales shares of each size class endogenously.

- The ParaChoice model is based on the $\mathrm{MA}^{3} \mathrm{~T}$ model, with some simplifications, but is integrated with an energy sector model that estimates hydrogen prices endogenously. For this analysis, parameters governing hydrogen prices were set to nearly match the Fuel Cell Technologies Office (FCTO)-supplied prices. 
The four models mentioned above give estimates of future sales shares by drivetrain technology: conventional (Conv) spark-ignition (SI), Conv compression-ignition (CI), hybrid electric vehicle (HEV), plug-in hybrid electric vehicle (PHEV), battery electric vehicle (BEV), and fuel cell vehicle (FCV). Table B-1 summarizes the key characteristics of the vehicle choice models as used in this analysis. One difference between the four LDV choice models is the level of aggregation of the powertrain types. Detailed discussion about these models and their inputs can be found in Stephens et al. (2017).

Future fuel prices were assumed to be those in the AEO 2016 Reference Case extrapolated to 2050 on the basis of the trend from 2035 to 2040. Future hydrogen prices for No Program were supplied by FCTO. Whereas the ParaChoice model used endogenously estimated hydrogen prices, parameters in the model were chosen to match the FCTO-supplied prices in 2015 and 2050, and differed slightly in other years. The assumed fuel prices, in 2015 dollars per gallon gasoline equivalent (gge), are shown in Figure B-1.

Biofuel was not modeled, except for the ethanol content in gasoline and E85. Flex fuel vehicles were not modeled explicitly in vehicle choice models, but a small fraction of the Conv SI vehicles were assumed to use E85. Fuel prices were assumed to be independent of fuel demand (no price elasticity).

TABLE B-1 Comparison of Key Characteristics of the LDV Choice Models

\begin{tabular}{lll}
\hline \multicolumn{1}{c}{ Model } & \multicolumn{1}{c}{ Powertrains Modeled } & \multicolumn{1}{c}{ Size Classes } \\
\hline LVCFlex & $\begin{array}{l}\text { SI Conv, CI Conv, HEV, PHEV25, PHEV50, } \\
\text { FCV, BEV100, BEV200, BEV300 }\end{array}$ & $\begin{array}{l}\text { Compact car, midsize car, compact } \\
\text { SUV, midsize SUV, pickup }\end{array}$ \\
LAVE-Trans & SI Conv, CI Conv, HEV, PHEV50, FCV, BEV300 & Car, light truck \\
MA ${ }^{3}$ T & SI Conv, CI Conv, HEV, PHEV25, PHEV50, & $\begin{array}{l}\text { Compact car, midsize car, compact } \\
\text { FCV, BEV100, BEV200, BEV300 }\end{array}$ \\
& FaraChoice & SI Conv, CI Conv, HEV, PHEV25, PHEV50, \\
& FCV, BEV100, BEV200, BEV300 & $\begin{array}{l}\text { Compact car, midsize car, small } \\
\text { SUV, midsize SUV, pickup }\end{array}$ \\
\hline
\end{tabular}




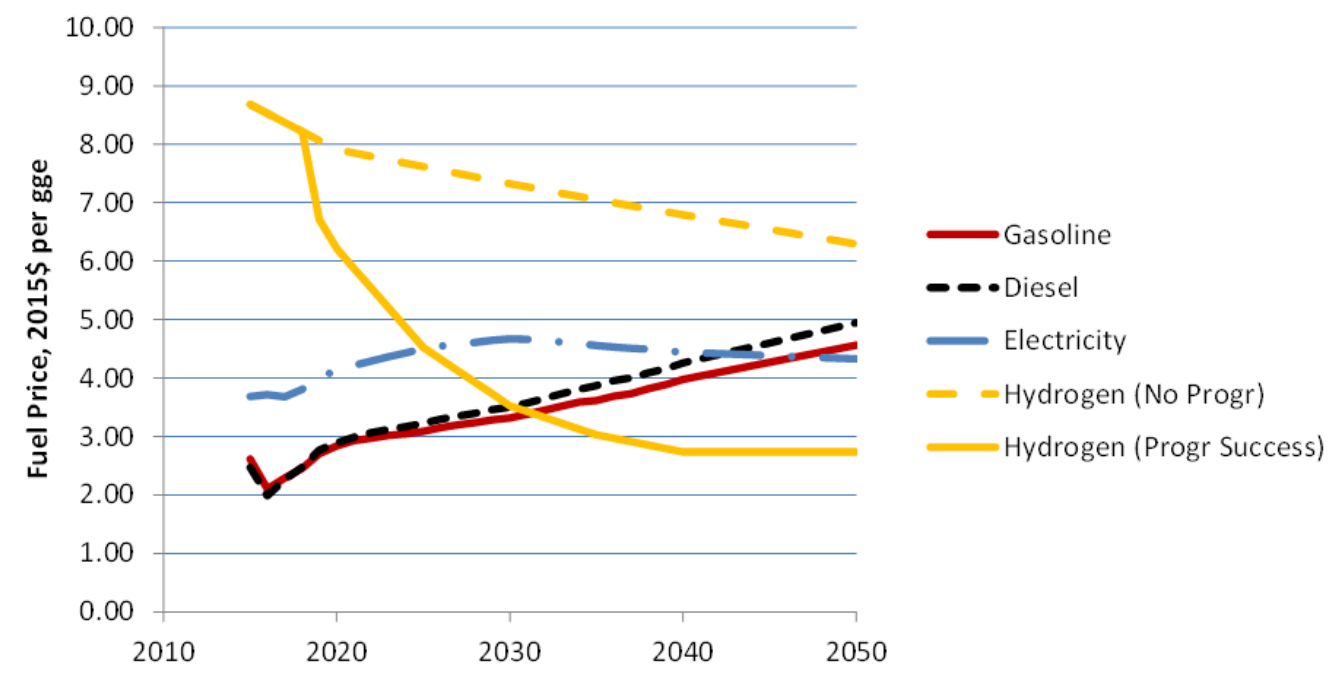

FIGURE B-1 Projected Fuel Prices Used for Modeling, in 2015\$ per gge $(1 \mathrm{GGE}=114,500 \mathrm{Btu})$

\section{B.2 COMPARISON OF LDV MARKET PENETRATION}

New LDV sales shares for the No Program and Program Success cases were projected by drivetrain technology for 2015-2050. Sales shares projected by the four LDV choice models described in Section2.1.2 are presented in Tables B-2 through B-5. Projections by drivetrain type calculated by the stock model in VISION using the sales shares outputs of each model are shown in Figures B-2 through B-5.

The LVCFlex model projected a very rapid market penetration by BEV200 in both the No Program and Program Success cases, and a large but slow increase in market share of FCVs in the Program Success case. $\mathrm{MA}^{3} \mathrm{~T}$ projected a large market share for plug-in vehicles, particularly for BEV100 for both cases. Shares of PHEV25 increase in both the No Program and Program Success cases, but less so in the Program Success case, which shows strong penetration by FCV.

The LAVE-Trans model also projected high penetration by advanced vehicle types in both Program Success and No Program, with higher penetration by PHEV40 and much higher penetration by FCV in Program Success. Projections from the ParaChoice model for the two cases were more similar, with Conv CI reaching a fairly high sales share in the mid-term (around 2030), but FCV shares were higher in Program Success in the long term.

The four LDV choice models using the same inputs based directly on the Vehicle Technologies Office (VTO) and FCTO goals for Program Success and inputs established for No Program give quantitatively different market penetration projections, but show similar market penetration by advanced-technology vehicles. The fuel economy of the LDV fleet is projected to increase with significant reductions in petroleum use and GHG emissions as a result of not only improvements in vehicle efficiency, but in increasing the share of vehicles that use little or no petroleum. 
TABLE B-2 LDV Market Penetration Estimates for the No Program and Program Success Cases from the LVCFlex Model

\begin{tabular}{|c|c|c|c|c|c|c|c|c|}
\hline \multirow[b]{2}{*}{ Drivetrain Type } & \multicolumn{4}{|c|}{ No Program (\%) } & \multicolumn{4}{|c|}{ Program Success (\%) } \\
\hline & 2025 & 2030 & 2040 & 2050 & 2025 & 2030 & 2040 & 2050 \\
\hline SI Conv & 68.2 & 59.3 & 52.0 & 44.6 & 52.4 & 43.1 & 34.5 & 27.9 \\
\hline CI Conv & 2.7 & 3.5 & 2.9 & 2.2 & 3.8 & 3.8 & 2.3 & 1.9 \\
\hline HEV Gasoline & 1.7 & 6.5 & 7.4 & 6.7 & 7.0 & 7.3 & 7.5 & 7.6 \\
\hline PHEV25 & 0.2 & 0.4 & 0.6 & 0.4 & 0.2 & 0.2 & 0.3 & 0.3 \\
\hline PHEV50 & 1.6 & 4.4 & 5.8 & 5.5 & 5.6 & 6.3 & 6.6 & 6.9 \\
\hline BEV100 & 0.2 & 0.6 & 1.0 & 1.0 & 0.3 & 0.5 & 0.4 & 0.4 \\
\hline BEV200 & 25.2 & 24.4 & 26.4 & 30.0 & 28.3 & 27.3 & 25.1 & 26.2 \\
\hline BEV300 & 0.2 & 0.7 & 1.3 & 2.4 & 0.8 & 2.6 & 3.8 & 6.1 \\
\hline FCV & 0.0 & 0.1 & 2.6 & 7.2 & 1.6 & 9.0 & 19.3 & 22.7 \\
\hline
\end{tabular}

TABLE B-3 LDV Market Penetration Estimates for the No Program and Program Success Cases from the $\mathrm{MA}^{3} \mathrm{~T}$ Model

\begin{tabular}{|c|c|c|c|c|c|c|c|c|}
\hline \multirow[b]{2}{*}{ Drivetrain Type } & \multicolumn{4}{|c|}{ No Program (\%) } & \multicolumn{4}{|c|}{ Program Success (\%) } \\
\hline & 2025 & 2030 & 2040 & 2050 & 2025 & 2030 & 2040 & 2050 \\
\hline SI Conv & 71.6 & 49.1 & 25.5 & 20.6 & 58.5 & 41.7 & 22.1 & 15.7 \\
\hline CI Conv & 1.0 & 0.7 & 0.1 & 0.0 & 1.5 & 1.7 & 0.2 & 0.0 \\
\hline HEV Gasoline & 7.1 & 9.3 & 7.3 & 6.5 & 10.2 & 9.8 & 6.9 & 7.8 \\
\hline PHEV25 & 0.2 & 3.0 & 20.8 & 27.3 & 0.7 & 3.1 & 12.7 & 15.3 \\
\hline PHEV50 & 0.0 & 0.3 & 0.8 & 1.1 & 0.1 & 0.6 & 1.9 & 3.5 \\
\hline BEV100 & 6.0 & 26.7 & 37.3 & 26.0 & 5.9 & 23.0 & 30.9 & 18.8 \\
\hline BEV200 & 14.0 & 10.4 & 5.6 & 12.8 & 21.8 & 13.8 & 5.2 & 10.7 \\
\hline BEV300 & 0.1 & 0.2 & 0.4 & 1.5 & 0.4 & 1.2 & 1.3 & 3.2 \\
\hline $\mathrm{FCV}$ & 0.0 & 0.3 & 2.2 & 4.3 & 0.9 & 5.2 & 18.9 & 24.9 \\
\hline
\end{tabular}

TABLE B-4 LDV Market Penetration Estimates for the No Program and Program Success Cases from the LAVE-Trans Model

\begin{tabular}{|c|c|c|c|c|c|c|c|c|}
\hline \multirow[b]{2}{*}{ Drivetrain Type } & \multicolumn{4}{|c|}{ No Program (\%) } & \multicolumn{4}{|c|}{ Program Success $(\%)$} \\
\hline & 2025 & 2030 & 2040 & 2050 & 2025 & 2030 & 2040 & 2050 \\
\hline SI Conv & 93.2 & 82.7 & 54.4 & 42.4 & 88.5 & 65.6 & 28.3 & 18.2 \\
\hline HEV Gasoline & 5.6 & 14.8 & 31.5 & 23.4 & 9.1 & 23.2 & 16.5 & 12.3 \\
\hline PHEV50 & 0.3 & 0.6 & 1.3 & 3.6 & 0.5 & 1.1 & 3.5 & 8.9 \\
\hline BEV300 & 0.6 & 1.4 & 10.6 & 19.4 & 0.6 & 3.5 & 17.4 & 19.8 \\
\hline FCV & 0.3 & 0.5 & 2.2 & 11.2 & 1.3 & 6.6 & 34.3 & 40.8 \\
\hline
\end{tabular}


TABLE B-5 LDV Market Penetration Estimates for the No Program and Program Success Cases from the ParaChoice Model

\begin{tabular}{|c|c|c|c|c|c|c|c|c|}
\hline \multirow[b]{2}{*}{ Drivetrain Type } & \multicolumn{4}{|c|}{ No Program $(\%)$} & \multicolumn{4}{|c|}{ Program Success $(\%)$} \\
\hline & 2025 & 2030 & 2040 & 2050 & 2025 & 2030 & 2040 & 2050 \\
\hline SI Conv & 70.7 & 46.7 & 29.3 & 23.0 & 57.3 & 41.4 & 22.8 & 11.7 \\
\hline CI Conv & 11.8 & 18.4 & 14.0 & 9.4 & 14.3 & 21.0 & 11.6 & 6.0 \\
\hline HEV Gasoline & 15.8 & 25.3 & 18.4 & 12.1 & 25.6 & 24.6 & 14.9 & 8.4 \\
\hline PHEV25 & 0.4 & 3.2 & 9.7 & 8.0 & 0.9 & 3.8 & 10.1 & 6.8 \\
\hline PHEV50 & 0.1 & 1.1 & 3.2 & 2.8 & 0.5 & 2.0 & 5.0 & 3.5 \\
\hline BEV100 & 1.0 & 4.0 & 14.4 & 21.5 & 1.1 & 4.3 & 9.1 & 7.5 \\
\hline BEV200 & 0.1 & 0.7 & 3.5 & 4.6 & 0.2 & 1.2 & 4.3 & 3.6 \\
\hline BEV300 & 0.0 & 0.0 & 0.2 & 0.7 & 0.0 & 0.0 & 0.5 & 1.1 \\
\hline FCV & 0.1 & 0.5 & 7.3 & 17.8 & 0.2 & 1.7 & 21.7 & 51.3 \\
\hline
\end{tabular}
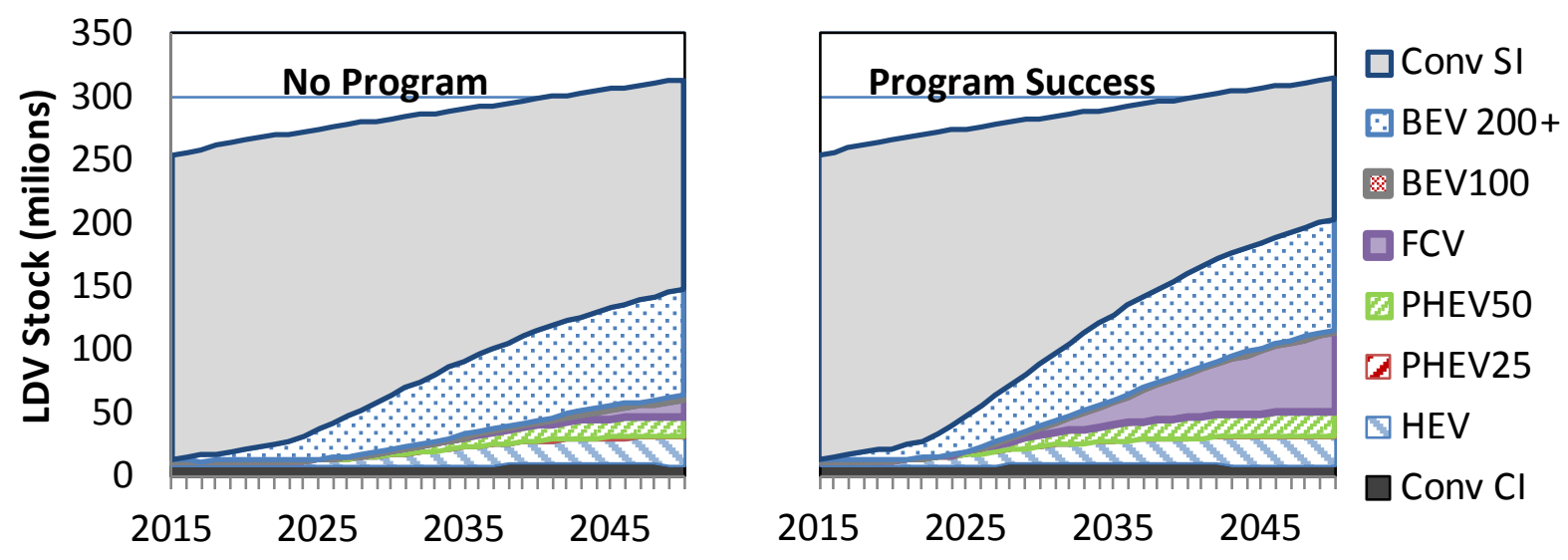

FIGURE B-2 LDV Stock by Powertrain Type for the No Program (left) and Program Success (right) Cases Projected by the LVCFlex Model
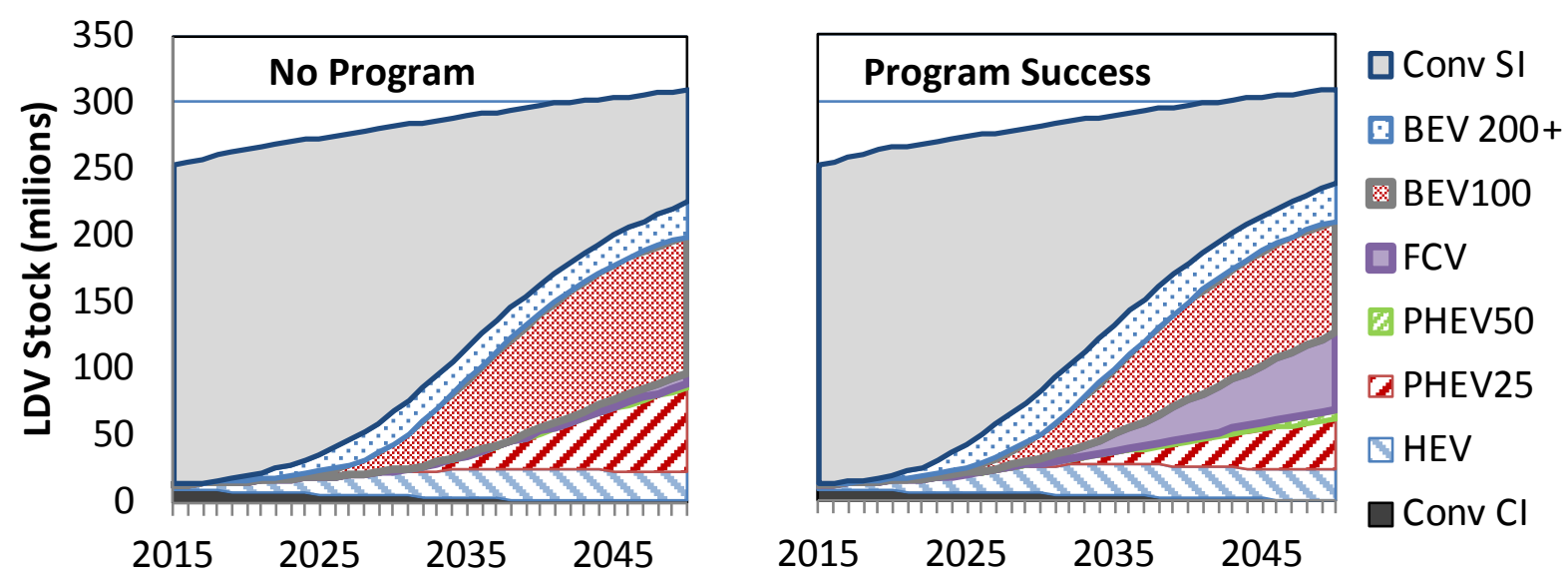

FIGURE B-3 LDV Stock by Powertrain Type for the No Program (left) and Program Success (right) Cases Projected by the $\mathrm{MA}^{3} \mathrm{~T}$ Model 

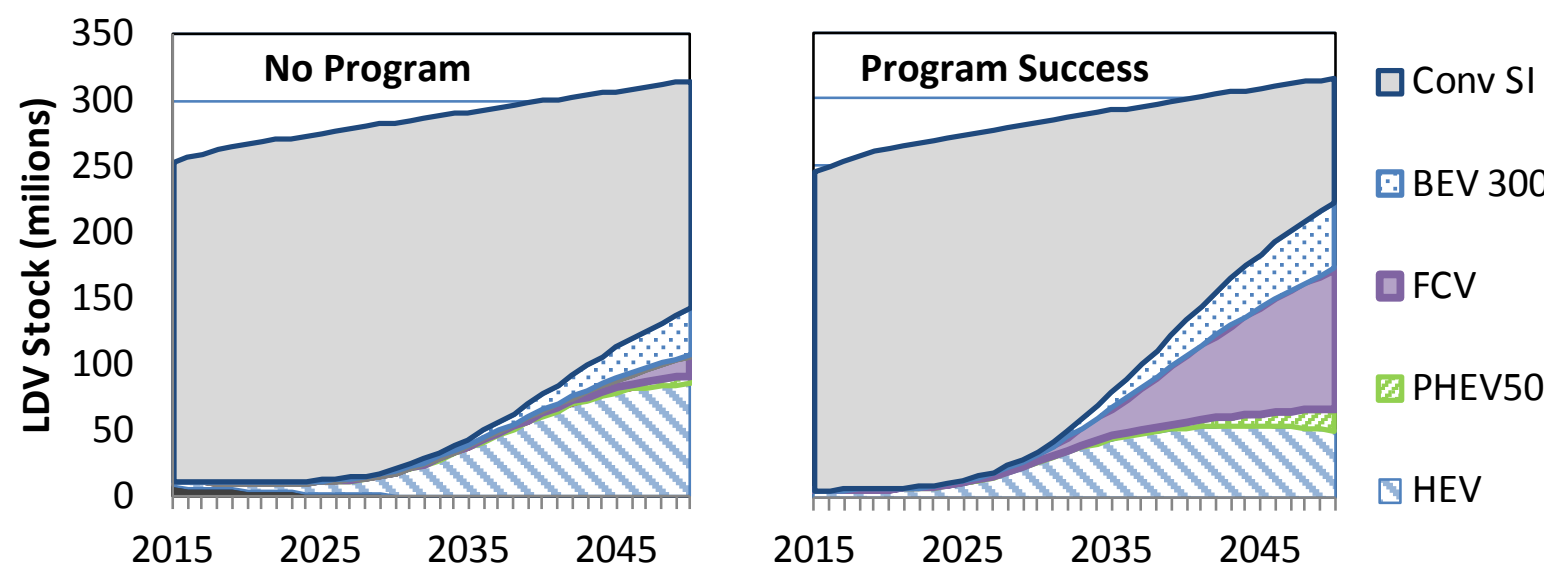

FIGURE B-4 LDV Stock by Powertrain Type for the No Program (left) and Program Success (right) Cases Projected by the LAVE-Trans Model
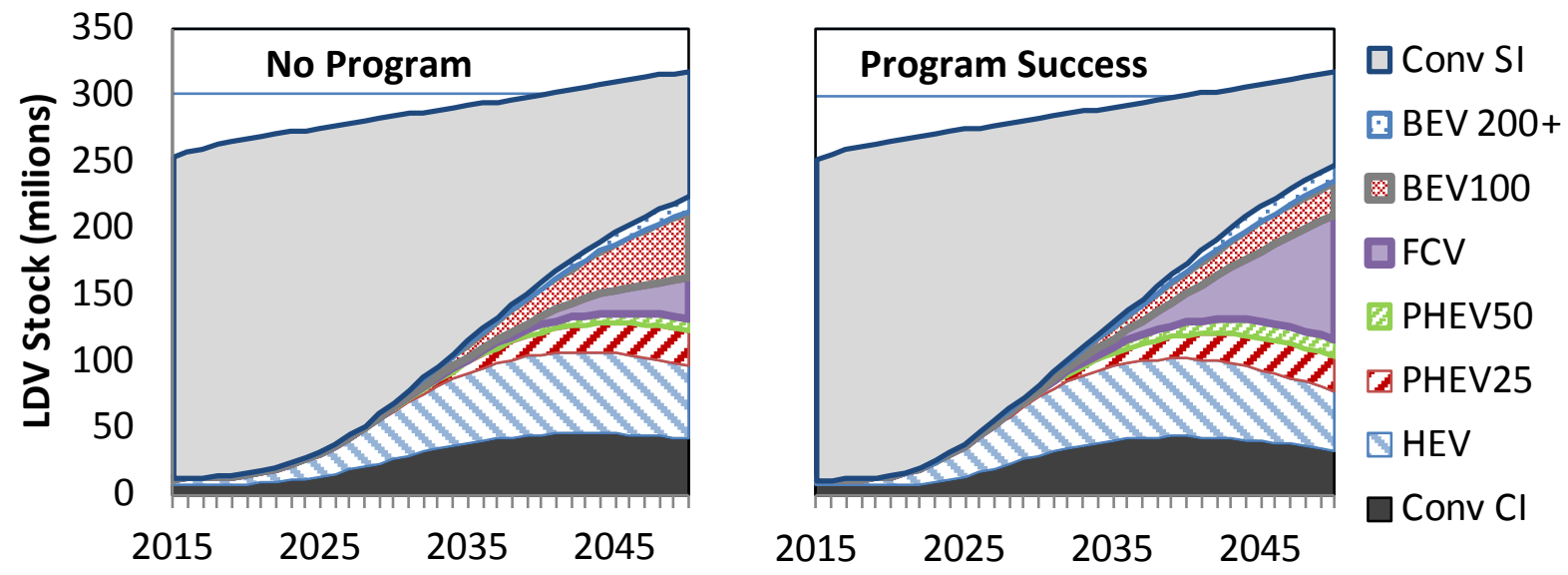

FIGURE B-5 LDV Stock by Powertrain Type for the No Program (left) and Program Success (right) Cases Projected by the ParaChoice Model

\section{B.3 LDV FUEL ECONOMY}

Vehicles in the Program Success case have higher fuel economy than those in the No Program case. The fuel economy values for each of the vehicles in this study are presented in detail in a forthcoming Argonne National Laboratory report (Islam et al., 2017).

The fleet-averaged fuel economy of new LDVs in the Program Success and No Program cases depends on the market share projections from the four vehicle choice modelsParaChoice, $\mathrm{MA}^{3} \mathrm{~T}$, LAVE-Trans, and LVCFlex. Harmonic averages of adjusted, combined, city/highway fuel economies were calculated from sales shares using on-road fuel economy degradation factors, with a city/highway vehicle miles traveled (VMT) weighting of 43\%/57\%. These are shown in Figure B-6 for new vehicle sales in each year. Using projected fuel economy values for new vehicles and the stock model in VISION, the on-road fleet-averaged fuel 


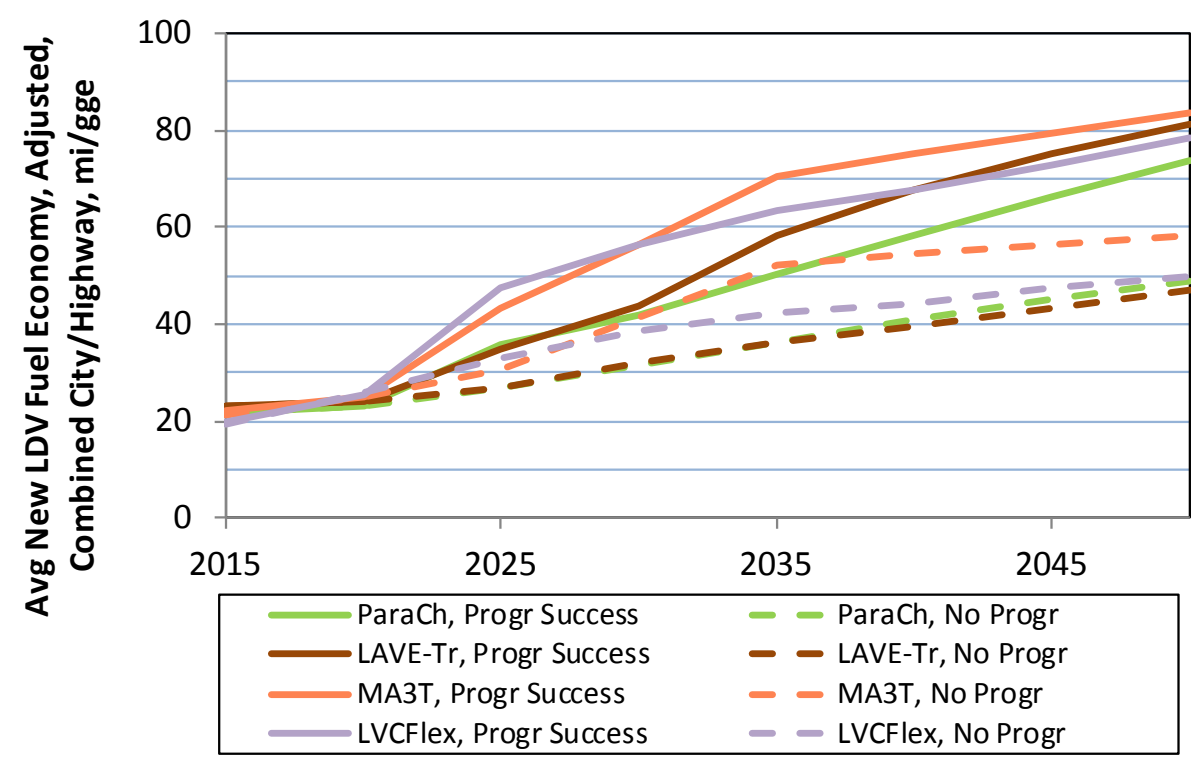

FIGURE B-6 Fleet-averaged Fuel Economies of New LDVs for the No Program (dashed lines) and Program Success (solid lines) Cases Based on Market Projections of the Four LDV Consumer Choice Models

economies were calculated for both cases and are shown in Figure B-7. The fuel economy averages are significantly higher for Program Success than for No Program, due both to efficiency improvements of vehicles and each powertrain type, as well as increased market shares of more efficient powertrain vehicles, such as PEVs and FCVs.

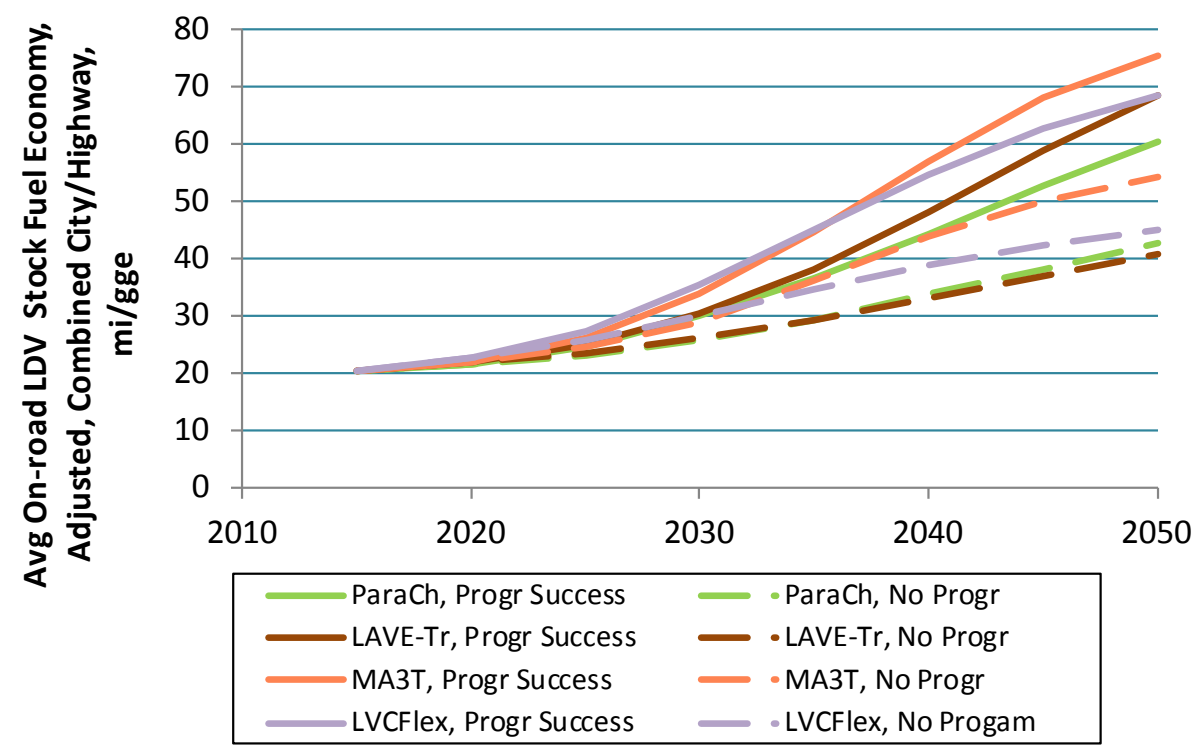

FIGURE B-7 Average Fuel Economy of On-road LDVs for the No Program (dashed lines) and Program Success (solid lines) Cases Based on Market Projections of the Four LDV Consumer Choice Models 


\section{B.4 REFERENCES}

EIA (Energy Information Administration), 2016, Annual Energy Outlook 2016: With Projections to 2040, DOE/EIA-0383(2016), Office of Integrated Analysis and Forecasting, Energy Information Administration, U.S. Department of Energy, Washington, D.C. Available at https://www.eia.gov/outlooks/aeo/pdf/0383(2016).pdf. Accessed Aug. 31, 2017.

Islam, E., A. Moawad, N. Kim, and A. Rousseau, 2017, An Extensive Study on Sizing, Energy Consumption and Cost of Advanced Vehicle Technologies, ANL/ESD-17/17, Argonne National Laboratory, Argonne, IL (forthcoming).

Stephens T.S., R.S. Levinson, A. Brooker, C. Liu, Z. Lin, A. Birky, and E. Kontou, 2017, Comparison of Vehicle Choice Models, ANL/ESD-17/19, Argonne National Laboratory, Argonne, IL, Oct. 


\section{APPENDIX C: \\ HEAVY TRUCK MODEL INPUTS AND OUTPUTS}

\section{C.1 HEAVY TRUCK MARKET PENETRATION}

Projections for market penetration of advanced technology heavy trucks (HTs) in the Program Success case are given in Table C-1 as fractions of total vehicle miles traveled (VMT) by new trucks in a calendar year. For all cases, the TRUCK model was used for HT market penetration projections. As described in Section 2.2.1, the baseline technology package for each size class represents No Program, and market shares of No Program are all 100\% baseline vehicles. Market penetration estimates are based on the time it takes for the fuel savings to offset the incremental cost of the technology - a calculation that depends on annual miles of travel. Therefore, fuel-saving technologies are adopted at a higher rate in applications with aboveaverage annual mileage. As a result, using a simple percentage of truck sales does not provide an accurate accounting of fuel consumption, so new-fleet fuel economy is calculated as a VMT-weighted average.

For Class 7-8 combination unit (CU) trucks, the advanced conventional diesel trucks also show significant market share (shown as VMT share in Table C-1), almost completely displacing the baseline technology by 2030. As mentioned above, hybrid electric vehicle (HEV) technology was not assumed to be offered in Class 7-8 combination unit trucks, since the benefit estimated

TABLE C-1 Medium- and Heavy-duty Truck Market Penetration Estimates for the Program Success Case, as Percentage of VMT

\begin{tabular}{lrrrr}
\hline & \multicolumn{3}{c}{$\%$ VMT } \\
\cline { 2 - 4 } Vehicle & & & \\
& 2020 & 2030 & 2040 & 2050 \\
\hline Medium (Classes 4-6) diesel & & & & \\
Baseline & 100.0 & 39.5 & 24.1 & 17.3 \\
Advanced conventional, low & 0.0 & 31.9 & 35.3 & 37.1 \\
Advanced conventional, high & 0.0 & 21.0 & 26.1 & 28.2 \\
Diesel HEV & 0.0 & 7.6 & 14.5 & 17.4 \\
& & & & \\
Heavy (Classes 7, 8) combination & & & & \\
unit & & & & \\
Baseline diesel & 100.0 & 5.4 & 2.2 & 1.7 \\
Advanced conventional, low & 0.0 & 58.3 & 51.8 & 51.6 \\
Advanced conventional, high & 0.0 & 36.3 & 46.0 & 46.7 \\
& & & & \\
Heavy (Classes 7, 8) single unit & & & & \\
Baseline diesel & 100.0 & 39.0 & 25.7 & 20.4 \\
Advanced conventional, low & 0.0 & 32.7 & 30.6 & 31.6 \\
Advanced conventional, high & 0.0 & 19.6 & 26.9 & 28.4 \\
Diesel HEV & 0.0 & 8.6 & 16.8 & 19.6 \\
\hline
\end{tabular}


by Assessment of Cycle Energy of Truck Technologies (AsCEnTT) analysis was very small. The advanced conventional technology, both low and high, penetrates the other truck size classes quickly. The mild hybrid truck gains more modest VMT share due to higher incremental costs and relatively small fuel economy benefits compared with the advanced conventional truck. By 2030, the hybrid platform achieves a share of 7.3\% of vehicle miles in Class 4-6 diesel, increasing to $12.7 \%$ by 2050 . Similar penetration by HEVs is seen for Class $7-8$ single unit (SU) trucks.

Overall, the advanced technology platforms achieve somewhat lower penetration into the Class 4-6 and Class 7-8 SU diesel truck market than in the Class 7-8 CU market, reflecting the fact that these trucks see lower annual mileage. However, advanced technologies penetrate all size classes significantly; in total, advanced vehicles account for nearly 55\% of VMT in 2050 . It should be noted that Class 4-6 and Class 7-8 vehicles are very diverse in their configurations and uses, but are modeled here each as a single vehicle, thus limiting the fidelity of the model. However, the average fuel economy and annual driving distance distributions used as input should adequately capture the fuel use of this range of vehicles.

\section{C.2 AVERAGE HT FUEL ECONOMY}

The projections of new vehicle fleet fuel economy values for medium- and heavy-duty trucks are shown in Figure C-1 for the Program Success and No Program cases. Fleet averages are mileage-weighted values. As a result of U.S. Department of Energy (DOE)-supported technologies, the fuel economy of the fleet of all new Class 7 and 8 trucks is projected to reach $31 \%$ above the same trucks in the No Program case in 2035 and $38 \%$ higher in 2050 . Because of the lower annual usage of Class 4-6 trucks, the market penetration is slightly slower, and the resulting impact of DOE-funded technologies is somewhat less in these vehicles, with a fuel economy ratio of 1.15 in 2035 and 1.21 in 2050.

The average fuel economy of the on-road stock of medium- and heavy-duty trucks of each range of size class analyzed are shown in Figure C-2. The on-road fuel economy increases

for each size class range. 


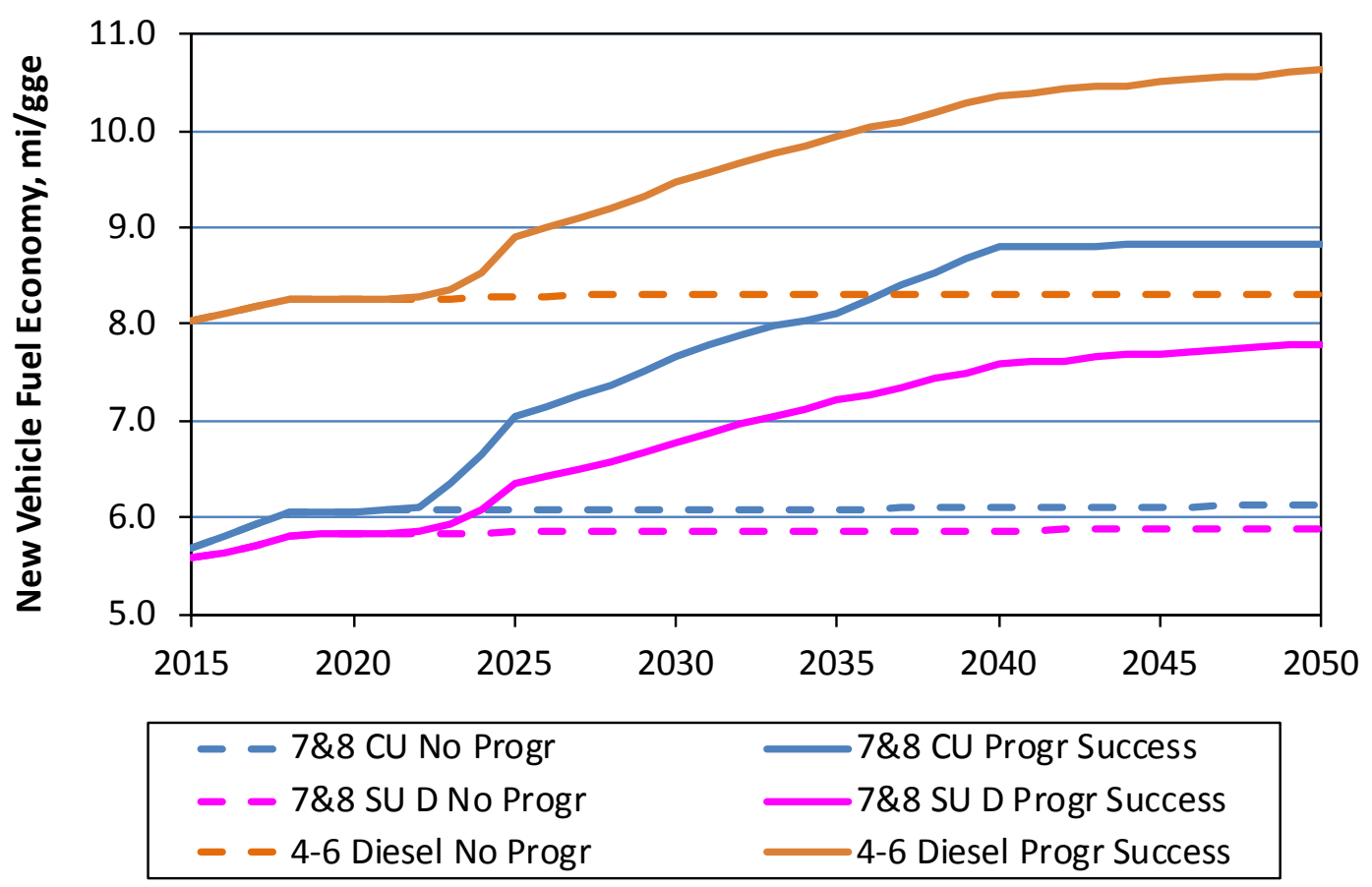

FIGURE C-1 Fleet-averaged Fuel Economy of New Medium- and Heavy-duty Trucks for the No Program (dashed lines) and Program Success (solid lines) Cases

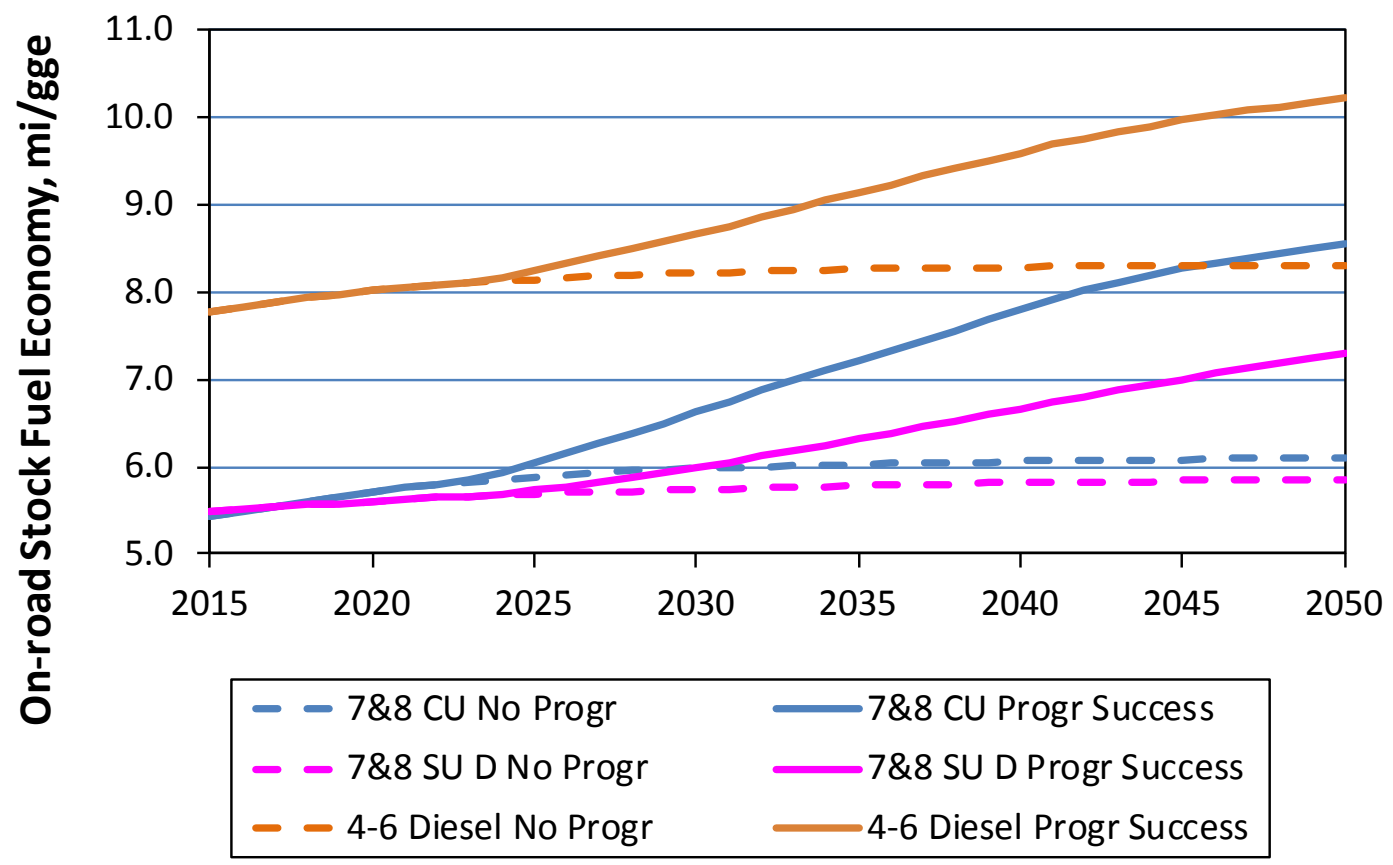

FIGURE C-2 Average Fuel Economy of On-road Stock of Medium- and Heavy-duty Trucks for the No Program (dashed lines) and Program Success (solid lines) Cases 
This page intentionally left blank. 


\section{APPENDIX D: \\ VARIATION IN AGGREGATE IMPACTS ACROSS LDV CHOICE MODELS}

\section{D.1 OIL SECURITY METRICS MODELING PROJECTIONS}

Figure 3-3 in Section 3.1.2 shows the mean value of the benefits to oil security due to successful implementation of Vehicle Technologies Office (VTO) and Fuel Cells Technologies Office (FCTO) technology as calculated by the Oil Security Metrics Model (OSMM). For each of the vehicle choice models that are used, confidence intervals can be applied based on uncertainty in future oil costs. Petroleum reductions of $7.6 \%$ to $13.7 \%$ lead to reduced costs, resulting in annual reductions of $\$ 40$ billion to $\$ 80$ billion. In the case of high oil prices and fluctuations, potential benefits can be more than $\$ 100$ billion per year.

Results from the OSMM Monte-Carlo simulation for each projection of petroleum reduction are shown in Figures D-1 through D-4, which show the projected distribution of reductions in oil security costs in any given year. The mean is shown in yellow, with one standard deviation of benefits shown in solid red and the 5th to 95th percentiles shown in pink. The OSMM results show a near-term increase of the estimated oil dependence cost, especially for the 95th percentile. This is mainly due to the unusually fast (compared to previous Annual Energy Outlook [AEO] projections) increase in projected oil prices in the AEO 2016 Reference Case during 2017-2021 (EIA, 2016). The model behavior implies that a period of rapidly increasing oil prices from a low point increases uncertainty about oil dependence costs. OSMM includes a delay effect of oil prices on the gross domestic product (GDP) and ultimately the oil dependence cost, which causes more uncertainty during the 2021-2025 time frame.

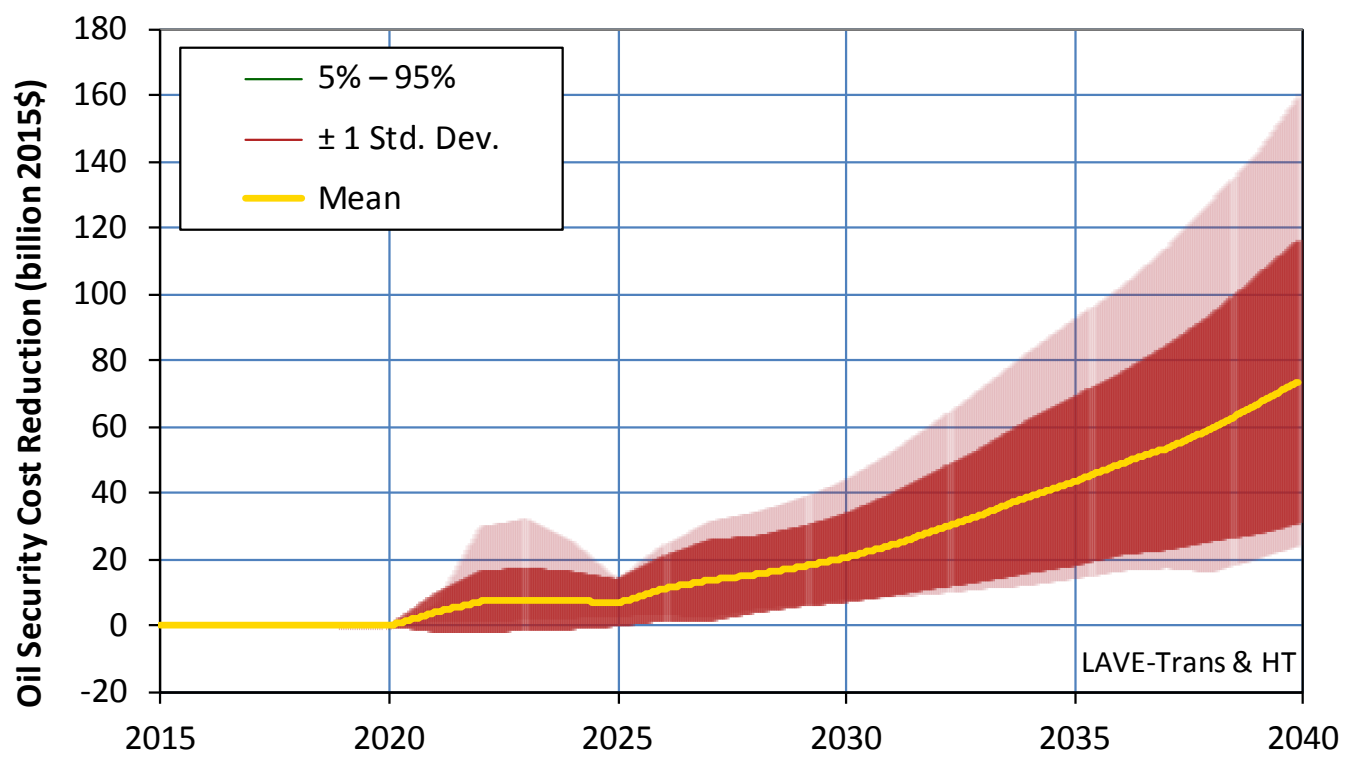

FIGURE D-1 Oil Security Metrics Model Results Using LAVE-Trans and TRUCK Model Projections 


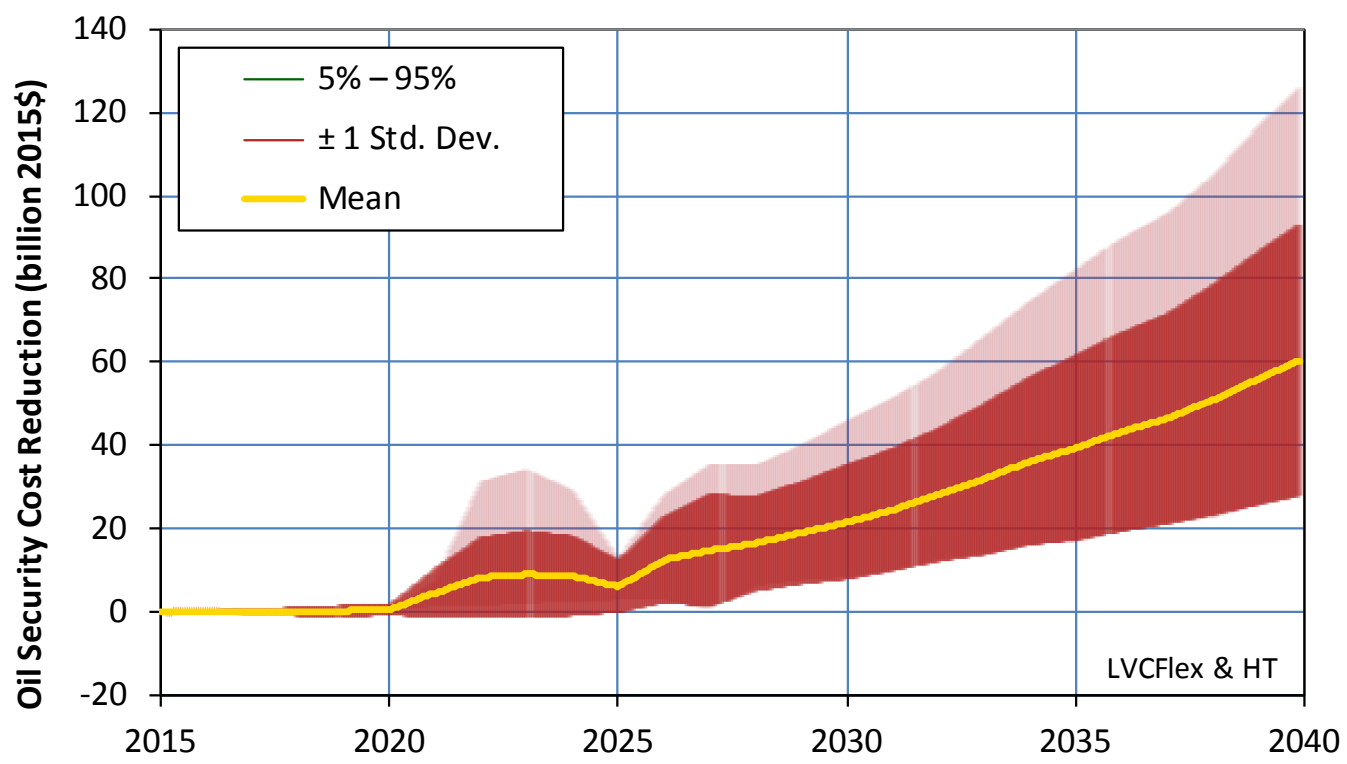

FIGURE D-2 Oil Security Metrics Model Results Using LVCFlex and TRUCK Model Projections

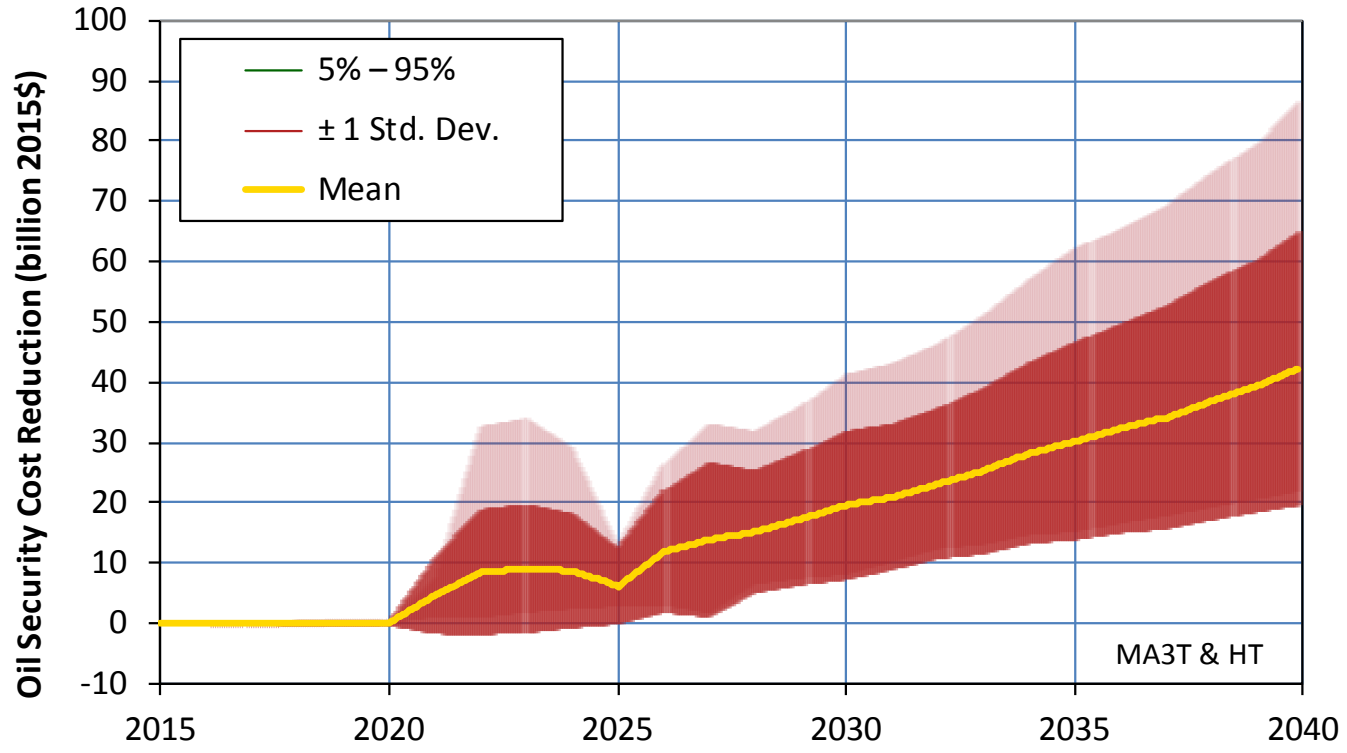

FIGURE D-3 Oil Security Metrics Model Results Using MA ${ }^{3}$ T and TRUCK Model Projections 


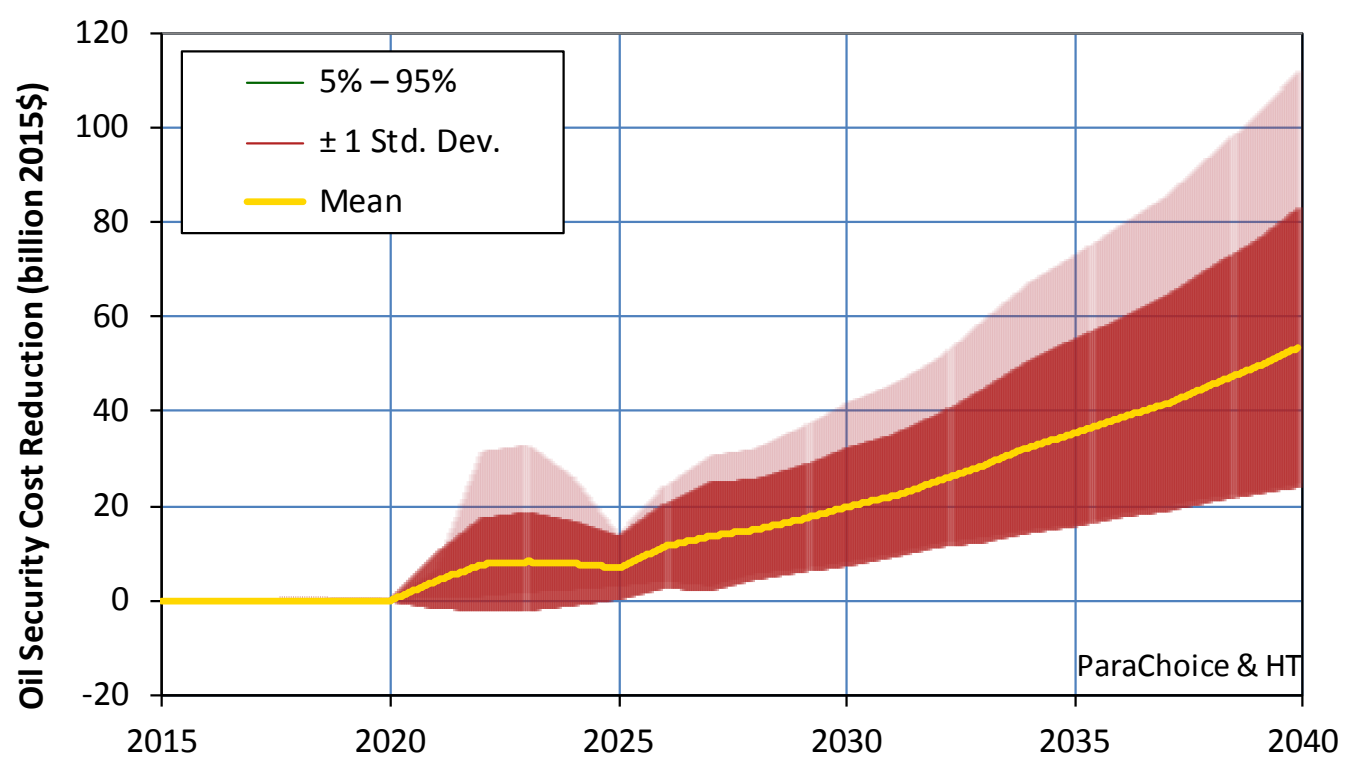

FIGURE D-4 Oil Security Metrics Model Results Using ParaChoice and TRUCK Model Projections

\section{D.2 CONSUMER COSTS OF LIGHT-DUTY VEHICLES (LDVS)}

The annual expenditures for LDVs are shown for the on-road vehicles projected by each vehicle choice model in Figures D-5 through D-8. These are not discounted costs, but the actual projected expenditures in each year (2015\$). In 2020, there are more expenditures for new vehicles than for fuel for each of the four LDV vehicle choice models. As time progresses, improvements in fuel economy are projected to change the balance between vehicle cost and fuel cost.

The total expenditures are lower in the Program Success case than in the No Program case for each model. For the Program Success case, fuel expenditures decrease through 2050 due to improved fuel economy. 

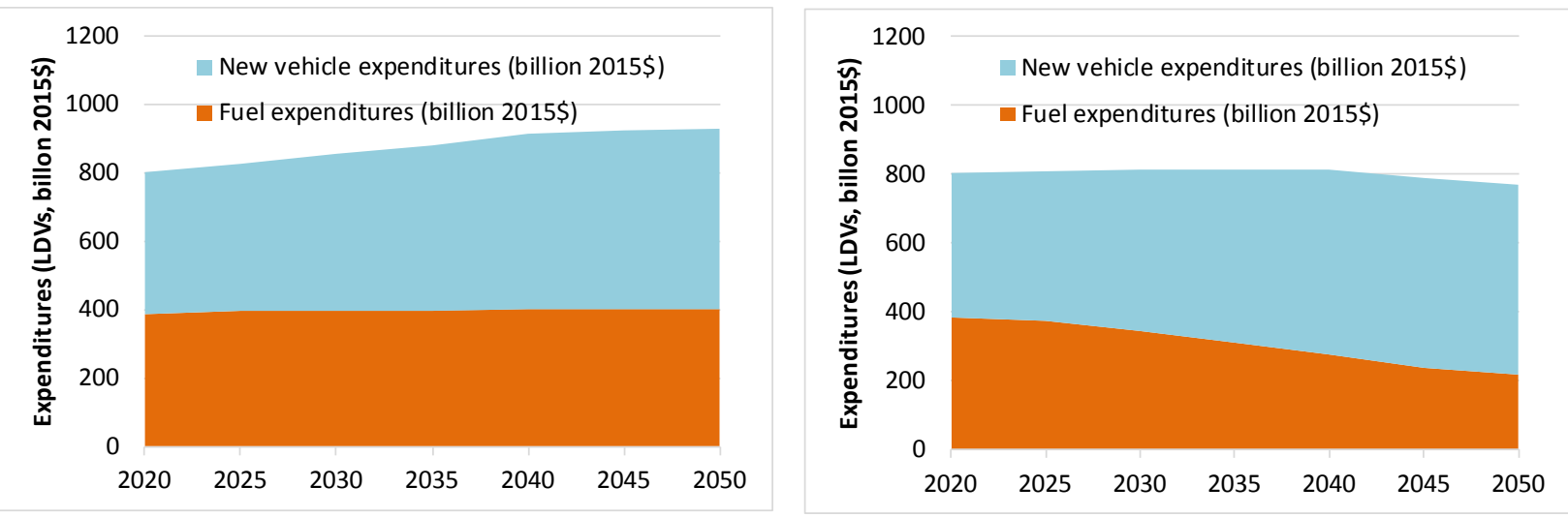

FIGURE D-5 Annual Expenditures for LDV Stock Modeled by LAVE-Trans for the No Program (left) and Program Success (right) Cases
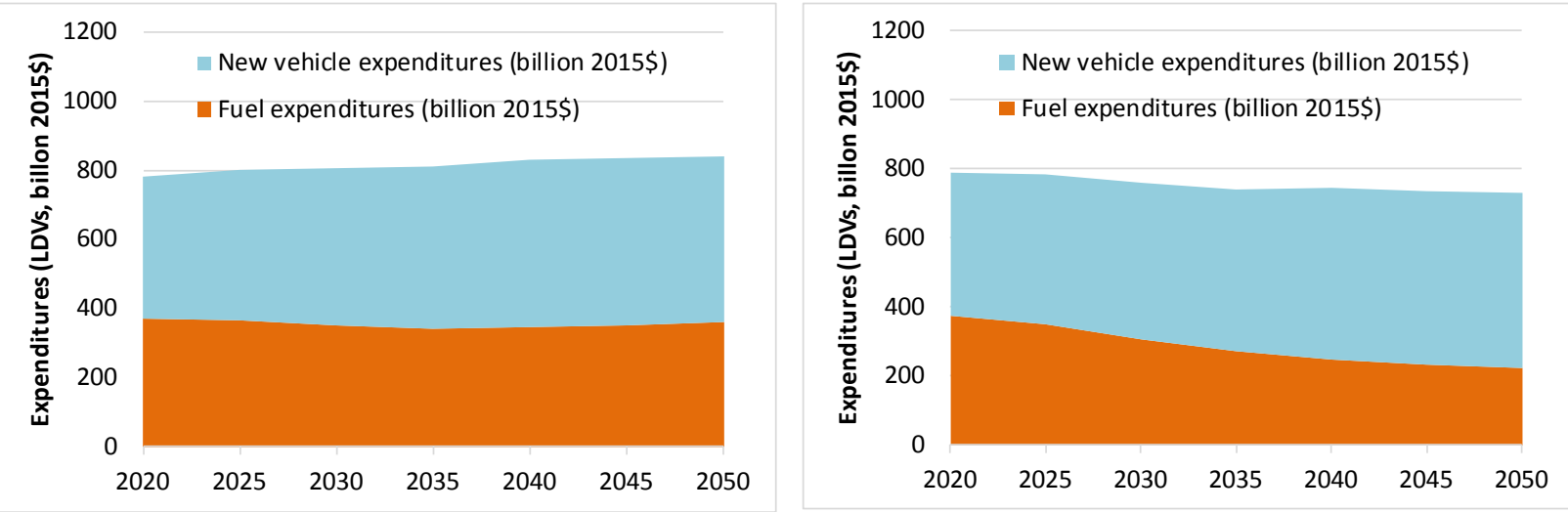

FIGURE D-6 Annual Expenditures for LDV Stock Modeled by LVCFlex for the No Program (left) and Program Success (right) Cases
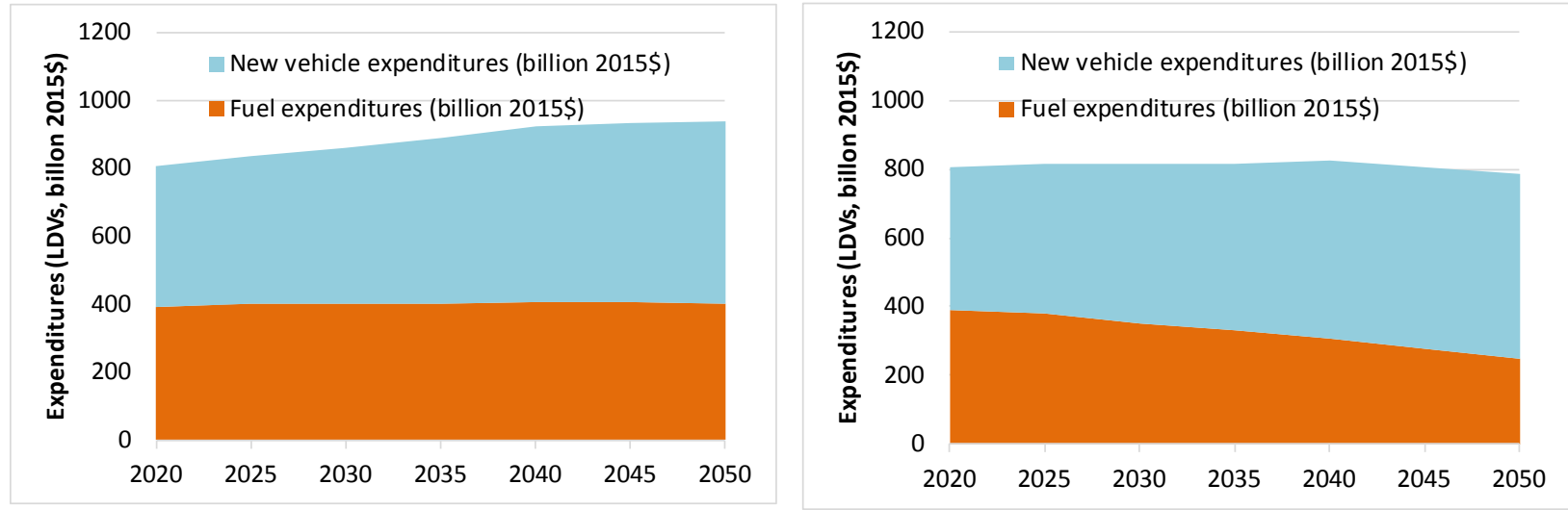

FIGURE D-7 Annual Expenditures for LDV Stock Modeled by MA ${ }^{3}$ T for the No Program (left) and Program Success (right) Cases 

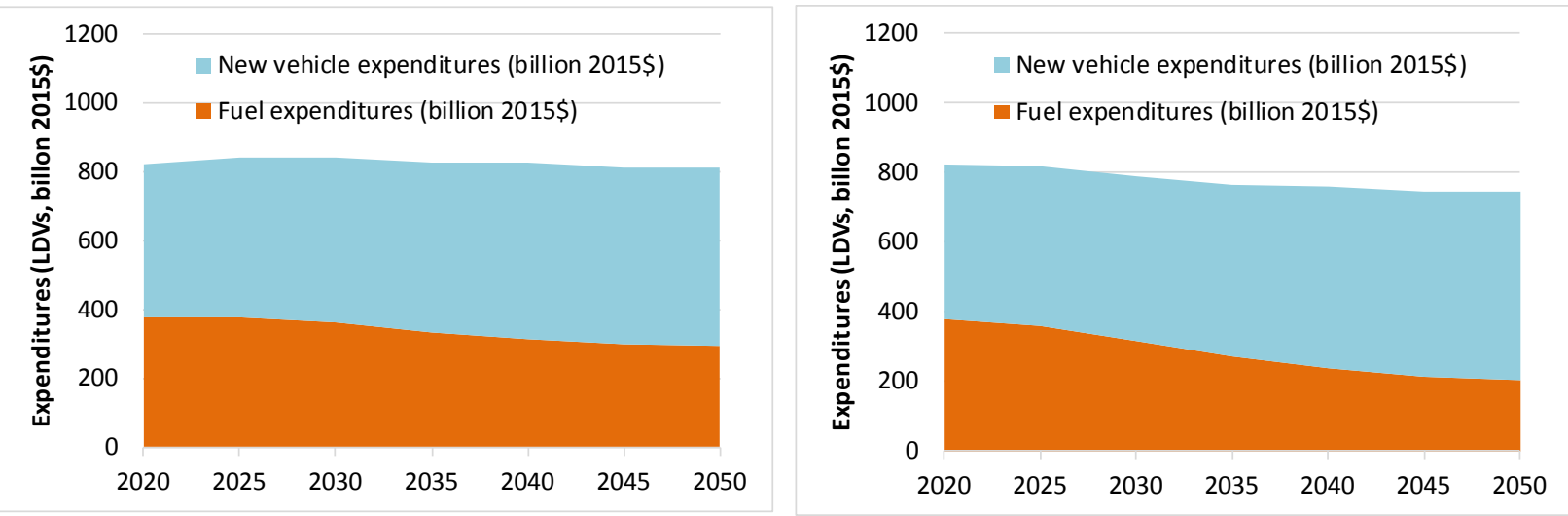

FIGURE D-8 Annual Expenditures for LDV Stock Modeled by ParaChoice for the No Program (left) and Program Success (right) Cases 
This page intentionally left blank. 



\section{Argonne}

\section{Energy Systems Division}

9700 South Cass Avenue, Bldg. 362

Argonne, IL 60439-4854

www.anl.gov 